\title{
Columbia University
}

Department of Economics

Discussion Paper Series

Trade, Quality Upgrading and Wage Inequality in the Mexican Manufacturing Sector

\author{
Eric Verhoogen
}

Discussion Paper No.: 0607-08

Department of Economics

Columbia University

New York, NY 10027

June 2007 


\title{
Trade, Quality Upgrading and Wage Inequality in the Mexican Manufacturing Sector
}

\author{
Eric A. Verhoogen* \\ June 2007
}

\begin{abstract}
This paper proposes a new mechanism linking trade and wage inequality in developing countries - the quality-upgrading mechanism - and investigates its empirical implications in panel data on Mexican manufacturing plants. In a model with heterogeneous plants and quality-differentiated goods, only the most productive plants in a country like Mexico enter the export market, they produce higher-quality goods to appeal to richer Northern consumers, and they pay high wages to attract and motivate a high-quality workforce. An exchange-rate devaluation leads initially more-productive, higher-wage plants to increase exports, upgrade quality, and raise wages relative to initially less-productive, lower-wage plants within each industry. Using the late-1994 peso crisis as a source of variation and a variety of proxies for plant productivity, I find that initially more-productive plants increased the export share of sales, white-collar wages, blue-collar wages, the relative wage of whitecollar workers, and ISO 9000 certification more than initially less-productive plants during the peso crisis period, and that these differential changes were greater than in periods without devaluations before and after the crisis period. A factor-analytic strategy that relies more heavily on the theoretical structure and avoids the need to construct proxies finds similar results. These findings support the hypothesis that differential quality upgrading induced by the exchange rate shock tended to increase within-industry wage inequality.
\end{abstract}

Keywords: Trade and wage inequality, quality upgrading, exchange-rate shock JEL classifications: F16, J31, O12, L11

\footnotetext{
* Columbia University, BREAD, CEPR, and IZA. Email: eric.verhoogen@columbia.edu. Address: 420 W. 118th St. Room 1022, New York NY 10027. I would like to thank, without implicating, Gerardo Leyva, Abigail Durán, Adriana Ramírez, Gerardo Durand, Gabriel Romero, Alejandro Cano, Lazaro Trujillo and many others at INEGI for tireless assistance with the establishment surveys; Sangeeta Pratap, John Romalis and Jim Tybout for further generous help with data; Rebeca Wong for crucial support at an early stage, without which the project would not have been possible; Andrew Bernard, Matteo Bugamelli, Ken Chay, Damon Clark, Gabriel Demombynes, Arindrajit Dube, Gordon Hanson, Kate Ho, Pablo Ibarraran, Jennifer Kaiser, Larry Katz, David Lee, Sebastian Martinez, Paco Martorell, Justin McCrary, Tom Mroz, MarcAndreas Muendler, Aviv Nevo, Cristian Pop-Eleches, Raymond Robertson, Jesse Rothstein, many seminar participants, and especially my dissertation committee at UC Berkeley, Pranab Bardhan (co-chair), David Card (co-chair), George Akerlof, and Ann Harrison, for helpful comments.
} 


\section{Introduction}

Beginning with a series of liberalizing reforms in 1985 and 1986, the Mexican economy experienced more than a decade of both rapidly expanding trade and rising wage inequality. In current U.S. dollar terms, non-petroleum exports and total imports rose an average of $16.5 \%$ and $15.7 \%$ per year respectively over the 1985-2000 period. Figure 1 illustrates the evolution of two measures of wage inequality: the log 90-10 ratio from a household employment survey, and the white-collar/blue-collar wage ratio from a balanced manufacturing plant panel. ${ }^{1}$ Both illustrate a substantial increase, reaching a peak in 1996-1998. A similar coincidence of expanding trade and rising inequality has been observed in many other developing countries. ${ }^{2}$

From the perspective of standard Hecksher-Ohlin trade theory, this coincidence is puzzling. The simplest version of the Hecksher-Ohlin model predicts that wage inequality will fall in a country like Mexico when it integrates with a country like the U.S., as production shifts toward unskilled-labor-intensive industries, raising the demand for unskilled labor. More sophisticated Hecksher-Ohlin-type models can account for a link between trade liberalization and wage inequality in a developing country like Mexico, ${ }^{3}$ but because such models rely on between-sector shifts as the mechanism through which trade affects labor markets, they can only explain a rise in inequality if trade causes a shift in resources toward skilledlabor-intensive sectors. Empirical studies have typically failed to find evidence of such shifts. ${ }^{4}$ Using aggregate data from the Mexican manufacturing censuses and schooling data from a household survey, Figures 2 and 3 present evidence of shifts toward less-skill-intensive and less-capital-intensive sectors within manufacturing in Mexico over the 1988-1998 period, consistent with the simplest Hecksher-Ohlin model. It is common in the literature to interpret increases in inequality that cannot be explained by between-sector shifts as evidence for non-trade-related factors such as exogenous skill-biased technical change (Berman, Bound, and Griliches, 1994; Berman, Bound, and Machin, 1998; Esquivel and Rodriguez-Lopez, 2003).

This paper proposes an alternative mechanism linking trade and wage inequality in de-

\footnotetext{
${ }^{1}$ The datasets are described in more detail in Section 4 and in Appendix B.

${ }^{2}$ See Goldberg and Pavcnik $(2004,2007)$ for reviews.

${ }^{3}$ Inequality may increase, for instance, if a unskilled-labor-abundant country Mexico opens trade simultaneously with a skill-abundant country like the U.S. and an even more unskilled-labor-abundant country like China (Davis, 1996) or if relatively unskilled-labor-intensive industries are more protected prior to liberalization (Revenga, 1997; Attanasio, Goldberg, and Pavcnik, 2004).

${ }^{4}$ Wacziarg and Seddon Wallack (2004) and Papageorgiou, Michaely, and Choksi (1991) find little evidence of shifts in response to trade liberalization in large samples of countries.
} 
veloping countries — the quality-upgrading mechanism — and investigates its empirical implications in panel data on Mexican manufacturing plants. The theoretical framework combines three main elements. First, plants are heterogeneous in productivity within industries and there is a fixed cost to entering the export market, such that only the most productive plants within each industry export, as in Melitz (2003). Second, goods are differentiated in quality and consumers differ in income and hence in willingness to pay for product quality across countries, such that a given poor-country exporting plant produces higher-quality goods for export than for the domestic market. Third, producing high-quality goods is assumed to require high-quality workers within each occupational category, along the lines of the O-ring models of Kremer (1993) and Kremer and Maskin (1996). In this context, an increase in the incentive to export in a developing country generates differential quality upgrading: initially more-productive plants increase exports, produce a greater share of higher-quality goods, and raise wages relative to initially less-productive plants in the same industry. Since initially more-productive plants also tend to be initially higher-wage, this process tends to increase within-industry wage dispersion.

The empirical part of the paper uses the peso devaluation of December 1994, as well as an earlier devaluation in 1985-86, to investigate this mechanism. I follow two separate approaches to deal with the fact that a key variable in the model, the underlying productivity parameter, is unobserved. The first approach uses observable variables to construct simple proxies for this parameter; I refer to this approach as the proxy-variable strategy. Using a number of different proxies, I compare differential changes in outcomes between initially more-productive and initially less-productive plants over the peso crisis period (1993-1997) to corresponding changes in periods without devaluations before (1989-1993) and after (1997-2001) the crisis period. I find greater differential changes in the export share of sales, white-collar wages, blue-collar wages, and the relative wage of white-collar workers in the peso crisis period. The results for 1986-1989, also a period of real depreciation of the peso, indicate patterns similar to those of 1993-1997. Using an auxiliary dataset, I find greater differential changes during the peso crisis period in the likelihood of ISO 9000 certification, an international production standard commonly associated with product quality. The basic results are not sensitive to the choice of proxy.

The second approach relies more heavily on the factor-analytic structure of the theoretical model and eliminates the need to construct proxies; I refer to it as the latent-factor strategy. The model implies that a number of observable variables are functions of the same 
unobserved productivity parameter, and that the peso crisis changes the relationship between the observables and this latent factor without changing the distribution of the factor itself. This implication is the basis for a maximum-likelihood estimation procedure that integrates over the distribution of the unobserved heterogeneity and estimates the parameters for all periods simultaneously. To avoid imposing strong distributional assumptions, I follow Heckman and Singer (1984) in positing a non-parametric mass-point distribution for the latent factor. The location and probability weights of the mass points are estimated simultaneously with the other parameters. The results of this latent-factor approach are consistent with those of the proxy-variable approach, as well as with the predictions of the theoretical model. The results from both empirical strategies together support the hypothesis that differential quality upgrading induced by the exchange-rate shock increased within-industry wage inequality.

In addition to the work cited above, this paper is related to a number of different strands of existing literature. In introducing quality-differentiated goods and asymmetric countries into a Melitz-type theoretical framework, it uses multinomial-logit microfoundations for consumer demand (McFadden, 1981; Anderson, de Palma, and Thisse, 1992), because they make transparent the dependence of willingness to pay for quality on consumer incomes. The paper is related to a growing literature using plant-level data from developing countries to examine plants' responses to exposure to international markets; leading contributions to this literature include Roberts and Tybout (1997); Currie and Harrison (1997); Clerides, Lach, and Tybout (1998); Levinsohn (1999), and Pavcnik (2002). (For reviews, see Tybout (2000, 2003).) The paper is related to work examining the role of product quality in international trade, including Burenstam Linder (1961), Gabszewicz et al. (1982), Shaked and Sutton (1982), Markusen (1986), Flam and Helpman (1987), Stokey (1991), Grossman and Helpman (1991), Copeland and Kotwal (1996), Murphy and Shleifer (1997), Brooks (2006), Hallak (2006), Hausmann et al. (2005), Hummels and Klenow (2005), and Schott (2004). ${ }^{5}$ The paper is also related to a growing body of non-Hecksher-Ohlin models of trade and wages, including Acemoglu (2003), Antras, Garicano, and Rossi-Hansberg (2006), and Yeaple (2005). I am not aware of previous work that has focused on shifts in the within-plant product mix between goods of different qualities destined for different markets. Previous

\footnotetext{
${ }^{5}$ This paper is also related to an older literature in radical political economy on labor market segmentation (Edwards, 1979; Gordon, Edwards, and Reich, 1982). In the terminology of that literature, the argument of this paper is that product market segmentation contributes to labor market segmentation within each industry; the exchange rate shock exacerbates segmentation in product markets, which in turn exacerbates segmentation in labor markets.
} 
studies that have used exchange-rate shocks as a source of identification, in the context of other research designs, include Revenga (1992), Abowd and Lemieux (1993), Maurin, Thesmar, and Thoenig (2002) and Forbes (2002). The sheer size of the exchange-rate shock - along with the fact that it was largely unexpected, unlike most trade agreements - may explain why this paper finds stronger evidence of plant behavioral responses than is typical in the literature using tariff changes. ${ }^{6}$

An important caveat is that the particular mechanism this paper focuses on - withinindustry quality upgrading in response to a currency devaluation - cannot explain the overall trend in Mexican wage inequality illustrated in Figure 1. There are many factors that may have contributed to changes in aggregate inequality, among them exogenous technological change, migration (both internal and international), and other liberalization policies that have accompanied the opening to trade. Figure 4 focuses more directly on the dimension of wage inequality that this paper may be able to explain: wage dispersion among manufacturing plants. The figure plots the variance of log average hourly wages in a balanced manufacturing plant panel, as well as the variance of the residuals from a regression of log average hourly wages on a full set of industry-year effects. ${ }^{7}$ Total wage dispersion rose sharply in 1994-1995 as well as in the period of the earlier devaluation, 1986-1987, and a non-negligible portion of the increase in variance can be attributed to an increase in residual (within-industry) variance. ${ }^{8}$

The next section provides background on the peso crisis and presents a concrete example - a case study of the Volkswagen plant in Puebla, Mexico - to illustrate the process of quality upgrading. Section 3 develops the theoretical model. Section 4 describes the datasets and presents descriptive statistics. Section 5 presents the proxy-variable strategy. Section 6 presents the latent-factor strategy. Section 7 addresses alternative explanations of those results, and Section 8 concludes.

\section{Background and Brief Case Study}

For several years prior to the peso crisis, the Mexican government constrained the peso to vary within a narrow band ( \pm .0004 pesos/day from Oct. 1992 to Dec. 1994). Over the same period, persistent trade and current-account deficits led to mounting pressure on

\footnotetext{
${ }^{6}$ See Levinsohn (1999), Currie and Harrison (1997), Harrison and Hanson (1999) and Tybout (2003).

${ }^{7}$ The dataset is described in more detail in Section 4 below and in Appendix B.

${ }^{8}$ For further discussion of wage trends in Mexico, see Cragg and Epelbaum (1996), Hanson and Harrison (1999), Hanson (2004), and Robertson (2004).
} 
government reserves. President Ernesto Zedillo took office on Dec. 1, 1994, and on Dec. 20 his new finance minister announced that the ceiling on the exchange-rate band would be raised $15.6 \%$, from 3.46 to 4.00 pesos/dollar. This set off a speculative attack, and two days later the government was forced to allow the peso to float. The peso devalued immediately to 4.90 pesos/dollar, and continued losing value. Figure 5 plots the real exchange rate, which reached a local maximum in March 1995 and recovered slowly thereafter. There are a variety of theories about what generated the extra pressure on the currency that prompted the government to devalue - a leading one points to a renewed offensive of Zapatista rebels in the Southern state of Chiapas (Economist Intelligence Unit, 1995) — but whatever the precipitating event, it appears that the devaluation was largely unexpected. Figure 6 presents monthly black market exchange rates ${ }^{9}$ and shows that both before and after the crisis, and in particular on Dec. 1, 2004, the black market and official exchange rates coincided almost exactly.

The devaluation led to a major recession in Mexico, with GDP dropping by $6.2 \%$ (at constant prices) from 1994 to 1995. Nominal wages remained roughly constant through the crisis and labor costs for Mexican manufacturers fell in real peso or dollar terms. The average wage for a male full-time worker with nine years of education fell from approximately $\$ 1.50$ per hour to approximately $\$ .90$ per hour from 1994 to 1995 , rising back only to $\$ 1.10$ per hour by $1999 .^{10}$

It is worth emphasizing that the peso crisis was a much larger shock than the North American Free Trade Agreement (NAFTA), which had taken effect the previous January. By 1993, after eight years of liberalizing policies, almost all Mexican quotas and other non-tariff barriers had been removed, and approximately $95 \%$ of all imports into Mexico were covered by tariffs of $20 \%$ or lower. On the U.S. side, approximately $80 \%$ of imports were covered by tariffs of $5 \%$ or less. A majority of commodities were assigned phase-out schedules of five or more years. Tariff changes under NAFTA for the majority of commodities were thus typically on the order of a few percent per year or less. A common view among observers in Mexico is that NAFTA's main role was as a commitment device to the general program of liberalization begun in the 1980s, rather than as a marked change in trade costs.

How did the manufacturing sector respond to the peso crisis? Consider the example of

\footnotetext{
${ }^{9}$ The black market rates are from Global Financial Data (http://www.globalfinancialdata.com/) and are based on monthly averages for wire transfers from New York to Mexico, as reported in Pick's World Currency Yearbook, as well as on operational rates of exchange used by the United Nations for personnel.

${ }^{10}$ These figures are from the Encuesta Nacional de Empleo Urbano (ENEU) [National Urban Employment Survey]. For details, refer to Appendix B.
} 
the Volkswagen automobile plant in Puebla, Mexico. The Puebla plant is the sole world producer of the New Beetle and the sole North American producer of the Jetta. Until July 2003, the plant also produced the Original Beetle, known in Mexico as the Sedan (or, more affectionately, the Vocho ${ }^{11}$ ), almost all of which were sold domestically. There are clear quality differences between the Original Beetle and the newer models, the New Beetle, Jetta, and Golf (a model from which the New Beetle borrows many components). The New Beetle and the Jetta have automatic window-raising mechanisms; the windows of the Original Beetle have to be cranked up by hand. The seats of the New Beetle and Jetta consist of polyurethane foam; the seats of the Original Beetle are made partly of lower-quality foam and partly of coconut fibers, a cheaper substitute. These and other differences are reflected in prices: in July 2003, the New Beetle was selling for US\$17,750, the Jetta for US $\$ 15,000$, and the Original Beetle for US\$7,500. Figure 7 illustrates the effect of the peso crisis on the plant's product mix. Between 1994 and 1995, exports as a share of total production rose sharply, due both to a decline in domestic sales and to an increase in exports. The increase in the export share was accompanied by a sharp increase in production of the higher-quality varieties as a share of output.

What consequences did this shift in product mix have inside the plant? A striking characteristic of the plant, which I visited in May 2003, was the juxtaposition of the production lines for the New Beetle and Jetta, which relied on state-of-the-art technology, and the production line for the Original Beetle, which employed essentially the same technology as when the plant opened in 1964, technology which had been in use in Germany since the 1950s. In the welding area, for instance, the conveyor belt on the Original Beetle line had been in continuous operation since 1967. The welding was done by hand, with sparks flying, and line-workers banged irregularities into shape with hammers. Under the same roof, perhaps twenty yards away, the welding for the Jetta body was performed entirely by robots; the labor requirements were limited to engineers to program the robots, and skilled maintenance workers to repair the machines in case of mechanical failure. One consequence of the shift in product mix, then, was a form of technological upgrading, an increase in the production-weighted average level of technological sophistication in the plant. This change occurred not because of an increase in the availability of new technologies, but because of a greater reliance on technologies that were already in use in the plant.

As a consequence of the shift toward the high-quality varieties, demand appears to

\footnotetext{
${ }^{11}$ Vochito if you really want to sound Mexican.
} 
have fallen for frontline production workers (técnicos), who typically have a junior high school (secundaria) education and whose starting wage in 2002 was US $\$ 11.18 /$ day. Demand appears to have risen for the skilled blue-collar workers who maintain robots and other automated machinery (especialistas), who are typically graduates of a 3-year postsecundaria vocational school on the plant grounds and whose starting wage in 2002 was US $\$ 18 /$ day. $^{12}$ I was unable to persuade the company to share detailed personnel data and hence am not able to make definitive statements about the changing skill composition, but conversations with both the former director of Human Resources and the president of the Volkswagen union confirm that the relative demand for especialistas rose with the shift in the product mix. At the white-collar level, it appears that the use of software engineers on the New Beetle and Jetta lines, highly skilled relative to the supervisors on the Original Beetle line, increased as well.

Does the example of Volkswagen generalize to the manufacturing sector as a whole? Figure 8 plots the export share of sales and the share of plants with positive exports for a balanced panel over the $1993-2001$ period; ${ }^{13}$ the shift toward exporting is evident. ${ }^{14}$ More than $80 \%$ of Mexican exports over the period went to the U.S.; the increase in exports thus largely represents an increase in sales on the U.S. market. Generalizing from the Volkswagen example, it appears likely that the increase in exports to the U.S. was accompanied by an increase in the average quality of goods produced and an upgrading of the industrial workforce in exporting plants.

\section{Theory}

To provide a framework for the empirical analysis, this section develops a model that formalizes the quality-upgrading process as it played out at Volkswagen and, anecdotal evidence suggests, across broad segments of the Mexican manufacturing sector. The model is partialequilibrium, focused on a single differentiated-goods industry assumed to be small relative to the economy as a whole in either country. Also, not all of the key implications hold for all parameter values; the model shows that there exist empirically plausible parameter values for which the implications do hold. My hope is that these sacrifices of mathematical elegance on one hand and realism on the other are justified by the extent to which the

\footnotetext{
${ }^{12}$ The source for the wage figures is the 2002-2004 Volkswagen-Puebla collective bargaining agreement.

${ }^{13}$ The dataset is described in more detail in Section 4 below and in Appendix B.

${ }^{14}$ It is a puzzle that the export share did not decline as the peso re-appreciated after the peso crisis, but given this we would not expect the quality-upgrading process to have reversed itself in the 1997-2001 period.
} 
model achieves two goals: to bring the insights of new trade theory — which, in assuming symmetric countries, has implicitly been focused on integration among developed countries - to bear on the distinctive experience of developing countries; and to tie the model directly to an empirical approach capable of investigating its implications in data on Mexican plants. $^{15}$

\subsection{Demand}

There are two countries, North and South. In each market, indexed by $d=n, s$, there is a mass $N_{d}$ of statistically identical consumers, each of which is assumed to buy one unit of a good from a continuum of goods indexed by $\omega$ and to have the indirect utility function:

$$
V(\omega)=\theta_{d} q(\omega)-\widetilde{p}_{d}(\omega)+\varepsilon
$$

where $q$ is product quality, assumed to be perfectly observable, and $\widetilde{p}$ is price relative to the price level in country $d$. The parameter $\theta_{d}$ captures the consumer's willingness to pay for quality. It can be interpreted as a function of income: given identical direct utility functions, richer consumers have a lower marginal utility of income and are willing to pay more for a given level of quality. ${ }^{16}$ I assume that $\theta_{d}$ is constant within a country but that Northern consumers are more willing to pay for quality than Southern ones: $\theta_{n}>\theta_{s}$. I treat $\theta_{d}$ as a fixed parameter, and abstract from changes in consumers' willingness to pay for quality arising from income changes due to the peso crisis. It will be convenient to keep track of prices relative to the price level in South, so let $\delta_{d}$ be the ratio of the price level in country $d$ to the price level in South; that is, $\delta_{s}=1$ and $\delta_{n}$ is the real exchange rate. The price of good $\omega$ relative to the Southern price level is then $p_{d}(\omega)=\delta_{d} \widetilde{p}_{d}(\omega)$.

The random consumer-product-match term, $\varepsilon$, is assumed to be independent and iden-

\footnotetext{
${ }^{15}$ The model is most closely related to that of Manasse and Turrini (2001), who also model heterogeneous firms producing quality-differentiated goods and frame their results in terms of wage inequality. Three features limit the usefulness of their model in this context: (1) it is not clear how to relate the utility function of their representative consumer to the choices of individual consumers, and hence not clear how to derive differences in aggregate quality demands from individual income differences; (2) product quality is a deterministic function of fixed firm characteristics, rather than a choice variable of the firm; and (3) each firm employs only one employee and the employee receives all the rents from production, with the result that it seems more natural to think of these individuals as entrepreneurs, and of dispersion of their payoffs as dispersion in profits rather than dispersion in wages.

${ }^{16}$ Following Tirole $(2000$, p. $97 \mathrm{fn} 1)$, if consumers have direct utility $U(\omega)=u(\kappa)+q(\omega)+\widetilde{\varepsilon}$ where $\kappa$ is the consumption of a non-differentiated numeraire good, then optimization yields the indirect utility function $\tilde{V}(\omega)=u\left(y_{d}-\tilde{p}_{d}(\omega)\right)+q(\omega)+\widetilde{\varepsilon}$. If $\tilde{p}_{d}(\omega)$ is small relative to the consumer's income, $y_{d}$, then a first-order expansion of the sub-utility function $u(\cdot)$ gives: $\widetilde{V}(\omega)=u\left(y_{d}\right)-\tilde{p}_{d}(\omega) u^{\prime}\left(y_{d}\right)+q(\omega)+\widetilde{\varepsilon}$. Let $\theta_{d} \equiv 1 / u^{\prime}\left(y_{d}\right), V \equiv\left[\widetilde{V} / u^{\prime}\left(y_{d}\right)\right]-\left[u\left(y_{d}\right) / u^{\prime}\left(y_{d}\right)\right], \varepsilon \equiv \widetilde{\varepsilon} / u^{\prime}\left(y_{d}\right)$. We then have (1).
} 
tically distributed across consumer with a type 1 extreme-value distribution, ${ }^{17}$ as in a standard multinomial-logit model of consumer demand (McFadden, 1981; Anderson, de Palma, and Thisse, 1992). A standard derivation yields the following expected demand for each good (Anderson, de Palma, and Thisse, 1992, theorem 2.2, p. 39):

$$
x_{d}(\omega)=\frac{N_{d} \exp \left[\frac{1}{\mu}\left(\theta_{d} q(\omega)-\frac{p_{d}(\omega)}{\delta_{d}}\right)\right]}{\int_{\Omega_{d}} \exp \left[\frac{1}{\mu}\left(\theta_{d} q(\omega)-\frac{p_{d}(\omega)}{\delta_{d}}\right)\right] d \omega}
$$

where $\mu$ is a parameter of the distribution of $\varepsilon$ that captures the degree of differentiation between goods and $\Omega_{d}$ is the set of goods available in consumer market $d$. I assume throughout that plants are risk-neutral, and write demand without the expectation operator. Note that this specification of demand combines horizontal differentiation, in the sense that if the prices of all goods are equal each will be purchased with positive probability, with vertical differentiation, in sense that if the prices of all goods are equal higher-quality goods will be purchased with higher probability.

\subsection{Production}

In each country, there is a continuum of potential entrepreneurs of mass 1 , heterogeneous in an exogenously fixed productivity parameter $\lambda$, which can be interpreted as technical knowhow or entrepreneurial ability. To streamline the exposition, consider only the decisions of Southern plants; the analysis for Northern plants is similar. It is convenient to think of a plant that enters both the domestic and export markets as producing on different production lines, indexed by $d=n, s$.

I assume that each unit of output carries fixed factor requirements: one white-collar worker, one blue-collar worker, and one machine. Product quality is assumed to depend on the "quality" of the two workers, the technical sophistication of the machine, and the ability of the entrepreneur, combining in Cobb-Douglas fashion: ${ }^{18}$

$$
q_{d}\left(k_{d}, e_{d}^{h}, e_{d}^{h} ; \lambda\right)=\lambda\left(k_{d}\right)^{\alpha^{k}}\left(e_{d}^{h}\right)^{\alpha^{h}}\left(e_{d}^{l}\right)^{\alpha^{l}}
$$

\footnotetext{
${ }^{17}$ That is, $F(\varepsilon)=\exp \left(-\exp \left(-\frac{\varepsilon}{\mu}+\gamma\right)\right)$, where $\gamma=.5772$ (Euler's constant) by assumption to ensure that the expectation of $\varepsilon$ is zero.

${ }^{18}$ This function can be interpreted as a reduced-form relationship between factor inputs and resulting product quality. It may arise, for instance, because producing high quality requires sophisticated machinery or other capital, which in turn requires high quality workers.
} 
where $k$ represents the amount of capital embodied in the machine, and $e^{h}$ and $e^{l}$ represent the quality of the white-collar and blue-collar worker, respectively. ${ }^{19}$ As in the O-ring production functions of Kremer (1993) and Kremer and Maskin (1996), which this function emulates, many low-skilled workers cannot substitute for one high-skilled one, and the qualities of different workers are strongly complementary. ${ }^{20}$ Let $\alpha \equiv \alpha^{k}+\alpha^{h}+\alpha^{l}$ and assume that improvements to product quality from a given increase in the skill and sophistication of inputs are diminishing: $\alpha<1$. This will ensure an interior solution in the choice of product quality.

Plants face a worker quality-wage schedule that is assumed to be upward-sloping and, in the interests of simplicity, linear:

$$
\begin{aligned}
& e_{d}^{h}\left(w_{d}^{h}\right)=z^{h}\left(w_{d}^{h}-\underline{w}_{c}^{h}\right) \\
& e_{d}^{l}\left(w_{d}^{l}\right)=z^{l}\left(w_{d}^{l}-\underline{w}_{c}^{l}\right)
\end{aligned}
$$

where $w_{d}^{h}$ and $w_{d}^{l}$ are the wages of white-collar and blue-collar workers on a particular production line and $z^{h}$ and $z^{l}$ are positive constants. The variables $\underline{w}^{h}$ and $\underline{w}^{l}$ represent the average wages of white-collar and blue-collar workers in the outside labor market, and are taken to be exogenous. ${ }^{21}$ These worker quality-wage schedules can be justified on the basis of a number of different models: a model in which worker quality represents general skill, workers are heterogeneous in skill levels within each occupational category, and plants must pay high wages to attract high-skill workers, as in Kremer (1993); a model in which worker quality represents effort and plants must offer efficiency wages in order to induce workers to supply it (Akerlof, 1982; Bowles, 1985; Shapiro and Stiglitz, 1984); ${ }^{22}$ or a model in which worker quality represents plant-specific skills and workers bargain for a share of the gains to investments in those skills (Hashimoto, 1981). For present purposes, the important point

\footnotetext{
${ }^{19}$ It is valid to interpret (3) as indicating that product quality is skill-intensive, as long as it is understood that this means intensive in worker skill or effort for given factor shares of employment, rather than a high white-collar share of employment.

${ }^{20}$ The ideal experiment to test the assumption that high-quality products require high-quality workers would randomly assign quality requirements to different plants, and then examine how plants adjust skill levels, skill shares, wages and technology. Although the assumption is the basis for a parsimonious account of a number of patterns presented in the empirical part of this paper, in the absence of such an experiment the ultimate validation of the assumption will depend on how well the model predicts out of sample, and hence must await future empirical work. For evidence on the related point that the production of newly invented goods requires highly skilled workers, see Xiang (2005).

${ }^{21}$ The model is thus implicitly focused on a single industry that is small relative to the economy as a whole. The task of making the model general-equilibrium and endogenizing the economy-wide wage level is left to future work.

${ }^{22}$ Dalmazzo (2002) integrates this efficiency-wage idea explicitly into the model of Kremer (1993).
} 
is that worker quality improves product quality and is costly to the plant to acquire. ${ }^{23}$

The rental cost of capital is $\rho$. I assume that there are fixed costs $f_{d}$ to entering each market and that a plant must enter the domestic market before entering the export market. The combination of constant marginal cost and the fixed cost of entry generates increasing returns to scale. There is no cost to differentiation and plants are constrained to offer just one variety. As a consequence, all plants differentiate and have a monopoly in the market for their particular variety.

\subsection{Plants' Optimization}

Each plant chooses the white-collar wage, the blue collar wage, capital intensity (which together determine quality) and prices to maximize profits, separately for each production line. As is standard in monopolistic competition models, I assume that each plant thinks of itself as small relative to the market as a whole, and treats the denominator in (2) as unaffected by its own choices. Given this assumption, optimization yields the following:

$$
\begin{aligned}
q_{d}^{*}(\lambda) & =\left(\eta \lambda \delta_{d}^{\alpha} \theta_{d}^{\alpha}\right)^{\frac{1}{1-\alpha}} \\
w_{d}^{h *}(\lambda) & =\underline{w}^{h}+\alpha^{h} \delta_{d} \theta_{d} q_{d}^{*}(\lambda) \\
w_{d}^{l *}(\lambda) & =\frac{\underline{w}^{l}}{\alpha^{k}} \alpha^{l} \delta_{d} \theta_{d} q_{d}^{*}(\lambda) \\
k_{d}^{*}(\lambda) & =\frac{\alpha^{k}}{\rho} \delta_{d} \theta_{d} q_{d}^{*}(\lambda) \\
p_{d}^{*}(\lambda) & =\mu \delta_{d}+\underline{w}^{h}+\underline{w}^{l}+\alpha \delta_{d} \theta_{d} q_{d}^{*}(\lambda) \\
x_{d}^{*}(\lambda) & =\frac{N}{D} \exp \left(\frac{\theta q(\lambda)-p(\lambda)}{\mu}\right) \\
\pi_{d}^{*}(\lambda) & =\mu x_{d}^{*}(\lambda)-f_{d}
\end{aligned}
$$

where $\eta \equiv\left(z^{h} \alpha^{h}\right)^{\alpha^{h}}\left(z^{l} \alpha^{l}\right)^{\alpha^{l}}\left(\frac{\alpha^{k}}{r}\right)^{\alpha^{k}}$ is a constant.

These equations carry several implications. First, all else equal, higher- $\lambda$ plants produce higher-quality goods, pay higher wages to both white-collar and blue-collar workers, are more capital-intensive, charge higher prices produce more output, and are more profitable than lower- $\lambda$ plants.

Second, if a plant enters both markets, then it chooses greater quality, prices, wages and capital intensity for goods sold in North than for goods sold in South, since $\theta_{n}>\theta_{s}$. The model can thus account for plants "shipping the good apples out" (Alchian and Allen,

\footnotetext{
${ }^{23}$ The implications of the three interpretations are examined in matched employer-employee data in Kaplan and Verhoogen (2006).
} 
1964; Hummels and Skiba, 2004) even in the absence of a per-unit transport cost.

Third, all else equal, plant size and wages are positively correlated, since both are increasing in $\lambda$. The model thus provides a natural explanation for the employer size-wage effect, documented by Brown and Medoff (1989) and others.

Fourth, all else equal, both prices and quality are positively correlated with plant size, since all are increasing in $\lambda$. This feature is not present in Melitz (2003), which predicts either that prices are decreasing and quality is constant in productivity (and hence plant size), or, in an alternative formulation, that quality is increasing and prices are constant in productivity (and hence plant size) (Melitz, 2003, p. 1699).

Fifth, whether the ratio of the white-collar wage to the blue-collar wage is increasing or decreasing in quality, and hence in $\lambda$ and $\theta_{d}$, depends on the sensitivity of product quality to the quality of each type of worker in (3). If product quality is more sensitive to the skill of white-collar workers, as conjectured by Kremer and Maskin (1996), then the wage ratio may be increasing in both $\lambda$ and $\theta_{d}{ }^{24}$

Finally, the fact that profitability is increasing in $\lambda$ implies that in equilibrium there will be a cut-off value for each destination, $\lambda_{d}^{\min }$, above which all plants will enter and earn positive profits, and below which no plants will enter. The cut-off is determined by the condition that the marginal plant have zero profits after paying the fixed cost of entry to the destination market.

\subsection{Observable Variables}

In practice it is rare to have data by production line within plants. In the Mexican data, we observe variables at the plant level; these can be thought of as weighted averages of the values of each production line, with the weights given by the export share of output. The

\footnotetext{
${ }^{24}$ From $(5 b)$ and $(5 c)$,$$
\frac{\partial}{\partial \lambda}\left(\frac{w_{d}^{h *}(\lambda)}{w_{d}^{l *}(\lambda)}\right)=\frac{\theta_{d} \delta_{d}}{\left(w_{d}^{l *}(\lambda)\right)^{2}}\left(\alpha^{h} \underline{w}^{l}-\alpha^{l} \underline{w}^{h}\right) \frac{\partial q_{d}^{*}(\lambda)}{\partial \lambda}
$$

A similar result holds for $\frac{\partial}{\partial \theta_{d}}\left(\frac{w_{d}^{h *}(\lambda)}{w_{d}^{l *}(\lambda)}\right)$. If $\frac{\alpha^{h}}{\alpha^{l}}>\frac{\underline{w}^{h}}{\underline{w}^{l}}$ then the wage ratio, $\frac{w_{d}^{h}(\lambda)}{w_{d}^{l}(\lambda)}$, is increasing in $\lambda$ and $\theta_{d}$.
} 
observable variables are:

$$
\begin{aligned}
\bar{w}^{h} & =\chi w_{n}^{h}+(1-\chi) w_{s}^{h} \\
\bar{w}^{l} & =\chi w_{n}^{l}+(1-\chi) w_{s}^{l} \\
\bar{k} & =\chi k_{n}+(1-\chi) k_{s} \\
\bar{q} & =\chi q_{n}+(1-\chi) q_{s} \\
E^{h} & =E^{l}=x_{s}+x_{n} \\
r_{n} & =p_{n} x_{n} \\
r_{s} & =p_{s} x_{s} \\
\nu & =\frac{r_{n}}{r_{s}+r_{n}}
\end{aligned}
$$

where $E$ is employment (of white-collar or blue-collar workers), $r$ is revenues, $\nu$ is the export share of revenues, and $\chi_{s} \equiv \frac{x_{n}}{x_{n}+x_{s}}$ is the export share of output.

Figure 9 summarizes the cross-sectional relationship between quality and $\lambda$. The dotted $\bar{q}^{*}(\lambda)$ curve represents average quality if all plants were to enter both markets, a weighted average of quality on the domestic production line, $q_{s}^{*}(\lambda)$, and quality on the export production line, $q_{n}^{*}(\lambda)$, with the weights given by the export share of output of each plant. This curve is steeper than $q_{s}(\lambda)$, both because $q_{n}(\lambda)$ is steeper than $q_{s}(\lambda)$ (since $\theta_{n}>\theta_{s}$ in (5a)), and because the export share of output is increasing in $\lambda .^{25}$ Only plants above $\lambda_{n}^{\min }$ in fact enter the export market; the solid curve represents actual average quality as a function of $\lambda$, taking into account entry patterns.

As equations (5a)-(5d) indicate, the model predicts cross-sectional patterns similar to that of the solid curve for observed white-collar wages, blue-collar wages, and capital intensity. If product quality is sufficiently more sensitive to the quality of white-collar than blue-collar workers, then we would also expect the wage ratio to follow a similar pattern.

\subsection{Discussion of Effects of Exchange-Rate Devaluation}

In the context of this model, we can think of the devaluation and the ensuing recession as having two effects: an increase in the real exchange rate, $\delta_{n}$, and a decline in the number of domestic consumers, $N_{s}$. I assume that the Northern economy is large relative to the Southern one, such that increased entry of Southern plants into the Northern market has a negligible effect on the profitability of other plants selling in North. The net effect of

\footnotetext{
${ }^{25}$ See A.7 in Appendix A.2.
} 
the exchange-rate shock on Southern plants' entry into the export market is clear: $\lambda_{n}^{\min }$ falls. The net effect on entry of Southern plants into the Southern market is ambiguous: on one hand, the devaluation makes Southern plants more competitive; on the other hand, domestic demand contracts. (Appendix A.1 demonstrates these results formally.)

Figure 10 illustrates the effect of the peso crisis on product quality. Quality on the domestic production line, $q_{s}(\lambda)$ does not depend on either $\delta_{n}$ or $N_{s}$ and hence is unaffected by the exchange-rate shock. ${ }^{26}$ Quality on the export line, $q_{n}(\lambda)$, increases for all values of $\lambda$ and to a greater extent for larger values of $\lambda$. Appendix A.2 shows that under the condition $\chi<1 / 2$, empirically realistic since on average even among exporters exports make up less than half of sales, the export share of output also increases for all values of $\lambda$ and to a greater extent for larger values of $\lambda$. Hence the dotted average quality line, $\bar{q}^{*}(\lambda)$, shifts up with the crisis, both because the $q_{n}(\lambda)$ curve shifts up and because the export share of output increases. The cut-off of entry to the export market shifts to the left. As noted above, the direction of movement of the cut-off for entry into the domestic market is ambiguous. The figure illustrates the case in which the demand contraction dominates, which appears to be the empirically relevant one; bankruptcies rose sharply during the crisis.

Figure 11 depicts the difference between the two solid lines in Figure 10, the change in observable quality taking into account entry patterns. The plants that switch into exporting (between $\lambda_{n}^{\min ^{\prime}}$ and $\lambda_{n}^{\min }$ ) see an especially large increase in average quality. Average quality is increasing in $\lambda$ within the category of switchers and within the category of always exporters (to the right of $\lambda_{n}^{\min }$ ). As suggested by equations (5a)-(5e), the model predicts a similar pattern for white-collar wages, blue-collar wages and capital intensity. If product quality is sufficiently more sensitive to the quality of white-collar than blue-collar workers (refer to footnote 24, then the wage ratio will follow a similar pattern. By assumption, there is no such prediction for the white-collar share of employment.

\section{Data}

The results in this paper are primarily based on the Encuesta Industrial Anual (EIA) [Annual Industrial Survey], a yearly panel survey conducted by the Instituto Nacional de Estadísticas, Geografía, e Información (INEGI), the Mexican government statistical agency.

\footnotetext{
${ }^{26}$ The peso crisis reduced real incomes of Mexican consumers. If we allowed this negative income shock to reduce consumers' willingness to pay for quality, as found by McKenzie (2006), then we would expect the $q_{s s}(\lambda)$ curve to shift down in response to the crisis, which would tend to accentuate the differential responses of low- $\lambda$ and high- $\lambda$ plants.
} 
The EIA is based on a deterministic sample of the largest plants in 205 of the 309 6-digit manufacturing industries in the Mexican industrial classification system. The EIA survey excludes maquiladoras, assembly plants that participate in a Mexican government exportpromotion program. ${ }^{27}$ I constructed two balanced panels from the EIA: the EIA 1993-2001 Panel, which contains 3,263 plants; and the EIA 1984-2001 Panel, which contains fewer plants - 1,114 - but over a longer period. ${ }^{28}$

INEGI carried out a more qualitative plant survey, the Encuesta Nacional de Empleo, Salarios, Tecnología y Capacitacion (ENESTyC) [National Survey of Employment, Wages, Technology and Training] in 1992, 1995, 1999 and 2001, with questions referring to the previous year. In 1995, 1999 and 2001 the ENESTyC elicited information on ISO 9000 certification, an international production standard. While ISO 9000 is mainly a procedural standard, the common view among Mexican managers is that ISO 9000 is a signal of high product quality, and I will take it as such for the purposes of this paper. ${ }^{29}$ I refer to the 844 plants that appear in both the EIA and the ENESTyC and that have data on ISO 9000 certification in 1995, 1999 and 2001 as the EIA-ENESTyC panel.

Details on the processing of these data as well as of the other datasets used in this paper, including the Encuesta Nacional de Empleo Urbano (ENEU) [National Urban Employment Survey] and the Estadísticas Mensuales de la Industria Maquiladora de Exportación (EMIME) [Monthly Statistics on Maquiladora Export Industry], are in Appendix B.

Panel A of Table 1 reports summary statistics for the EIA 1993-2001 Panel for the initial year, 1993, separately by export status. ${ }^{30}$ As observed by Bernard and Jensen (1999) in U.S. data, there are systematic differences between exporters and non-exporters in cross-section: exporters are larger in terms of employment and total sales; are more capital-intensive; and pay higher wages, especially to white-collar workers. They also have greater domestic sales. Panel B of Table 1 reports means by export status for relevant variables from the EIA-ENESTyC Panel. We see further that exporters are more likely to have ISO 9000 certification, hire white-collar and blue-collar workers with more years of schooling, and

\footnotetext{
${ }^{27}$ In Mexico, the participants in this program are referred to as maquiladoras de exportación (exporting maquiladoras). The word maquiladora is used more generally to apply to any plant producing under subcontract. I use the term only to refer to the former group.

${ }^{28}$ I also constructed an unbalanced panel for the 1993-2001 period, which I refer to as the EIA 1993-2001 Unbalanced Panel; refer to footnote 42 and the data construction details in Appendix B.

${ }^{29}$ ISO 9000 certification is not cheap talk. Obtaining certification typically takes between nine months and two years and costs $\$ 187,000$ (1996 U.S. dollars) on average (Guler, Guillen, and Macpherson, 2002).

${ }^{30}$ The EIA 1984-2001 Panel contains a greater share of large plants than the EIA 1993-2001 Panel but the qualitative differences between non-exporters and exporters are similar to those reported here.
} 
have lower rates of absenteeism, accidents and turnover. ${ }^{31}$

\section{$5 \quad$ Proxy-Variable Strategy}

\section{$5.1 \quad$ Econometric Model}

The main implication of the theoretical model is that the pattern illustrated by Figure 11 should hold for a number observable variables - export share, white-collar wage, bluecollar wage, capital intensity, and ISO 9000 certification - to a greater extent during the peso crisis period than in other periods without an exchange-rate devaluation. A central econometric challenge in testing this implications is that the key variable, entrepreneurial ability $\lambda$, is unobserved. This section presents an econometric strategy that uses simple observable proxies for this parameter, $\lambda$. Section 6 below uses an alternative strategy that avoids the need for proxies.

The theoretical model suggests a number of variables that are correlated with $\lambda$ in crosssection and hence that are candidates to be proxies. My preferred proxy is log domestic sales, deviated from industry means. The main argument for this proxy is that sales is the only variable that is observed separately by production line. In cross-section, domestic sales thus bears a smooth, continuous relationship to $\lambda$, without the discontinuity at the cut-off for entry into the export market. The domestic sales variable has the additional advantage that it is relatively well measured. I present results for a variety of alternative proxies below.

The discontinuous, non-linear function depicted in Figure 11 is unlikely to hold empirically, both because of the noise in domestic sales (and the other proxies) and because the costs of entering the export market are likely to be heterogeneous across plants and industries. Rather than attempting to estimate that curve, I approximate it with a linear function. In the absence of background trends between higher- $\lambda$ and lower- $\lambda$ plants, we would expect a positively sloped line during the peso-crisis period and a horizontal line in other periods. In practice such background trends are likely to exist, however, so the testable prediction is that the slope of changes in the observable variables - export share, white-collar wage, blue-collar wage, capital intensity, and product quality — against $\lambda$ will be greater in periods with major devaluations than in periods without.

\footnotetext{
${ }^{31}$ These differences are significant at the $5 \%$ level for training, white-collar schooling, and absentee rate, but not for ISO 9000 certification, blue-collar schooling, the accident rate or the turnover rate.
} 
The main estimating equation is the following:

$$
\triangle y_{i j r}=\alpha+\widetilde{\lambda}_{i j r} \beta+\delta_{j}+\xi_{r}+u_{i j r}
$$

where $i, j$ and $r$ index plants, industries and states, respectively; $\triangle y_{i j r}$ is a change in one of the outcome variables; $\alpha$ is an intercept term; $\widetilde{\lambda}_{i j r}$ is the value of entrepreneurialability proxy in the initial year; $\delta_{j}$ is an industry fixed effect; $\xi_{r}$ is a state fixed effect; and $u_{i j r}$ is a mean-zero disturbance. I estimate this equation separately by period and compare the coefficient estimates $\widehat{\beta}$ across periods. When using the EIA 1993-2001 Panel, I estimate for the periods 1993-1997 and 1997-2001. When using the EIA 1984-2001 Panel (for which exports are available beginning in 1986), I use the periods 1986-1989, 1989-1993, 1993-1997, and 1997-2001. The theoretical predictions are that $\widehat{\beta}_{1993-1997}>\widehat{\beta}_{1997-2001}$, $\widehat{\beta}_{1993-1997}>\widehat{\beta}_{1989-1993}$, and $\widehat{\beta}_{1986-1989}>\widehat{\beta}_{1989-1993}$ when the dependent variable is the change in the export share, white-collar wage, blue-collar wage, capital intensity or ISO 9000 certification. Note that if there were just two groups of plants, high- $\tilde{\lambda}$ and low- $\tilde{\lambda}$, then this strategy would amount to a familiar triple-differences strategy: $\widehat{\beta}_{1993-1997}$ would reflect the difference in differences between high- $\tilde{\lambda}$ and low- $\tilde{\lambda}$ plants from 1993 to 1997, $\widehat{\beta}_{1997-2001}$ the difference in differences from 1997 to 2001 , and $\widehat{\beta}_{1993-1997}-\widehat{\beta}_{1997-2001}$ the difference in difference in differences.

The analogy with triple-difference designs highlights a potential pitfall in the estimation. If we use information from many years of pre- or post-crisis data without taking into account serial correlation across periods, then we may overstate the amount of independent variation in the pre-treatment and post-treatment periods and understate the standard errors on the coefficient estimates, as discussed by Bertrand, Duflo, and Mullainathan (2004). My strategy is to select just one year of data pre-crisis and one year post-crisis, i.e. 1993 and 1997 for the peso crisis period, 1997 and 2001 for the placebo period without an exchangerate shock. ${ }^{32}$ Bertrand, Duflo, and Mullainathan (2004) refer to this strategy as "ignoring time-series information" and find that it performs reasonably well in a Monte Carlo study. ${ }^{33}$

A potential concern with regression (7) when the change in export share appears on the left-hand side and initial log domestic sales on the right is that domestic sales appears in the denominator of the export share in the initial period and hence any measurement

\footnotetext{
${ }^{32}$ I have examined the robustness of the results to the choice of beginning and end years. The basic results are not sensitive to these choices.

${ }^{33}$ I have varied the years used as initial and final years of each period; the basic results are insensitive to these changes.
} 
error in domestic sales will generate a mechanical positive bias in the estimate of $\beta$. Under the assumption that the measurement error in domestic sales is uncorrelated over time, an IV strategy instrumenting log domestic sales with its lag will correct this bias. ${ }^{34} \mathrm{~A}$ disadvantage of this IV strategy is that it requires two years of pre-devaluation data. In the case of the EIA 1993-2001 Panel, this means using 1993 as the lagged value and looking at changes over the 1994-1997 period. It may be that in 1994 plants were already responding to NAFTA, which had been implemented at the beginning of the year. For this reason, I present both the OLS and the IV results below.

It is important to consider the possibility that plants are characterized by time-varying productivity shocks in addition to the time-invariant productivity represented by $\lambda$. It may be that the productivity shocks are correlated with $\lambda$ if, for instance, new technologies periodically become available to all plants but more technologically advanced plants are better able to adopt the new technology. If so, and if the productivity shocks also affect the dependent variable, $\triangle y$, then the OLS estimate of $\beta$ will be inconsistent. This problem is not addressed by instrumenting with lagged domestic sales. Note, however, that as long as the distribution of the productivity shocks and the effect of the shocks on the dependent variable are constant over time, then the difference in OLS coefficients (e.g. $\widehat{\beta}_{1993-1997}-\widehat{\beta}_{1997-2001}$ ) will be consistent. This underlines the need to have a "control" period without a devaluation against which to compare the "treatment" period of the peso crisis. The treatment period-control period comparison can difference out any such differential background trends between higher- and lower- $\lambda$ plants. ${ }^{35}$

\subsection{Results}

Let us begin with a set of graphs that illustrate the main results. Figures 12a-d plot non-parametric regressions of the levels of the export share, log white-collar wages, log blue-collar wages, and the log wage ratio in pre- and post-crisis years against log domestic sales in 1993. The dark, bold curves are for the pre-crisis year, the gray curves for the postcrisis year. All variables have been deviated from year-specific industry means. Figure 12a

\footnotetext{
${ }^{34}$ The assumption that the measurement error in domestic sales is uncorrelated over time is admittedly quite strong, and for this reason the IV results should be treated with caution.

${ }^{35} \mathrm{~A}$ related point is that caution is warranted in drawing causal inferences from regressions of, for instance, changes in wages on changes in the export share or in other measures of export status, as in Bernard and Jensen (1997) or Bustos (2005). The theoretical model suggests that a positive productivity shock will generate both an increase in exports and an increase in wages, giving rise to a positive omitted-variables bias in the coefficient on the change in exports.
} 
illustrates that the difference in export share between $1994^{36}$ and 1997 is larger for plants with higher domestic sales in 1993. ${ }^{37}$ Figures 12b-d illustrate both that log white-collar wages, log blue-collar wages, and the log wage ratio are increasing in cross-section, and also that initially higher-domestic-sales plants saw greater increases in these wage variables than initially lower-domestic-sales plants over the period. It is also worth emphasizing that these figures do not impose linearity; the fact that they are approximately linear suggests that the linearization of the model reflected in (7) is not an unreasonable approximation, at least for the observable wage variables that are the outcomes of primary interest. Figures 13a-d compare changes in our key variables over 1993-1997 period (dark, bold curves) to changes over the 1997-2001 period (gray curves), using deviated log domestic sales in the initial years (1993 and 1997) on the x-axes. The changes over the 1993-1997 period are visibly larger for higher- $\lambda$ plants for all three wage variables, log white-collar wages, log blue-collar wages, and the log wage ratio.

To get a better sense of the statistical significance of these patterns, we now turn to the regression results. Panel A of Table 2 reports cross-sectional regressions of six different outcome variables on log domestic sales in 1993 (and industry and region effects), using plants in the EIA 1993-2001 Panel. As expected, white-collar wages, blue-collar wages and capital intensity are positively correlated with the $\lambda$ proxy within industries. The coefficient in the export share equation is negative, but this appears to be due to a mechanical bias generated by measurement error in domestic sales, negative in this case; when log domestic sales in 1994 is instrumented with its lag, the coefficient is .005 and significant at the $5 \%$ level. ${ }^{38}$

Panel B of Table 2 reports estimates of (7) for the same six different outcome variables, estimated separately for 1993-1997 and 1997-2001. In the OLS results, that the coefficient on log domestic sales is significantly larger in 1993-1997 than in 1997-2001 for the export share, white-collar wages, blue-collar wages, the wage ratio, and capital intensity. The magnitudes indicate economically significant effects. Consider two plants, one of which is $10 \%$ larger in log domestic sales terms than the other. Column 2 indicates that the

\footnotetext{
${ }^{36}$ I use 1994 as the pre-crisis year for the export share to avoid the mechanical negative bias in the relationship between the export share in 1993 and domestic sales in 1993.

${ }^{37}$ The high values of export shares at low values of log domestic sales on both curves are due to a small number of plants that appear to be maquiladoras, that were included in the EIA dataset by mistake, and that my cleaning procedures failed to filter out (see Appendix B).

${ }^{38}$ Non-parametric cross-sectional regressions of these outcome variables against log domestic sales (deviated from industry means) suggest that the assumption of linearity in (7) is not unreasonable, at least for the observable wage variables that are the outcomes of primary interest. See Figures 12-13.
} 
larger plant had an approximately .7\% greater wage increase for white-collar workers than the smaller plant during the 1993-1997 period, and a .16\% greater increase during 19972001. It is notable that there is a significant difference in differential changes in the log wage ratio of white-collar to blue-collar workers. This is consistent with the conjecture of Kremer and Maskin (1996) that product quality is more sensitive to the skill of managerial workers. There is no evidence of differential trends in the ratio of white-collar hours to total hours; the coefficients are precisely estimated and essentially zero in both periods. The IV estimates, instrumenting initial log domestic sales with its lag, are of smaller magnitude than the OLS estimates, in part a consequence of the fact that the dependent variables are changes over a shorter period, ${ }^{39}$ but the differences in slopes between the two periods for the wage variables and capital intensity are robust.

Table 3 presents OLS results for the EIA 1984-2001 Panel, which allows us to look before the peso crisis period as well as after. As was illustrated by Figure 5, the peso depreciated sharply in 1985-1986 and subsequently re-appreciated over the 1987-1993 period. Although the aggregate export response to the 1985-1986 devaluation was smaller than to the peso crisis, we would nonetheless expect to see greater differential trends between higher- and lower- $\lambda$ plants in the 1986-1989 and 1993-1997 periods than in the 1989-1993 period. The coefficients in the export share equations are just marginally distinguishable, and there is an anomalous result for capital intensity, but the important message of the table is that for the wage outcomes the earlier devaluation period (1986-1989) resembles the pesocrisis period (1993-1997), and the 1989-1993 period of re-appreciation resembles the postcrisis re-appreciation period (1997-2001). This particular time pattern of changes points to exchange-rate movements as a driving force of the differential wage changes.

Table 4 presents results for additional variables available only in the EIA-ENESTyC panel. Panel A presents cross-sectional linear regressions similar to those of Panel A of Table 2 for variables from the ENESTyC survey. There is strong evidence of cross-sectional correlation between log domestic sales and indicators that are plausibly associated with high-quality production. Controlling for industry and region effects, larger plants are significantly more likely to have ISO 9000 certification, to have a formal training program, to employ white-collar and blue-collar workers with higher average schooling, and to have lower turnover, accident, and the absentee rates. Panel B reports estimates of (7) for these outcome variables. For ISO 9000 certification there is strong evidence of differential trends

\footnotetext{
${ }^{39}$ In the case of the export share, the IV procedure also removes the mechanical positive bias arising from the fact that domestic sales appears in the denominator.
} 
between initially smaller and initially larger plants, and the difference in differential trends across periods is marginally significant. There is also evidence of a greater differential increase in the average schooling of blue-collar workers in the earlier period. ${ }^{40}$ There is no strong evidence of differential changes in the other variables. One interpretation of these results is that quality upgrading requires changing the composition of the blue-collar workforce but not other workplace practices. Another plausible explanation, however, is simply that the other workplace-practice variables are too poorly measured to pick up subtle changes in plant behavior. The results using the ENESTyC variables should be treated with caution — ISO 9000 is not an ideal measure of product quality, sample sizes are relatively small, and the intervals between waves of the ENESTyC are of different lengths, among other reasons - but the cross-sectional patterns and the difference in differential trends in ISO 9000 certification and blue-collar schooling are corroborative evidence for the quality-upgrading hypothesis.

While the domestic sales proxy has much to recommend it, it can be criticized on the grounds that plant size may reflect a number of factors that are unrelated to entrepreneurial ability or productivity. Table 5 reports estimates of (7) for the export share, white-collar wages, blue-collar wages and the wage ratio using a variety of alternative proxies that theory predicts will be correlated with $\lambda$ : log employment; predicted export share; predicted ISO 9000 certification; the first principal component of a number of variables hypothesized to be correlated with $\lambda$; total factor productivity; log domestic sales per worker; and actual export share. Details on the construction of each of these proxies are in Appendix B.6. Unsurprisingly, they tend to be highly correlated within industries; Appendix Table 1 reports bivariate correlations among them. The results for the export share, white-collar wages and blue-collar wages are generally quite robust to the choice of proxy: the difference in coefficients is at least marginally significant in all but one case. ${ }^{41}$ The results for the wage ratio are somewhat less robust, but are generally consistent with those using the domestic-sales proxy in Table $2 .{ }^{42}$

\footnotetext{
${ }^{40}$ It is worth emphasizing, however, that the schooling measures are based on managers' estimates of the number of workers in broad schooling categories, and are likely to be quite noisy.

${ }^{41}$ Note that in any given year more than half of plants have zero exports, and the actual export share proxy only varies among the initially exporting plants. This may explain the non-robustness of the estimate for white-collar wages when using actual export share as the $\lambda$ proxy.

${ }^{42}$ Using an unbalanced panel from the EIA for 1993-2001, I have also estimated a Heckman selectioncorrection model to correct for endogenous exit (Heckman, 1976); see Appendix Table 2. The model is identified on the basis of functional form assumptions, rather than an excluded instrument, and the estimates should be treated with caution, but it is nonetheless reassuring that they correspond closely to the results using the EIA 1993-2001 balanced panel.
} 


\section{Latent-Factor Strategy}

\subsection{Econometric Model}

Despite the fact that the results from the proxy-variable strategy appear to be robust to the choice of proxy, one might argue that all proxies are indirectly picking up the effects of size or other factors that are unrelated to the notion of entrepreneurial ability that underpins the theoretical model. In addition, one might object that any one proxy on its own does not make efficient use of the available data. This section takes an alternative approach to the problem of unobservability of the productivity parameter. It uses the factor-analytic structure of the theoretical model to estimate the parameters relating productivity and the observable variables for all period simultaneously by maximum likelihood, without the first-step construction of proxies.

As in the proxy-variable strategy, I take a linearized version of the theoretical model. Appendix A.3 shows that a first-order approximation of the equations for the observable variables, (6a)-(6h), yields the following: ${ }^{43}$

$$
\begin{aligned}
\nu_{i j t} & =a_{1, j t}+b_{1, t} \tilde{\lambda}_{i j}+\varepsilon_{1, i j t} \\
\bar{w}_{i j t}^{h} & =a_{2, j t}+b_{2, t} \tilde{\lambda}_{i j}+\varepsilon_{2, i j t} \\
\bar{w}_{i j t}^{l} & =a_{3, j t}+b_{3, t} \tilde{\lambda}_{i j}+\varepsilon_{3, i j t} \\
\bar{k}_{i j t} & =a_{4, j t}+b_{4, t} \tilde{\lambda}_{i j}+\varepsilon_{4, i j t} \\
\bar{q}_{i j t} & =a_{5, j t}+b_{5, t} \tilde{\lambda}_{i j}+\varepsilon_{7, i j t} \\
E_{i j t}^{h} & =a_{6, j t}+b_{6, t} \tilde{\lambda}_{i j}+\varepsilon_{5, i j t} \\
E_{i j t}^{l} & =a_{7, j t}+b_{7, t} \tilde{\lambda}_{i j}+\varepsilon_{6, i j t} \\
r_{s, i j t} & =a_{8, j t}+b_{8, t} \tilde{\lambda}_{i j}+\varepsilon_{8, i j t}
\end{aligned}
$$

where $i, j$ and $t$ index plants, industries and periods; $\tilde{\lambda}_{i j}$ is productivity deviated from industry means (that is, $\tilde{\lambda}_{i j} \equiv \lambda_{i j}-\bar{\lambda}_{j}$, where $\bar{\lambda}_{j}$ is the mean for industry $j$ ); and the dependent variables are defined as above, with wages, the capital-labor ratio, employment (hours) and revenues measured in logs. The slope terms $b_{m, t}$ for $m=1,2, \ldots, 8$ are assumed

\footnotetext{
${ }^{43}$ The linearization is complicated by the fact that the export share is discontinuous at the cut-off value for entry into the export market, $\lambda_{n}^{\mathrm{min}}$. My approach is to simplify the problem by treating the export share of output as a differentiable function of $\lambda$. One interpretation of this is that the export share is observed with error, for the reasons discussed in footnote 52 below, and noise should be added to the non-differentiable curve in Figure 11. The non-parametric regressions in Figure 12 suggest that the linearization is not wildly inappropriate, at least for the wage variables that are of primary interest.
} 
to be constant across industries within a given year but to vary across years. Note that each of the equations (8a)-(8h) is a restatement of (7) in levels rather than changes. ${ }^{44}$ The coefficient $\beta$ in (7) in, for instance, the peso-crisis period corresponds here to a difference in slope coefficients between 1993 and $1997, b_{m, 1997}-b_{m, 1993}$. In the context of (8a)-(8h), the predictions of the theoretical model are (refer to Appendix A.3):

$$
\begin{aligned}
& b_{m, t}>0 \forall m, t \\
& \left(b_{m, 1997}-b_{m, 1993}\right)-\left(b_{m, 2001}-b_{m, 1997}\right)>0 \text { for } m=1,2,3,4,5
\end{aligned}
$$

Equations (8a)-(8h) make clear that the model has a factor-analytic structure, with a form similar to the "multiple indicator" models of Jöreskog and Goldberger (1975). In a given period, the observable variables are all functions of the same unobserved factor, $\tilde{\lambda}_{i j}$. The peso devaluation is hypothesized to affect the slope of each dependent variable with respect to the unobserved factor, but the unobserved factor itself is fixed over time. If one knew the distribution of the entrepreneurial-ability term, one could integrate over that distribution and estimate all of the parameters, $a_{m, j t}, b_{m, t} \forall m, j, t$, simultaneously by maximum likelihood. In this approach, one would prefer to avoid making strong assumptions about the distribution of the unobserved heterogeneity, since one would have no theoretical justification for the choice. Here I follow Heckman and Singer (1984) in approximating the distribution of underlying heterogeneity non-parametrically using a discrete mass-point distribution. The number, height and length of the steps of the step-function cdf are estimated simultaneously with the other model parameters in the maximum likelihood procedure. The resulting semi-parametric estimator is related to estimators used by Keane, Moffitt, and Runkle (1988) and Clerides, Lach, and Tybout (1998). ${ }^{45}$

This latent-factor strategy is not costless: to estimate the model I must impose distributional assumptions on the idiosyncratic errors, $\varepsilon_{k, i j t}$. In particular, I assume that the error terms have a multivariate normal distribution and are uncorrelated across equations and years. That is, setting $\varepsilon_{i j t} \equiv\left(\varepsilon_{1, i j t} \varepsilon_{2, i j t} \varepsilon_{3, i j t} \varepsilon_{4, i j t} \varepsilon_{5, i j t} \varepsilon_{6, i j t} \varepsilon_{7, i j t} \varepsilon_{8, i j t}\right)^{\prime}$, the assumption is:

$$
\varepsilon_{i j t} \mid \tilde{\lambda}_{i j}, j, t \sim \mathcal{N}(0, Q)
$$

\footnotetext{
${ }^{44}$ In this section, I omit the region effects.

${ }^{45}$ Mroz (1999) presents a valuable exposition of the discrete-approximation approach. Bigsten et al. apply the method in investigating learning-by-exporting among African plants.
} 
where $Q$ is a diagonal matrix with diagonal elements $\left\{\sigma_{m}^{2}\right\}$, for $m=1,2, \ldots, 8$. The flexibility that is gained in the specification of the distribution of the underlying factor is important compensation for this cost, however.

Let $\boldsymbol{y}_{i j t} \equiv\left(\nu_{i j t}, \bar{w}_{i j t}^{h}, \bar{w}_{i j t}^{l}, \bar{k}_{i j t}, E_{i j t}^{h}, E_{i j t}^{l}, \bar{q}_{i j t}, r_{s, i j t}\right)^{\prime}$, a vector of the dependent variables in (8a)-(8h). Let $\boldsymbol{b}$ be a vector of the $8 * T$ coefficients of interest, $b_{m, t}$, and let $\boldsymbol{a}$ be a vector of the industry-year specific intercepts, $a_{j t}$. The likelihood conditional on $\tilde{\lambda}_{i j}$ is:

$$
\mathcal{L}\left(\boldsymbol{a}, \boldsymbol{b} \mid \tilde{\lambda}_{i j}, \boldsymbol{y}_{i j t}\right)=\prod_{i=1}^{J} \prod_{i=1}^{I_{j}} \prod_{t=1}^{T} \prod_{m=1}^{8} \frac{1}{\sigma_{m}} \varphi\left(\frac{y_{m, i j t}-a_{j t}-b_{m, t} \tilde{\lambda}_{i j}}{\sigma_{m}}\right)
$$

where $J$ is the total number of industries, $I_{j}$ is number of plants in industry $j, T$ is the total number of periods, and $\varphi(\cdot)$ is the standard normal pdf.

It is not feasible to maximize (11), since $\tilde{\lambda}_{i j}$ is not known. Assuming that the underlying heterogeneity has a discrete distribution with $V$ points of support, the likelihood becomes a summation over $V$ conditional likelihood functions:

$$
\begin{aligned}
\mathcal{L}\left(\boldsymbol{a}, \boldsymbol{b} \mid \boldsymbol{y}_{i j t}\right) & =\sum_{v=1}^{V} \tau_{v} \mathcal{L}\left(a, b \mid \tilde{\lambda}_{v}, y_{i j t}\right) \\
& =\sum_{v=1}^{V} \tau_{v} \prod_{i=1}^{J} \prod_{i=1}^{I_{j}} \prod_{t=1}^{T} \prod_{m=1}^{8} \frac{1}{\sigma_{m}} \varphi\left(\frac{y_{m, i j t}-a_{j t}-b_{m, t} \tilde{\lambda}_{v}}{\sigma_{m}}\right)
\end{aligned}
$$

where $\tau_{v}$ is the probability corresponding to the $v^{t h}$ mass-point $\tilde{\lambda}_{v}$. The $\tau_{v}$ and the $\tilde{\lambda}_{v}$ for $v=1,2, \ldots, V$ can then be estimated simultaneously with the vectors of coefficients, $\boldsymbol{a}$, and b. The Monte Carlo study by Mroz (1999) for a simpler model suggests that this method performs well under a variety of assumptions, and avoids the errors of inference that would arise from imposing an incorrect distribution on the underlying heterogeneity.

A number of practical issues must be addressed in the estimation. First, the coefficients $b_{m, t}$ are not identified separately from the scale of the latent factor, $\tilde{\lambda}$, and normalizations have to be imposed. I normalize the discrete factor such that $\tilde{\lambda}_{\bar{v}}-\tilde{\lambda}_{\underline{v}}=1$ and $\sum_{v=1}^{V} \tau_{v} \tilde{\lambda}_{v}=0$, where $\underline{v}$ and $\bar{v}$ represent the lowest and highest mass-points. (See Appendix A.4 for details.) Second, to reduce the computational burden it is convenient to concentrate the industryyear-specific intercepts out of the likelihood function. Given the normalizations for $\tau_{v}$ and $\tilde{\lambda}_{v}$, it is straightforward to show that the first order condition for these intercept parameters implies that the optimal estimate for each $a_{m, j t}$ is simply $\bar{y}_{m, j t}$, the industry-year mean of 
the corresponding dependent variable, regardless of the $b_{m, t}, \tau_{v}$ and $\tilde{\lambda}_{v},{ }^{46}$ and I insert those estimates before searching over the other parameters. Third, while the locations of the mass-points, the probability associated with each mass-point, and the error variances are bounded, it is convenient to allow the search algorithm to search over auxiliary parameters defined over the real line and then transform those auxiliary parameters to satisfy the constraints. (See Appendix A.4 for details.) Fourth, one must choose starting values for the search algorithm. My approach is to use OLS estimates from the estimation of (8a)-(8e) using log domestic sales in each period (deviated from industry-year means and standardized to have variance 1) as a measure of $\tilde{\lambda}_{i j}$. Fifth, one must choose the number of mass-points, $V$. There is little agreement among empirical researchers about the best way to make this choice. Mroz (1999) suggests beginning with a small number of points and using likelihoodratio tests to determine whether to add an additional point of support. I begin with two points; if the likelihood ratio test indicates that the model can be rejected at $95 \%$ confidence in favor of a model with an additional point of support, I add the additional point. ${ }^{47}$ The lowest number of mass-points that is not rejected by this procedure is 10 ; hence I set $V=10$.

\subsubsection{Estimates}

Table 6 reports the results from maximizing the likelihood function (12) for the variables available in the EIA $1993-2001$ panel (i.e. for $m=1, \ldots 4,6, \ldots 8) .{ }^{48}$ The standard errors

${ }^{46}$ The first-order condition $\frac{\partial \mathcal{L}\left(a, b \mid y_{i j t}\right)}{\partial a_{m, j t}}=0$ implies

$$
\hat{a}_{m, j t}=\bar{y}_{m, j t}-b_{m, t} \sum_{v=1}^{V} \tau_{v} \tilde{\lambda}_{v}
$$

where $\bar{y}_{m, j t} \equiv \frac{1}{I_{j}} \sum_{i=1}^{I_{j}} y_{m, i j t}$ and $I_{j}$ is the number of plants in industry $j$. Given the above normalizations, the second term is zero.

${ }^{47}$ Mroz (1999) uses a $75 \%$ criterion, rather than $95 \%$.

${ }^{48}$ Figure 12 suggests that the assumption of linearity of the relationship between the log wage variables and the underlying productivity term, as proxied by domestic sales, is not unreasonable, but one might be more concerned about the export share variable, which is censored at zero for many plants and is more likely to show a sharp discontinuity at the margin for entry into the export market. To address this concern, I estimated a separate model that drops the export share equation (8a) and instead includes a discrete choice for whether to be an exporter and an equation for log export sales conditional on being an exporter, allowing for correlation in the error terms between the two equations. With the introduction of the nonlinearity, it is no longer possible to deviate from industry-year means to avoid estimating intercept terms. For the two new equations, I estimated separate industry-year intercepts for the 9 two-digit industries in manufacturing, adding 54 parameters to the model. The model yielded slope coefficients in the discretechoice exporter equation and the export sales equation increasing over 1993-1997 more than over 1997-2001, and slope estimates for the other dependent variables that were qualitatively consistent with those in Table 6. Because the results are qualitatively similar between the two models, I focus here on the simpler, fully linearized model. 
in brackets are based on 50 bootstrap replications using the reported point estimates as starting values. In the bootstrap procedure, I re-sample the nine-year histories of plants, rather than particular plant-year observations, as suggested by Kapetanios (2004). Consider the results for the export share, white-collar wages, blue-collar wages, and capital intensity (Columns 1-4). We see that these slope estimates in the top panel are all positive and highly significant, consistent with the theoretical model and the reduced-form patterns illustrated in Figure 12. ${ }^{49}$ Note also that the slope coefficients for white-collar wages are significantly greater than the slopes for blue-collar wages in each year; this indicates that the slopes for the wage ratio would also be positive. The results in the bottom panel indicate that the differences in slopes between 1993 and 1997 for these variables are greater than the differences in slopes between 1997 and 2001. The differences in differences in slopes for these variables are significant at the $1 \%$ level. These results are consistent with the results from the proxy-variable strategy above.

An advantage of the latent-factor strategy over the proxy-variable strategy is that we can treat plant size as an outcome variable. Consider the results for white-collar hours, bluecollar hours, and domestic sales in Columns 5-7. The estimates of the slope coefficients in the top panel indicate that higher- $\tilde{\lambda}$ plants are indeed larger, in terms of both employment and domestic sales. Turning to changes in slopes in the bottom panel, we see that the difference in slope coefficients for white-collar hours is close to zero and insignificant for both the 1993-1997 period and the 1997-2001 period. The difference in differences in slopes is also insignificant. Interestingly, there is some evidence of a greater differential increase in blue-collar hours in higher- $\tilde{\lambda}$ plants in the peso-crisis period. But the key point is that there is no evidence of differential increases in demand for white-collar hours in higher$\tilde{\lambda}$ plants that might explain the wage patterns in Columns 2-3. In addition, note that in 1997 and 2001, the slopes for the white-collar and blue-collar hours equations are not statistically distinguishable from one another, indicating that higher- $\tilde{\lambda}$ plants did not employ a greater share of white-collar workers. The results for differences in slopes for domestic sales in Column 7, bottom panel, suggest that there are indeed differential background trends between higher- and lower-domestic-sales plants. The differences in slopes between 1993 and 1997 and between 1997 and 2001 are of the same magnitude, however. The difference in differences in slopes is not significant.

\footnotetext{
${ }^{49}$ The magnitudes of these coefficients depend on the arbitrary normalization assumption for the masspoint estimates described above. The information content of the estimates lies in their relation to one another, not in their magnitudes.
} 
I extend the baseline latent-factor estimates by adding ISO 9000 certification as an observable variable and estimating using the EIA-ENESTyC Panel. Table 7 presents the results. ${ }^{50}$ The key results are for ISO 9000 certification in Column 1. There is clear evidence that the slope coefficient increased more over the peso-crisis period than over the later period. The results for wages, capital-intensity and hours are similar to those in Table 6 . Once again, caution is warranted in interpreting these results, since ISO 9000 certification is far from an ideal measure of product quality. But it is reassuring that these results are consistent with those for the proxy-variable strategy, as well as with the theoretical model.

\section{Alternative Hypotheses}

The identification strategy of this paper, like other triple-difference-type research designs, relies on the assumption that there are no other factors generating a difference in differential wage trends between high- $\lambda$ and low- $\lambda$ plants. But the peso crisis had many effects on the Mexican economy, and one might argue that some of them generated such a difference in differential trends. The leading candidate is the banking crisis and general contraction of credit that followed the exchange-rate devaluation.

To address this concern, I draw on balance sheet data from publicly listed firms on the Mexican stock market over the 1989-2000 period. These are the data used by Pratap and Urrutia (2004) and Aguiar (2005), and are the most detailed micro-data with balance-sheet information available in Mexico. Summary statistics are in Table 8. In these data, exporting plants have a significantly larger share of their debt in dollar-denominated loans than do non-exporting plants. In manufacturing in 1993, the dollar-denominated shares of shortterm debt were $38 \%$ and $20 \%$ for exporters and non-exporters respectively. For long-term debt, the corresponding figures were $36 \%$ and $13 \%$. As a consequence, the balance sheets of exporting plants are likely to have been more adversely affected by the peso devaluation than those of non-exporters. However, exporters also face a lower cost of capital (defined as the ratio of total interest payments to total debt) than non-exporters; in manufacturing in 1993, the cost of capital was $12.5 \%$ for exporters and $17.8 \%$ for non-exporters. This suggests that increased exports may have differentially reduced the cost of capital for initially moreproductive plants. To investigate this, Table 9 presents regressions of the form of (7) with the change in the cost of capital as the dependent variable. In order for the lower cost of

\footnotetext{
${ }^{50}$ I also estimated the non-linear model described in footnote 48 with a discrete choice for whether a plant has ISO 9000 certification. The results were again qualitatively similar to those presented here.
} 
capital for exporters to explain the differential wage changes, it would have to be the case that the cost of capital declined more for initially larger plants than initially smaller ones during the peso crisis period, and that this relative decline was greater in magnitude during the peso crisis period than during the 1989-1993 or 1997-2000 periods. In fact, the point estimates for the 1993-1997 period are positive in all specifications, and not significantly smaller than the coefficients for the other periods. There is no evidence that differential changes in the cost of capital can explain the differential wage changes of Table $2 .^{51}$

One might still be worried that some factor unrelated to exports generated the difference in differential trends. One way to investigate this possibility is to examine whether the same differential trends are displayed even within a set of plants that saw no differential change in exports over the period - the maquiladora plants participating in the government's export-promotion program. ${ }^{52}$ When the maquiladora program began in 1965, maquiladoras were required to export $100 \%$ of their output. Although this requirement has gradually been loosened since 1989, maquiladora plants continue to export nearly all of their output. ${ }^{53}$ Thus the peso devaluation, although it was a boon to the sector as a whole, did not generate a differential change in the extent of exporting between larger and smaller, or more-productive and less-productive, maquiladora plants. Table 10 presents a comparison of results for the non-maquiladora sector (from the EIA 1993-2001 panel) and the maquiladora sector (from a balanced panel for the same period created from the EMIME data, described in Appendix B). The proxy for initial productivity is log employment and the wage variables are average hourly wages, white-collar yearly earnings, and blue-collar yearly earnings since those are the variables that can be compared across datasets. The results for the maquiladora sector are quite distinct from those for the non-maquiladora sector. The point estimates on initial log employment for the 1993-1997 period are negative. In the later period the coefficients are significantly larger than in the earlier period. It does not appear that the differential wage

\footnotetext{
${ }^{51}$ This is consistent with the conclusion of Aguiar (2005, p. 106): "Given that export propensity and foreign debt composition are significantly correlated ... the balance sheet effect is offsetting much of the benefits of the real devaluation."

${ }^{52}$ An alternative approach would be to focus on initially small plants that are likely to be below the export margin even after the devaluation. Estimates of (7) for plants initially below median domestic sales in each industry yield differential wage trends similar to those in Table 2, which ostensibly casts doubt on the quality upgrading hypothesis. But this test is not as clean as the comparison with maquiladoras, because even plants that report zero domestic sales may be producing intermediate goods for plants that export or may be selling on the export market through a distributor; export-driven quality upgrading may be present even among plants that report zero direct exports.

${ }^{53}$ Although the fraction of revenues from export vs. domestic sales is not reported in the published statistics, INEGI has carried out unpublished surveys, and has consistently found that maquiladoras sell less than $5 \%$ of their output domestically. (Source: personal communication with Gerardo Durand, Director of Statistics of International Trade, Administrative Records, and Prices, INEGI.)
} 
changes in the non-maquiladora sector are due to a generalized differential trend between larger and smaller, or more-productive and less-productive plants. ${ }^{54}$

These results for the maquiladora sector also argue against the outsourcing hypothesis of Feenstra and Hanson (1996) as an explanation for the differential wage trends in Table 2. Feenstra and Hanson hypothesize that U.S. firms outsource production activities that are low-skill for the U.S. but high-skill for Mexico, raising skill demands in both places. One would expect this mechanism to be strongest in the maquiladoras, which are explicitly dedicated to outsourcing from Northern firms. The outsourcing hypothesis provides a compelling account of the upgrading of the maquiladora sector over time, but the fact that we do not see the greater differential wage changes between larger and smaller plants in the peso-crisis period in the maquiladora sector suggests the outsourcing hypothesis is unlikely to explain the differential wage changes we observe in non-maquiladora sector. ${ }^{55}$

Rent-sharing may also explain the wage patterns we observe, if upgrading plants are more profitable and those profits are shared with workers. There are two distinct theories often lumped under the rubric of rent-sharing. The first is that plants or firms share profits for profit-maximizing reasons: employee morale would suffer if rents were not shared. In the context of this paper, it may be that production of higher-quality goods for the export market is particularly sensitive to employee morale, and for this reason quality upgrading requires increased rent-sharing. This hypothesis can be viewed as a friendly variant of the efficiency-wage interpretation of equations (4a)-(4b), rather than as an alternative to the quality-upgrading hypothesis.

The second theory is that managers have an objective apart from maximizing profits to live a quiet life, for instance - that leads them to share more rents than would be optimal

\footnotetext{
${ }^{54}$ This conclusion is reinforced by two additional findings. First, using data from the Mexican social security agency that covers a set of non-tradable sectors (construction, transportation, retail, and service) in addition to the manufacturing (tradable) sector, Appendix Table 3 provides evidence of a significantly greater difference in differential trends in manufacturing than in the non-tradable sectors. For further details, see Appendix B and Kaplan and Verhoogen (2006). Second, Kandilov (2005, Ch. 2), building explicitly on the framework of an earlier incarnation of this paper (Verhoogen, 2004), uses exogenous variation in the incentive to export from an export-subsidy program in Chile, rather than a macroeconomic shock, and finds that industries offered the subsidy displayed greater wage growth for white-collar workers than nonsubsidized industries, and that within subsidized industries initially larger and more productive plants saw greater wage increases for both white-collar and blue-collar workers than initially smaller or less productive plants.

${ }^{55}$ It is also worth noting that the Feenstra-Hanson mechanism relies on shifts between activities of different skill intensity within industries to explain wage changes. Although the model does not carry predictions for which particular plants will undertake the new skill-intensive activities, one would expect the higher- $\lambda$ plants to be the most likely candidates. We have seen that there is no evidence that higher- $\lambda$ plants raised their white-collar employment share more than lower- $\lambda$ plants in the same industry. Hence it seems unlikely that shifts between activities of different skill intensities are driving the differential wage changes.
} 
for the plant or firm as a whole. We might term this "non-profit-maximizing rent-sharing." In this view, one might argue that the increased exports of high- $\tilde{\lambda}$ plants led them to raise wages relative to low $-\tilde{\lambda}$ plants simply because the high- $\tilde{\lambda}$ plants saw a differential increase in profits. One could add the additional twist that managers are likely to be more friendly with, and offer rents to, white-collar workers. This theory is quite flexible, and difficult to refute for that reason, but three arguments suggest that the non-profit-maximizing rentsharing hypothesis is not a complete explanation of the wage patterns we observe.

First, one might expect local managers at foreign-owned plants to have less latitude to share rents, since they have to report to financial officers in far-away corporate headquarters who presumably do not share those managers' non-profit-maximizing objectives. Table 11 presents estimates of (7) separately for plants with more than $10 \%$ and less than $10 \%$ foreign ownership in 1994. The qualitative patterns within each subgroup are similar to the results for the entire sample. Although there is no evidence of differential changes in blue-collar wages in foreign-owned plants (Column 3, top panel), there is strong evidence of a differential effect of the peso crisis on white-collar wages in those plants (Column 2, top panel). Second, it is possible to control for the effect of improved plant performance in a regression context, and when we do, the basic patterns of differential changes in wages between high- $\tilde{\lambda}$ and low- $\tilde{\lambda}$ plants hold up. Table 12 presents regressions of the form of (7), but including the change in log revenues as an additional covariate to capture the rent-sharing effect. ${ }^{56}$ The coefficients on change in log revenues are positive and significant for the export share and wage variables, and negative and significant for the capital-labor ratio and the employment ratio. These estimates are consistent with the view that plants share rents and that plants are able to adjust blue-collar employment more quickly than white-collar employment and capital intensity to a positive demand shock for exports. But the important message of the table is that the coefficients on the initial log domestic sales term in each period are largely unaffected by the inclusion of the change in log revenues. Third, the non-profit-maximizing rent-sharing hypothesis cannot explain the results from the EIA-ENESTyC panel reported in Table 4 - in particular, the differential trends in ISO 9000 certification and average schooling of blue-collar workers. While it is certainly possible that non-profit-maximizing rent-sharing is playing some role, it seems unlikely that rent-sharing is the entire explanation for the various empirical patterns we observe.

\footnotetext{
${ }^{56}$ The differential changes in wages between high- $\tilde{\lambda}$ and low- $\tilde{\lambda}$ plants also hold up if the change in price-cost margins are included as a covariate in place of the change in log revenues. The change in log revenues is preferable as a covariate because it is more accurately measured, and wage changes enter into the calculation of changes in price-cost margins, which makes them susceptible to biases introduced by measurement error.
} 
A final alternative hypothesis to be considered is the scale-economies hypothesis of Yeaple (2005). Yeaple (2005) presents a model in which firms can choose between a more modern, high-fixed-cost, low-variable-cost technology that requires more-skilled workers and an older, low fixed cost, high variable cost technology that requires less-skilled workers. An increase in the scale of production leads more firms to adopt the more modern technology, raising the demand for skill and the wages of more-skilled workers. ${ }^{57}$ If we extend the model to our context, the argument would be that the exchange-rate devaluation generated a differential change in the scale of production between high- $\tilde{\lambda}$ and low- $\tilde{\lambda}$ plants, which generated differential changes in technology choice, which in turn generated differential changes in skill demands. Three pieces of evidence argue against this mechanism in this case. First, there is little evidence that initially more-productive plants increased in scale more than initially less-productive ones, since they saw a greater decrease in domestic sales at the same time as a greater increase in exports; see Table 6 Columns 5-7 and the accompanying discussion. Second, when the change in scale is controlled for explicitly as in Table 12, the estimates of the coefficient on the initial value of the $\lambda$ proxy are largely unaffected. Third, the scale-effects hypothesis, like the outsourcing hypothesis, relies on increases in the employment share of skilled workers to drive wage changes; as noted above, there is no evidence that upgrading plants increased the white-collar share of employment or increased average skill within the white-collar category.

\section{Conclusion}

This paper has proposed a new mechanism linking trade and wage inequality in Mexico: quality upgrading due to increased exports. It has offered robust evidence that initially larger, more productive plants were more likely to increase exports, white-collar wages, blue-collar wages, and ISO 9000 certification than initially smaller, less productive plants during the peso-crisis period (1993-1997), and that this differential change was greater than during adjacent periods without devaluations (1989-1993 and 1997-2001). The pattern in 1986-1989, also a period of devaluation of the peso, is similar to that of 1993-1997. These findings are robust to the choice of proxy for plant productivity, and do not appear to be explained by a variety of alternative hypotheses. There is also (somewhat less robust) evidence that the differential wage changes were greater for white-collar than for blue-collar

\footnotetext{
${ }^{57}$ Bustos (2005) has recently incorporated this insight into a monopolistic competition framework with heterogeneous firms.
} 
workers, suggesting that quality upgrading leads to increases in within-plant wage inequality as well as to increased wage dispersion across plants. Results from a latent-factor strategy that avoids the need to construct proxies reinforce these findings. These results support the hypothesis that exporting-induced quality upgrading has contributed to rising wage inequality within industries in the Mexican manufacturing sector.

An important question that remains unanswered is the extent to which the qualityupgrading mechanism can be generalized to other contexts. On the basis of the theoretical model, we would expect any bilateral reduction in trade costs - due to a trade agreement or declining transport costs, for instance - to have effects similar to those of an exchangerate devaluation. The incentive to export would increase and domestic sales would decrease - in this case because of an increase in import competition rather than a contraction of domestic demand - generating a differential increase in the export share and hence differential quality upgrading within industries. Case-study evidence (Gereffi, 1999; Nadvi, 1999) also suggests that quality upgrading may be a more general phenomenon. If so, the quality upgrading hypothesis may be a part of the explanation of the link between trade liberalization and wage inequality more broadly.

The main relevance of the quality-upgrading hypothesis to policy debates may lie in its identification of a new dimension of relative winners and losers from trade in developing countries. In the simplest Hecksher-Ohlin model, the relative winners are unskilled workers, and the relative losers are skilled workers and owners of capital. From this perspective, it is a mystery why many unskilled workers in developing countries protest against globalization, and why many of the foremost proponents of globalization are educated, urban elites. In the quality-upgrading view, by contrast, the relative winners are the entrepreneurs and employees, especially the most skilled, with either the qualifications or the good fortune to be employed in the most modern, export-oriented plants within each industry, and the relative losers are the entrepreneurs and employees, especially the unskilled, in less-productive, domestically oriented plants. In this view, both the enthusiasm for globalization of the relatively better-off and the pessimism of the relatively worse-off may make economic sense. 


\section{References}

Abowd, J., And T. Lemieux (1993): "The Effects of Product Market Competition on Collective Bargaining Agreements: The Case of Foreign Competition in Canada," Quarterly Journal of Economics, 108(4), 983-1014.

Abowd, J. M., And S. Woodcock (2001): "Disclosure Limitation in Longitudinal Linked Data," in Confidentiality, Disclosure and Data Access: Theory and Practical Applications for Statistical Agencies, ed. by P. Doyle, J. Lane, L. Zayatz, and J. Theeuwes, pp. 215-277. North Holland, Amsterdam.

Acemoglu, D. (2003): "Patterns of Skill Premia," Review of Economic Studies, 70, 199230.

Aguiar, M. (2005): "Investment, Devaluation, and Foreign Currency Exposure: The Case of Mexico," Journal of Development Economics, 78(1), 95 - 113.

Akerlof, G. (1982): "Labor Contracts as Partial Gift Exchange," Quarterly Journal of Economics, 97(4), 543-569.

Alchian, A. A., And W. R. Allen (1964): University Economics. Wadsworth, Belmont, CA.

Anderson, S., A. De Palma, and J.-F. Thisse (1992): Discrete-Choice Theory of Product Differentiation. MIT Press, Cambridge, MA.

Angrist, J., And A. Krueger (1999): "Empirical Strategies in Labor Economics," in Handbook of Labor Economics, ed. by O. Ashenfelter, and D. Card, vol. 3A. Elsevier Science.

Antras, P., L. Garicano, and E. Rossi-Hansberg (2006): "Offshoring in a Knowledge Economy," Quarterly Journal of Economics, 121(1), 31-79.

Attanasio, O., P. Goldberg, and N. Pavcnik (2004): "Trade Reforms and Wage Inequality in Colombia," Journal of Development Economics, 74, 331-366.

Berman, E., J. Bound, and Z. Griliches (1994): "Changes in the Demand for Skilled Labor within U.S. Manufacturing: Evidence from the Annual Survey of Manufactures," Quarterly Journal of Economics, 109(2), p367 - 397.

Berman, E., J. Bound, And S. Machin (1998): "Implications of Skill-Biased Technological Change: International Evidence," Quarterly Journal of Economics, 113(4), p1245 1279 .

Bernard, A. B., And J. B. Jensen (1997): "Exporters, Skill Upgrading and the Wage Gap," Journal of International Economics, 42, 3-31.

- (1999): "Exceptional Exporter Performance: Cause, Effect, or Both?," Journal of International Economics, 47, 1-25.

Bertrand, M., E. Duflo, and S. Mullainathan (2004): "How Much Should We Trust Difference-in-Differences Estimates?," Quarterly Journal of Economics, (1), 249-276.

Bigsten, A., P. Collier, S. Dercon, M. Fafchamps, B. Gauthier, J. W. Gunning, A. Oduro, R. Oostendorp, C. Pattillo, M. Soderbom, F. Teal, and A. ZeUFACK (2004): "Do African Manufacturing Firms Learn from Exporting?," Journal of Development Studies, 40(3), 115-141.

Bowles, S. (1985): "The Production Process in a Competitive Economy: Walrasian, NeoHobbesian and Marxian Models," American Economic Review, 75(1), 16-36. 
Brooks, E. L. (2006): "Why Don't Firms Export More? Product Quality and Colombian Plants," Journal of Development Economics, 80(1), 160-178.

Brown, C., And J. Medoff (1989): "The Employer Size-Wage Effect," Journal of Political Economy, 97(5).

Burenstam Linder, S. (1961): An Essay on Trade and Transformation. Wiley \& Sons, New York NY.

Bustos, P. (2005): "Rising Wage Inequality in the Argentinean Manufacturing Sector: The Impact of Trade and Foreign Investment on Technology and Skill Upgrading," Unpub. Paper, Harvard University.

Clerides, S., S. Lach, and J. Tybout (1998): "Is Learning by Exporting Important? Micro-Dynamic Evidence from Colombia, Mexico and Morocco," Quarterly Journal of Economics, pp. 903-947.

Copeland, B., And A. Kotwal (1996): "Product Quality and the Theory of Comparative Advantage," European Economic Review, 40, 1745-1760.

Cragg, M., and M. Epelbaum (1996): "Why Has Wage Dispersion Grown in Mexico? Is it the Incidence of Reforms or the Growing Demand for Skills?," Journal of Development Economics, 51, 99-116.

Currie, J., And A. Harrison (1997): "Sharing the Costs: The Impact of Trade Reform on Capital and Labor in Morocco," Journal of Labor Economics, 15(3), s44-s71.

Dalmazzo, A. (2002): "Technological Complexity, Wage Differentials, and Unemployment," Scandinavian Journal of Economics, 104(4), 515-530.

DAvis, D. R. (1996): "Trade Liberalization and Income Distribution," NBER Working Paper \# 5693.

Economist Intelligence Unit (1995): Mexico: Country Report. Economist Intelligence Unit, London, 1st quarter.

EdWARds, R. (1979): Contested Terrain: The Transformation of the Workplace in the Twentieth Century. Basic Books, New York.

Esquivel, G., and J. Rodriguez-Lopez (2003): "Technology, Trade, and Wage Inequality in Mexico Before and After NAFTA," Journal of Development Economics, 71, $543-565$.

Feenstra, R., and G. Hanson (1996): "Foreign Investment, Outsourcing and Relative Wages," in Political Economy of Trade Policy: Essays in Honor of Jagdish Bhagwati, ed. by R. Feenstra, and G. Grossman. MIT Press, Cambridge MA.

Flam, H., and E. Helpman (1987): "Vertical Product Differentiation and North-South Trade," American Economic Review, 77(5), 810-822.

Forbes, K. J. (2002): "How Do Large Depreciations Affect Firm Performance?," IMF Staff Papers, 49, 214-238.

Gabszewicz, J. J., A. Shaked, J. Sutton, and J.-F. Thisse (1982): "International Trade in Differentiated Products," International Economic Review, 22(3), 527-535.

Gereffi, G. (1999): "International Trade and Industrial Upgrading in the Apparel Commodity Chain," Journal of International Economics, 48, 37-70.

Goldberg, P. K., And N. Pavcnik (2004): "Trade, Inequality, and Poverty: What Do We Know? Evidence from Recent Trade Liberalization Episodes in Developing Countries," in Brookings Trade Forum 2004: Globalization, Poverty and Inequality, ed. by S. M. Collins, and D. Rodrik, pp. 223-269. Brookings Institutions Press, Washington D.C. 
- (2007): "Distributional Effects of Globalization in Developing Countries," Journal of Economic Literature, 45(1).

Gordon, D. M., R. Edwards, and M. Reich (1982): Segmented Work, Divided Workers: The Historical Transformations of Labor in the United States. Cambridge University Press, Cambridge.

Grether, J.-M. (1996): "Mexico, 1985-1990: Trade Liberalization, Market Structure and Manufacturing Performance," in Industrial Evolution in Developing Countries, ed. by M. J. Roberts, and J. R. Tybout, chap. 11. Oxford University Press for the World Bank, New York.

Griliches, Z. (1986): "Economic Data Issues," in Handbook of Econometrics, ed. by Z. Griliches, and M. Intrilligator, vol. 3. North-Holland, Amsterdam.

Grossman, G. M., and E. Helpman (1991): Innovation and Growth in the Global Economy. MIT Press, Cambridge MA.

Guler, I., M. Guillen, and J. M. Macpherson (2002): "Global Competition, Institutions and the Diffusion of Organizational Practices: The International Spread of ISO 9000 Quality Certificates," Administrative Science Quarterly, 47, 207-232.

Hallak, J. C. (2006): "Product Quality and the Direction of Trade," Journal of International Economics, 68, 238-265.

Hanson, G. (2004): "What Has Happened to Wages in Mexico Since NAFTA?," in FTAA and Beyond: Prospects for Integration in the Americas, ed. by T. Estevadeordal, D. Rodrik, A. Taylor, and A. Velasco. Harvard University Press, Cambridge.

Hanson, G., And A. HARrison (1999): "Trade Liberalization and Wage Inequality in Mexico," Industrial and Labor Relations Review, 52(2), 271-288.

Harrison, A., and G. Hanson (1999): "Who Gains from Trade Reform? Some Remaining Puzzles," Journal of Development Economics, 59, 125-154.

Hashimoto, M. (1981): "Firm-Specific Human Capital as a Shared Investment," American Economic Review, 71(3), 475-482.

Hausmann, R., J. Hwang, and D. Rodrik (2005): "What You Export Matters," NBER Working Paper \# 11905.

Heckman, J. (1976): "The Common Structure of Statistical Models of Truncation, Sample Selection, and Limited Dependent Variables and a Simple Estimator for Such Models," Annals of Economic and Social Measurement, 5, 475-492.

Heckman, J., And B. Singer (1984): "A Method for Minimizing the Impact of Distributional Assumptions in Econometric Models for Duration Data," Econometrica, 52(2), 271-320.

Hummels, D., and P. J. Klenow (2005): "The Variety and Quality of a Nation's Exports," American Economic Review, 95(3), 704-723.

Hummels, D., And A. Skiba (2004): "Shipping the Good Apples Out? An Empirical Confirmation of the Alchian-Allen Conjecture," Journal of Political Economy, 112(6), $1384-1402$.

Jöreskog, K. G., And A. S. Goldberger (1975): "Estimation of a Model with Multiple Indicators and Multiple Causes of a Single Latent Variable," Journal of the American Statistical Association, 70(351), 631-39. 
Kandilov, I. (2005): "How International Trade Affects Wages and Employment," Ph.D. Dissertation, University of Michigan.

Kapetanios, G. (2004): "A Bootstrap Procedure for Panel Data with Many CrossSectional Units," Unpub. paper, Queen Mary, University of London.

Kaplan, D. S., and E. Verhoogen (2006): "Exporting and Individual Wage Premia: Evidence from Mexican Employer-Employee Data," Unpub. paper, ITAM and Columbia University.

Keane, M., R. Moffitt, and D. Runkle (1988): "Real Wages over the Business Cycle: Estimating the Impact of Heterogeneity with Micro Data," Journal of Political Economy, 96(6), 1232-1266.

Kremer, M. (1993): "The O-Ring Theory of Economic Development," Quarterly Journal of Economics, 108(3), 551-575.

Kremer, M., and E. MAskin (1996): "Wage Inequality and Segregation by Skill,” NBER Working Paper \#5718.

Levinsohn, J. (1999): "Employment Responses to International Liberalization in Chile," Journal of International Economics, 47(2), 321-344.

Levinsohn, J., And A. Petrin (2003): "Estimating Production Functions Using Inputs to Control for Unobservables," Review of Economic Studies, 70, 317-341.

Manasse, P., And A. Turrini (2001): "Trade, Wages and Superstars," Journal of International Economics, 54, 97-117.

Markusen, J. (1986): "Explaining the Volume of Trade: An Eclectic Approach," American Economic Review, 76(5), 1002-1011.

Maurin, E., D. Thesmar, and M. Thoenig (2002): "Globalization and the Demand for Skill: An Export Based Channel," CEPR discussion paper 3406.

McFadden, D. (1981): "Econometric Models of Probabilistic Choice," in Structural Analysis of Discrete Data with Econometric Applications, ed. by C. F. Manski, and D. McFadden. MIT Press, Cambridge MA.

McKenzie, D. J. (2006): "The Consumer Response to the Mexican Peso Crisis," Economic Development and Cultural Change, 55(1), 139-172.

Melitz, M. (2003): "The Impact of Trade on Intra-Industry Reallocations and Aggregate Industry Productivity," Econometrica, 71(6), 1695-1725.

Mroz, T. A. (1999): "Discrete Factor Approximations in Simultaneous Equation Models: Estimating the Impact of a Dummy Endogenous Variable on a Continuous Outcome," Journal of Econometrics, 92, 233-274.

Murphy, K., And A. Shleifer (1997): "Quality and Trade," Journal of Development Economics, 53, 1-15.

Nadvi, K. (1999): "Collective Efficiency and Collective Failure: The Response of the Sialkot Surgical Instrument Cluster to Global Quality Pressures," World Development, 27(9), 1605-1626.

Olley, G. S., And A. Pakes (1996): "The Dynamics of Productivity in the Telecommunications Industry," Econometrica, 64(6), 1263-1297.

Papageorgiou, D., M. Michaely, and A. Choksi (eds.) (1991): Liberalizing Foreign Trade, vol. 7 of Lessons of Experience in the Developing World. Cambridge MA: Blackwell Publishers, for World Bank. 
PAVCNIK, N. (2002): "Trade Liberalization, Exit and Productivity Improvements: Evidence from Chilean Plants," Review of Economic Studies, 69, 245-276.

Pratap, S., and C. Urrutia (2004): "Firm Dynamics, Investment and Debt Portfolio: Balance Sheet Effects of the Mexican Crisis of 1994," Journal of Development Economics, $75(2), 535-563$.

Raghunathan, T. E., J. M. Lepkowski, J. V. Hoewyk, and P. Solenberger (2001): "A Multivariate Technique for Multiply-Imputing Missing Values Using a Sequence of Regression Models," Survey Methodology Program Working Paper 081, University of Michigan.

Revenga, A. (1992): "Exporting Jobs? The Impact of Import Competition on Employment and Wages in U.S. Manufacturing," Quarterly Journal of Economics, 107, 255-284.

- (1997): "Employment and Wage Effects of Trade Liberalization: The Case of Mexican Manufacturing," Journal of Labor Economics, 15(3), s20-s43.

Roberts, M. J., And J. R. Tybout (1997): "The Decision to Export in Colombia: An Empirical Model of Entry with Sunk Costs," American Economic Review, 87(4), 545-564.

Robertson, R. (2004): "Relative Prices and Wage Inequality: Evidence from Mexico," Journal of International Economics, 64(2), 387-409.

Schafer, J. L., And M. K. Olsen (2000): "Modeling and Imputation of Semi-continuous Survey Variables," The Methodology Center, Technical Paper 00-39, Pennsylvania State University.

Schотт, P. (2004): "Across-Product versus Within-Product Specialization in International Trade," Quarterly Journal of Economics, 119(2), 647-678.

Shaked, A., And J. Sutton (1982): "Relaxing Price Competition through Product Differentiation," Review of Economic Studies, 49, 3-13.

Shapiro, C., And J. Stiglitz (1984): "Equilibrium Unemployment as a Worker Discipline Device," American Economic Review, 74(3), 433-44.

Simon, C. P., And L. Blume (1994): Mathematics for Economists. W. W. Norton \& Company, New York.

Stokey, N. (1991): "The Volume and Composition of Trade Between Rich and Poor Countries," Review of Economic Studies, 58, 63-80.

Tirole, J. (2000): The Theory of Industrial Organization. MIT Press, Cambridge MA, 11 th edn.

Tybout, J. (2000): "Manufacturing Firms in Developing Countries: How Well Do They Do, and Why?," Journal of Economic Literature, 38, 11-44.

- (2003): "Plant- and Firm-Level Evidence on the 'New' Trade Theories," in Handbook of International Trade, ed. by E. K. Choi, and J. Harrigan. Basil Blackwell, Oxford.

Verhoogen, E. A. (2004): "Trade, Quality Upgrading and Wage Inequality in the Mexican Manufacturing Sector," Chap. 2 of Ph.D. dissertation, University of California, Berkeley.

Wacziarg, R., and J. Seddon Wallack (2004): "Trade Liberalization and Intersectoral Labor Movements," Journal of International Economics, 64(2), 411-439.

Xiang, C. (2005): "New Goods and the Relative Demand for Skilled Labor," Review of Economics and Statistics, 87(2), $285-298$.

YeAple, S. R. (2005): "A Simple Model of Firm Heterogeneity, International Trade, and Wages," Journal of International Economics, 65(1), 1-20. 


\section{A Theory Appendix}

\section{A.1 Comparative-Static Results for Entry}

This appendix signs the comparative statics for the entry cutoffs for Southern plants into the Southern and Northern markets. It is convenient to rewrite (5a)- $(5 \mathrm{~g})$ so that they are symmetric for Southern and Northern plants. To this end, let $c$ index the location of production $(c=n, s)$ and $\psi_{c d}$ be the ratio of the price level in destination market $d$ to the price level in production location $c$, and write prices in terms of the home-country price level, as in (1). (That is, $\psi_{s s}=\psi_{n n}=\delta_{s}=1$ and $\psi_{s n}=\frac{1}{\psi_{n s}}=\delta_{n}$.) Then (5a)-(5g), dropping the asterisks, become:

$$
\begin{aligned}
q_{c d}(\lambda) & =\left(\eta \lambda \psi_{c d}^{\alpha} \theta_{d}^{\alpha}\right)^{\frac{1}{1-\alpha}} \\
w_{c d}^{h}(\lambda) & =\underline{w}_{c}^{h}+\alpha^{h} \psi_{c d} \theta_{d} q_{c d}(\lambda) \\
w_{c d}^{l}(\lambda) & =\underline{w}_{c}^{l}+\alpha^{l} \psi_{c d} \theta_{d} q_{c d}(\lambda) \\
k_{c d}(\lambda) & =\frac{\alpha^{k}}{\rho} \psi_{c d} \theta_{d} q_{c d}(\lambda) \\
\tilde{p}_{c d}(\lambda) & =\mu \psi_{c d}+\underline{w}_{c}^{h}+\underline{w}_{c}^{l}+\alpha \psi_{c d} \theta_{d} q_{c d}(\lambda) \\
x_{c d} & =\frac{N_{d}}{D_{d}} \exp \left(\frac{\theta_{d} q_{c d}(\lambda)-\frac{\tilde{p}_{c d}(\lambda)}{\psi_{c d}}}{\mu}\right) \\
\pi_{c d}(\lambda) & =\mu \psi_{c d} x_{c d}(\lambda)-f_{c d}
\end{aligned}
$$

In this notation, the four entry cut-offs, $\lambda_{s s}^{\min }, \lambda_{s n}^{\min }, \lambda_{n s}^{\min }$, and $\lambda_{s n}^{\min }$, are determined by four zero-profit conditions:

$$
\pi_{c d}\left(\lambda_{c d}^{\min }\right)=\frac{\mu \psi_{c d} N_{d}}{D_{d}} \exp \left\{\frac{\theta_{d} q_{c d}\left(\lambda_{c d}^{\min }\right)-\frac{\tilde{p}_{c d}\left(\lambda_{c d}^{\min }\right)}{\psi_{c d}}}{\mu}\right\}-f_{c d}=0
$$

for $c, d=n, s$. Here $D_{d}$ involves an aggregation in over plants from each location selling in market $d$ :

$$
D_{d}\left(\lambda_{s d}^{\min }, \lambda_{n d}^{\min }\right) \equiv \sum_{c=n, s} \int_{\lambda_{c d}^{\min }}^{\infty} \exp \left\{\frac{\theta_{d} q_{c d}(\lambda)-\frac{\tilde{p}_{c d}(\lambda)}{\psi_{c d}}}{\mu}\right\} g_{c}(\lambda) d \lambda
$$

Using (A.2), define the Jacobian for the profit functions $\pi_{c d}$ for $c, d \in\{s, n\}$ (suppressing the explicit dependence on $\lambda_{c d}^{\min }$ to reduce clutter):

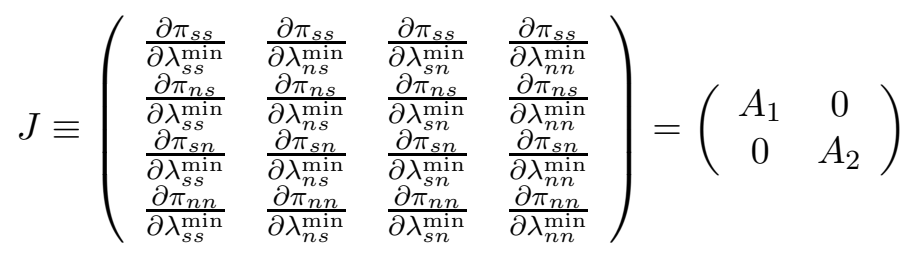


where:

$$
\begin{aligned}
& A_{1}=\left(\begin{array}{cc}
\frac{f_{s s}}{\mu}\left[\frac{\theta_{s} q_{s s}}{\lambda_{s s}^{\min }}+\frac{f_{s s} g_{s}\left(\lambda_{s s}^{\min }\right)}{\psi_{s s} N_{s}}\right] & \frac{f_{s s} f_{n s} g_{n}\left(\lambda_{n s}^{\min }\right)}{\mu \psi_{n s} N_{s}} \\
\frac{f_{n s} f_{s s} g_{s}\left(\lambda_{s s}^{\min }\right)}{\mu \psi_{s s} N_{s}} & \frac{f_{n s}}{\mu}\left[\frac{\theta_{s} q_{n s}}{\lambda_{n s}^{\min }}+\frac{f_{n s} g_{n}\left(\lambda_{n s}^{\min }\right)}{\psi_{n s} N_{s}}\right]
\end{array}\right) \\
& A_{2}=\left(\begin{array}{cc}
\frac{f_{s n}}{\mu}\left[\frac{\theta_{n} q_{s n}}{\lambda_{s n}^{\min }}+\frac{f_{s n} g_{s}\left(\lambda_{s n}^{\min }\right)}{\psi_{s n} N_{n}}\right] & \frac{f_{s n} f_{n n} g_{n}\left(\lambda_{n n}^{\min }\right)}{\mu \psi_{n n} N_{n}} \\
\frac{f_{n n} f_{s n} g_{s}\left(\lambda_{s n}^{\min }\right)}{\mu \psi_{s n} N_{n}} & \frac{f_{n n}}{\mu}\left[\frac{\theta_{n} q_{n n}}{\lambda_{n n}^{\min }}+\frac{f_{n n} g_{n}\left(\lambda_{n n}^{\min }\right)}{\psi_{n n} N_{n}}\right]
\end{array}\right)
\end{aligned}
$$

Note that:

$$
\begin{aligned}
& \operatorname{det} A_{1} \equiv\left|A_{1}\right|=\frac{f_{s s} f_{n s}}{\mu^{2}}\left[\frac{\theta_{s}^{2} q_{s s} q_{n s}}{\lambda_{s s}^{\min } \lambda_{n s}^{\min }}+\frac{\theta_{s} q_{s s} f_{n s} g_{n}\left(\lambda_{n s}^{\min }\right)}{\lambda_{s s}^{\min } \psi_{n s} N_{s}}+\frac{\theta_{s} q_{n s} f_{s s} g_{s}\left(\lambda_{s s}^{\min }\right)}{\lambda_{n s}^{\min } \psi_{s s} N_{s}}\right]>0 \\
& \operatorname{det} A_{2} \equiv\left|A_{2}\right|=\frac{f_{n n} f_{s n}}{\mu^{2}}\left[\frac{\theta_{n}^{2} q_{n n} q_{s n}}{\lambda_{n n}^{\min } \lambda_{s n}^{\min }}+\frac{\theta_{n} q_{n n} f_{s n} g_{s}\left(\lambda_{s n}^{\min }\right)}{\lambda_{n n}^{\min } \psi_{s n} N_{n}}+\frac{\theta_{n} q_{s n} f_{n n} g_{n}\left(\lambda_{n n}^{\min }\right)}{\lambda_{s n}^{\min } \psi_{n n} N_{n}}\right]>0
\end{aligned}
$$

By the implicit function theorem (see e.g. Simon and Blume (1994, theorem 15.7, p. 355)):

$$
\left(\begin{array}{c}
\frac{\partial \lambda_{s s}^{\min }}{\partial N_{s}} \\
\frac{\partial \lambda_{n s}^{\min }}{\partial N_{s}} \\
\frac{\partial \lambda_{s n}^{\min }}{\partial N_{s}} \\
\frac{\partial \lambda_{n n}^{\min }}{\partial N_{s}}
\end{array}\right)=-J^{-1}\left(\begin{array}{c}
\frac{\partial \pi_{s s}}{\partial N_{s}} \\
\frac{\partial \pi_{n s}}{\partial N_{s}} \\
\frac{\partial \pi_{s n}}{\partial N_{s}} \\
\frac{\partial \pi_{n n}}{\partial N_{s}}
\end{array}\right)=-\left(\begin{array}{cc}
A_{1}^{-1} & 0 \\
0 & A_{2}^{-1}
\end{array}\right)\left(\begin{array}{c}
\frac{f_{s s}}{N_{s}} \\
\frac{f_{n s}}{N_{s}} \\
0 \\
0
\end{array}\right)=-\left(\begin{array}{c}
\frac{f_{s s} f_{n s} \theta_{s} q_{n s}}{\mu N_{s} \lambda_{n s}^{\min }\left|A_{1}\right|} \\
\frac{f_{s s} f_{n s} \theta_{s} q_{s s}}{\mu N_{s} \lambda_{s s}^{\min }\left|A_{1}\right|} \\
0 \\
0
\end{array}\right)
$$

Hence $\frac{\partial \lambda_{s s}^{\min }}{\partial N_{s}}<0, \frac{\partial \lambda_{n s}^{\min }}{\partial N_{s}}<0, \frac{\partial \lambda_{s n}^{\min }}{\partial N_{s}}=0$ and $\frac{\partial \lambda_{n n}^{\min }}{\partial N_{s}}=0$.

Similarly,

$$
\left(\begin{array}{c}
\frac{\partial \lambda_{s s}^{\min }}{\partial \psi_{s n}} \\
\frac{\partial \lambda_{n s}^{n n}}{\partial \psi_{s n}} \\
\frac{\partial \lambda_{s n}}{\partial \psi_{s n}} \\
\frac{\partial \lambda_{n n}^{n i n}}{\partial \psi_{s n}}
\end{array}\right)=-J^{-1}\left(\begin{array}{c}
\frac{\partial \pi_{s s}}{\partial \psi_{s n}} \\
\frac{\partial \pi_{n s}}{\partial \psi_{s n}} \\
\frac{\partial \pi_{s n}}{\partial \psi_{s n}} \\
\frac{\partial \pi_{n n}}{\partial \psi_{s n}}
\end{array}\right)=-\left(\begin{array}{cc}
A_{1}^{-1} & 0 \\
0 & A_{2}^{-1}
\end{array}\right)\left(\begin{array}{c}
-\frac{f_{s s}}{D_{s}} \frac{\partial D_{s}}{\partial \psi_{s n}} \\
-f_{n s}\left[\frac{1}{\psi_{s n}}+\frac{1}{D_{s}} \frac{\partial D_{s}}{\partial \psi_{s n}}+\frac{\underline{w}_{n}^{h}+\underline{w}_{n}^{l}+\alpha \psi_{n s} \theta_{s} q_{n s}}{\mu}\right] \\
f_{s n}\left[\frac{1}{\psi_{s n}}-\frac{1}{D_{n}} \frac{\partial D_{n}}{\partial \psi_{s n}}+\frac{\underline{w}_{s}^{h}+\underline{w}_{s}^{l}+\alpha \psi_{s n} \theta_{n} q_{s n}}{\mu \psi_{s n}^{2}}\right] \\
-\frac{f_{n n}}{D_{n}} \frac{\partial D_{n}}{\partial \psi_{s n}}
\end{array}\right)
$$

Hence:

$$
\begin{aligned}
\frac{\partial \lambda_{s s}^{\min }}{\partial \psi_{s n}} & =\frac{f_{n s} f_{s s}}{\mu\left|A_{1}\right|}\left\{\frac{\theta_{s} q_{s s}}{D_{s} \lambda_{n s}^{\min }} \frac{\partial D_{s}}{\partial \psi_{s n}}-\frac{f_{s s} g_{n}\left(\lambda_{n s}^{\min }\right)}{N_{s}}\left(1+\frac{\underline{w}_{n}^{h}+\underline{w}_{n}^{l}+\alpha \psi_{n s} \theta_{s} q_{n s}}{\mu \psi_{n s}}\right)\right\} \\
\frac{\partial \lambda_{s n}^{\min }}{\partial \psi_{s n}} & =-\frac{f_{s n} f_{n n}}{\mu \psi_{s n}\left|A_{2}\right|}\left\{\left(\frac{\theta_{n} q_{n n}}{\lambda_{n n}^{\min }}+\frac{f_{n n} g_{n}\left(\lambda_{n n}^{\min }\right)}{\psi_{n n} s_{n}}\right)\left(1+\frac{\underline{w}_{s}^{h}+\underline{w}_{s}^{l}+\alpha \psi_{s n} \theta_{n} q_{s n}}{\mu \psi_{s n}}\right)-\frac{\theta_{n} q_{n n}}{D_{n} \lambda_{n n}^{\min }} \frac{\partial D_{n}}{\partial \psi_{s n}}\right\}
\end{aligned}
$$

From (A.3):

$$
\frac{\partial D_{s}}{\partial \psi_{s n}}=-\int_{\lambda_{n s}^{\min }}^{\infty}\left[\frac{\underline{w}_{n}^{h}+\underline{w}_{n}^{l}+\alpha \psi_{n s} \theta_{s} q_{n s}}{\mu}\right] \exp \left\{\frac{\theta_{s} q_{n s}(\lambda)-\frac{\tilde{p}_{n s}(\lambda)}{\psi_{n s}}}{\mu}\right\} g_{n}(\lambda) d \lambda<0
$$

which implies $\frac{\partial \lambda_{s s}^{\min }}{\partial \psi_{s n}}<0$. Under the assumption the Northern market is large relative to 
the number of plants in South, $\frac{\partial D_{n}}{\partial \psi_{s n}} \approx 0$ and $\frac{\partial \lambda_{s n}^{\min }}{\partial \psi_{s n}}<0$. The increase in $\psi_{s n}$ with the devaluation leads to more entry of Southern plants into both markets.

\section{A.2 Changes in Export Share of Output}

In the notation of (5a)-(5g) (not the notation of Appendix A.1), consider the effect of the exchange-rate shock on the export share of output of Southern plants (suppressing the dependence of $x_{s}, x_{n}$ and hence $\chi$, the export share, on $\lambda$ ):

$$
\begin{aligned}
\mathrm{d} \chi & =\frac{\partial \chi}{\partial \delta_{n}} \mathrm{~d} \delta_{n}+\frac{\partial \chi}{\partial N_{s}} \mathrm{~d} N_{s} \\
& =\chi(1-\chi)\left\{\left[\frac{\partial \ln x_{n}}{\partial \delta_{n}}-\frac{\partial \ln x_{s}}{\partial \delta_{n}}\right] \mathrm{d} \delta_{n}+\left[\frac{\partial \ln x_{n}}{\partial N_{s}}-\frac{\partial \ln x_{s}}{\partial N_{s}}\right] \mathrm{d} N_{s}\right\} \\
& =\chi(1-\chi) \underbrace{\left\{\frac{1}{\mu \delta_{n}}\left[\theta_{n} \alpha q_{n}(\lambda)+\frac{\underline{w}^{h}+\underline{w}^{l}}{\delta_{n}}\right] \mathrm{d} \delta_{n}-\frac{1}{N_{s}} \mathrm{~d} N_{s}\right\}}_{\equiv \Gamma}>0
\end{aligned}
$$

where the inequality follows from the facts that $\mathrm{d} \delta_{n}>0$ and $\mathrm{d} N_{s}<0$.

Now consider how the change in the export share varies with entrepreneurial ability, that is, how $\mathrm{d} \chi$ varies with $\lambda$. As a preliminary step, note that:

$$
\begin{aligned}
\frac{\partial \chi}{\partial \lambda} & =\chi(1-\chi)\left[\frac{\partial \ln x_{n}}{\partial \lambda}-\frac{\partial \ln x_{s}}{\partial \lambda}\right] \\
& =\frac{\chi(1-\chi)}{\mu \lambda}\left[\theta_{n} q_{n}(\lambda)-\theta_{s} q_{s}(\lambda)\right]>0
\end{aligned}
$$

since by assumption $\theta_{n}>\theta_{s}$ and hence $q_{n}(\lambda)>q_{s}(\lambda)$ by $(5 \mathrm{a})$. Note also that:

$$
\frac{\partial \Gamma}{\partial \lambda}=\frac{\theta_{n} \alpha}{\mu \delta_{n}} \frac{\partial q_{n}(\lambda)}{\partial \lambda} \mathrm{d} \delta_{n}>0
$$

using (5a), where $\Gamma$ is defined in (A.6). Then from (A.6):

$$
\frac{\partial}{\partial \lambda}(\mathrm{d} \chi)=\left(1-2 \chi_{s}\right) \Gamma \frac{\partial \chi_{s}}{\partial \lambda}+\chi(1-\chi) \frac{\partial \Gamma}{\partial \lambda}
$$

Given (A.7) and (A.8), the condition $\chi<\frac{1}{2}$ is sufficient for $\frac{\partial}{\partial \lambda}(\mathrm{d} \chi)>0$.

\section{A.3 Linearization}

Assuming differentiability of the export share of output, a first-order Taylor approximation of $(6 \mathrm{a})-(6 \mathrm{~h})$ around $\bar{\lambda}$ yields $(8 \mathrm{a})-(8 \mathrm{~h})$, where the $\varepsilon_{m}$ for $m=1,2, \ldots, 8$ are the approximation 
errors and the parameters are defined as follows:

$$
\begin{aligned}
& a_{1}=\nu(\bar{\lambda}) \\
& b_{1}=\frac{\nu(\bar{\lambda})(1-\nu(\bar{\lambda}))}{\bar{\lambda}}\left\{\frac{\alpha}{(1-\alpha)}\left[\frac{\delta_{n} \theta_{n} q_{n}(\bar{\lambda})}{p_{s n}(\bar{\lambda})}-\frac{\delta_{s} \theta_{s} q_{s}(\bar{\lambda})}{p_{s s}(\bar{\lambda})}\right]+\frac{1}{\mu}\left[\theta_{n} q_{n}(\bar{\lambda})-\theta_{s} q_{s}(\bar{\lambda})\right]\right\} \\
& a_{2}=\bar{w}^{h}(\bar{\lambda}) \\
& b_{2}=\frac{1}{\bar{\lambda}}\left\{\frac{\alpha^{h} \chi(\bar{\lambda})(1-\chi(\bar{\lambda}))}{\mu}\left[\delta_{n} \theta_{n} q_{n}(\bar{\lambda})-\delta_{s} \theta_{s} q_{s}(\bar{\lambda})\right]\left[\theta_{n} q_{n}(\bar{\lambda})-\theta_{s} q_{s}(\bar{\lambda})\right]+\frac{\bar{w}^{h}(\bar{\lambda})-\underline{w}_{s}^{h}}{1-\alpha}\right\} \\
& a_{3}=\bar{w}^{l}(\bar{\lambda}) \\
& b_{3}=\frac{1}{\bar{\lambda}}\left\{\frac{\alpha^{l} \chi(\bar{\lambda})(1-\chi(\bar{\lambda}))}{\mu}\left[\delta_{n} \theta_{n} q_{n}(\bar{\lambda})-\delta_{s} \theta_{s} q_{s}(\bar{\lambda})\right]\left[\theta_{n} q_{n}(\bar{\lambda})-\theta_{s} q_{s}(\bar{\lambda})\right]+\frac{\bar{w}^{l}(\bar{\lambda})-\underline{w}_{s}^{l}}{1-\alpha}\right\} \\
& a_{4}=\bar{k}(\bar{\lambda}) \\
& b_{4}=\frac{1}{\bar{\lambda}}\left\{\frac{\alpha^{k} \chi(\bar{\lambda})(1-\chi(\bar{\lambda}))}{\mu \rho}\left[\delta_{n} \theta_{n} q_{n}(\bar{\lambda})-\delta_{s} \theta_{s} q_{s}(\bar{\lambda})\right]\left[\theta_{n} q_{n}(\bar{\lambda})-\theta_{s} q_{s}(\bar{\lambda})\right]+\frac{\bar{k}(\bar{\lambda})}{1-\alpha}\right\} \\
& a_{5}=\bar{q}(\bar{\lambda}) \\
& b_{5}=\frac{1}{\bar{\lambda}}\left\{\frac{\chi(\bar{\lambda})(1-\chi(\bar{\lambda}))}{\mu}\left[\theta_{n} q_{n}(\bar{\lambda})-\theta_{s} q_{s}(\bar{\lambda})\right]\left[q_{n}(\bar{\lambda})-q_{s}(\bar{\lambda})\right]+\frac{\bar{q}(\bar{\lambda})}{1-\alpha}\right\} \\
& a_{6}=a_{7}=E_{i j t}^{h}(\bar{\lambda})=E_{i j t}^{l}(\bar{\lambda}) \\
& b_{6}=b_{7}=\frac{1}{\mu \bar{\lambda}}\left[x_{s n}(\bar{\lambda}) \theta_{n} q_{n}(\bar{\lambda})+x_{s s}(\bar{\lambda}) \theta_{s} q_{s}(\bar{\lambda})\right] \\
& a_{8}=r_{s}(\bar{\lambda}) \\
& b_{8}=\left\{\frac{\alpha \delta_{s} \theta_{s} q_{s}(\bar{\lambda})}{(1-\alpha) \bar{\lambda} p_{s}(\bar{\lambda})}+\frac{\theta_{s} q_{s}(\bar{\lambda})}{\mu \bar{\lambda}}\right\} r_{s}(\bar{\lambda})
\end{aligned}
$$

It follows from (5a)-(5f) and the facts that $\theta_{n}>\theta_{s}$ and $\delta_{n} \geq \delta_{s}$ that $b_{m}>0$ for $m=1,2, \ldots, 8$. In addition, it follows from these facts and (A.6) (under the assumption that $\chi(\bar{\lambda})<\frac{1}{2}$ ) that the increase in $\delta_{n}$ and the decrease in $N_{s}$ have the effect of increasing $b_{1}, b_{2}, b_{3}, b_{4}$ and $b_{5}$. Note, by contrast, that the effect of the exchange rate shock on $b_{6}$ and $b_{7}$ is ambiguous; the shock raises $x_{n}(\bar{\lambda})$ and $q_{n}(\bar{\lambda})$ but may reduce $x_{s}(\bar{\lambda})$.

\section{A.4 Parameterizations for Maximum-Likelihood Estimation}

This section details the parameter transformations used by the search algorithm to maximize the likelihood function (12). ${ }^{58}$

\section{Parameterization for the Probabilities}

Given the constraint that they must sum to 1 , the probabilities $\tau_{v}$ for $v=1,2, . ., V$ can be expressed in terms of $V-1$ auxiliary parameters, $h_{v}$, where each $h_{v}$ is defined over the real

\footnotetext{
${ }^{58} \mathrm{I}$ am indebted to Tom Mroz for suggesting the parameterization for the probabilities and a parameterization for the mass points very similar to the one employed below.
} 
line:

$$
\begin{aligned}
\tau_{v} & =1+\sin \left(\frac{3 \pi}{2}+h_{v}\right) \text { for } v=1,2, \ldots, V-1 \\
\tau_{V} & =1+\sin \left(\sum_{1}^{V-1} h_{v}\right)
\end{aligned}
$$

\section{Parameterization for the Mass Points}

Given the scale normalization discussed in Section 6.1.1, the mass points $\tilde{\lambda}_{v}$ for $v=1,2, \ldots, V$ can be expressed in terms of $V-2$ auxiliary parameters, $\xi_{v}$, where each $\xi_{v}$ is defined over the real line. First consider an intermediate transformation:

$$
\begin{aligned}
& \tilde{\lambda}_{1}^{\prime}=0 \\
& \tilde{\lambda}_{v}^{\prime}=\frac{1+\sin \left(\xi_{v}\right)}{2} \\
& \tilde{\lambda}_{V}^{\prime}=1
\end{aligned}
$$

Then deviate from the expected mean of $\tilde{\lambda}^{\prime}$ :

$$
\tilde{\lambda}_{v} \equiv \tilde{\lambda}_{v}^{\prime}-\frac{1}{V} \sum_{1}^{V} \tau_{v} \tilde{\lambda}_{v}^{\prime}
$$

\section{Parameterization for the Error Variances}

The standard errors in (12), $\sigma_{m}$ for $m=1,2, \ldots, 8$, are expressed in terms of auxiliary parameters $f_{m}$ that are defined on the real line as:

$$
\sigma_{m}=e^{f_{m}} \text { for } m=1,2, \ldots, 8
$$




\section{B Data Appendix}

\section{B.1 Encuesta Industrial Anual (EIA)}

The Encuesta Industrial Anual (EIA) is carried out yearly, in the spring, with data referring to the previous calendar year. It contains information on employment, hours, wages, expenditures, sales, other revenues, inventories, and capital assets and investment. A companion survey, the Encuesta Industrial Mensual (EIM) [Monthly Industrial Survey], is carried out monthly using a less extensive survey at the same set of plants; the EIM is the source of information on wages and employment for the two occupational categories, obreros (production, or blue-collar, workers) and empleados (non-production, or white-collar, workers). INEGI has two separate datafiles, one covering the 1993-2001 period and an earlier on covering the 1984-1994 period. ${ }^{59}$ On the basis of these datasets, I created two balanced panels, which I refer to simply as the EIA 1993-2001 Panel and the EIA 1984-2001 Panel, and one unbalanced panel, which I refer to as the EIA 1993-2001 Unbalanced Panel.

\section{B.1.1 Sampling Design}

In 1993, 205 of the 309 6-digit industries (clases) in the Mexican industrial classification system were chosen to be included in the EIA. ${ }^{60}$ From a list of the universe of manufacturing plants in Mexico (generated in preparation for the upcoming 1994 industrial census), non-maquiladora plants within each clase were ranked in decreasing order of the value of production (valor de producción), the value of the output of the plant priced at the "factory" price (venta de fabrica). Plants were then selected in decreasing order of value of output until the set of selected plants made up $85 \%$ of the total value of output (not including maquiladoras) of the clase. This rule was subject to the following qualifications:

1. If a plant employed 100 or more workers, it was added to the sample, regardless of whether the $85 \%$ level had been reached.

2. If more than 100 plants were required to cover $85 \%$ of output within the clase, the number of plants was limited to 100. (There were no cases in which this rule conflicted with (1).)

3. If four or fewer plants made up $85 \%$ or more of total output of the clase, then to preserve the confidentiality of those plants, all plants in the clase were included, superseding rule (2).

These criteria generated an initial sample of 7,157 plants in 1993. These plants were subsequently followed over time. Specific analysts in the INEGI offices in Aguascalientes, Mexico, are assigned to follow particular plants over time, and to double-check inconsistencies or sudden changes in the plant, in many cases by calling the establishment on the

\footnotetext{
${ }^{59}$ The earlier dataset is also described in the data appendix of Grether (1996).

${ }^{60}$ The Mexican industrial classification on which the surveys used in this paper are based is the Clasificacion Mexicana de Actividades y Productos (CMAP) [Mexican Classification of Activities and Products]. It is organized in 6-digit industries called clases (classes), 4-digit industries called ramas (branches), and 2-digit industries called divisiones (divisions). The classification was revised in 1993. The initial sample for the 1993-2001 EIA and EIM panels was drawn in 1993 using the updated classification, usually referred to as CMAP-94. (It was published in 1994.) In the manufacturing sector in the CMAP-94, there are 309 clases, 54 ramas, and 9 divisiones.
} 
phone. The same is true for the monthly EIM survey of the same plants. As a result, the quality of the data in the EIA and EIM tends to be better than in surveys with less regular contact between the INEGI analysts and the survey respondents.

A small number of plants were added to the survey after 1993, but they were not added in a systematic way, and I ignore the new establishments. The questionnaire used in the EIA changed over time prior to 1997. In 1997, a consistent format for the questionnaire was settled upon, and has since remained in effect. Variables collected prior to 1997 that are no longer included in the survey have been discarded from the dataset. An exception is foreign ownership, which was collected in 1994 but not thereafter, which has been preserved and can still be linked to the ongoing panel.

An important advantage of the EIA and the EIM is that the analysts tracking each establishment keep track of why some establishments fail to respond or respond in an irregular way. I classified plants that went bankrupt or suspended operations as non-random exiters. ${ }^{61}$ I classified plants that switched to industries not covered by the survey, that switched from manufacturing to wholesale or retail sales, that merged with other establishments, or that failed to provide data for an unexplained reason are classified as random exiters. I assume that these random exiters are ignorable in the sense of Griliches (1986).

The 1984-2001 panel used in this paper was formed by linking the 1993-2001 panel with the earlier 1984-1994 panel. The design of the 1984-1994 sample was similar to that of the 1993-2001 sample. In 1984, under an earlier industrial classification system, 129 clases were selected for the panel. Establishments within each clase were chosen following the same criteria described for the 1993-2001 panel above. The principal difference was that establishments were included within each industry until $80 \%$ of the total value of production in the industry was covered. The initial sample consisted of 3,199 plants. The EIA surveys prior to 1992 did not elicit information on exports. Information on exports is available from supplementary surveys funded by the World Bank for the same sample of plants, but only for the years 1986-1990. Data on exports are thus not available for 1984-1985 or 1991 . Many plants can not be linked from the 1984-1994 to 1993-2001 samples because industry definitions and the set of industries surveyed differ between the two panels. Because the EIA focuses on large plants, however, it is still possible to link a significant number of establishments.

At least since 1989, the instructions for the EIA have request that respondents report the average number of workers, either permanent or casual, paid or unpaid, who worked in the plant and were under the control of the plant's management. In 2000, the instructions were clarified to specify that this includes workers working under subcontract for other firms. No information is available on whether the workers are formal, in the sense of being officially registered with the Mexican social security agency, or informal. Anecdotal evidence suggests that many workers not registered with the social security agency are still reported in the EIA, and hence that the EIA employment totals include some informal workers.

\section{B.1.2 Cleaning Procedure}

The cleaning procedure for the 1993-2001 data was the following:

1. I removed establishments that report data for more than one establishment or that

\footnotetext{
${ }^{61}$ The set of plants that suspended operations includes plants that suspended operations due to strikes or to shortages of materials.
} 
have their data reported by another establishment. In some multi-establishment firms, survey respondents are unable or unwilling to report information separately for each establishment. In these cases, respondents report joint data for the establishments on a single survey. Only in 1998 did INEGI begin keeping track systematically of the reporting patterns. Establishments that have their information reported elsewhere are easy to identify; their records appears in zeros. Establishments that report information for more other establishments in the same firm are more difficult to identify. I discarded any establishment that had its information reported elsewhere in any year, and discarded any establishment that reported information from another establishment in 1998 or later.

2. I removed establishments owned in whole or in part by government entities.

3. I removed establishments that appear in any year to be maquiladoras. It is possible that some were included in the EIA sample by mistake, either because of errors in sampling or because plants entered the government's maquiladora program subsequent to the drawing of the EIA sample. I classify a plant as a maquiladora if either of the following conditions is satisfied:

(a) The plant derives $95 \%$ or more of its sales from exports.

(b) The plant derives $95 \%$ or more of its total revenues from income from subcontracting services (ingresos por servicios de maquila), which are not reported under sales. ${ }^{62}$

4. I removed establishments that exited randomly, by the above definition, in any year during the 1993-2001 period.

5. I set to missing the values of key variables that changed by more than a factor of five from one year to the next. This procedure was carried out for: total employment, bluecollar employment, white-collar employment, total hours, blue-collar hours, whitecollar hours, real total remuneration, real blue-collar remuneration, real white-collar remuneration, real domestic sales.

6. I imputed new values for missing values using a variant of the sequential regression multivariate imputation technique (Raghunathan, Lepkowski, Hoewyk, and Solenberger, 2001) as implemented by Abowd and Woodcock (2001). The steps were the following:

(a) I classified variables into five groups:

Group 1: total employment, total hours, total remuneration, total sales.

Group 2: materials costs, electricity costs, revenues, capital stock.

Group 3: blue-collar employment, white-collar employment, blue-collar hours, white-collar hours, blue-collar remuneration, white-collar remuneration.

Group 4: initial capital stock in machinery and equipment, initial capital stock in land and buildings, initial capital stock in transportation equipment and other assets, all in 1993.

\footnotetext{
${ }^{62}$ While it is possible that the income from subcontracting services is for domestic subcontracting, the more likely explanation is that such income reflects assembly for export.
} 
Group 5: foreign ownership, investment in machinery and equipment, investment in land and buildings, investment in transportation equipment and other assets, export share, imported inputs share.

(b) For Group 1, I regressed each variable (in the order given) on the other variables in the group, a lead and lag of the same variable, and year dummies, using the plants remaining in the sample after the steps above. (All variables in logs, deflated as described in section B.1.3 below.) The predicted values from this regression were imputed for the missing values. ${ }^{63}$

(c) For Group 2, I regressed each variable on the other variables in Groups 1-2, a lead and a lag of the same variable, and year dummies, and imputed with the predicted values. For Group 3, I did the same, including variables from Groups $1-3$.

(d) For Group 4, I regressed each variable on the variables in Groups 1-3 and a lead of the same variable, and imputed with the predicted values.

(e) The Group 5 variables had to be dealt with specially, due to their discreteness or censoring. For foreign ownership, I estimated a probit on Group 1-4 variables in 1994 (the only year during 1993-2001 that foreign ownership is observed), then drew randomly from a Bernoulli distribution with probability of success equal to the predicted probability from the probit. For each of the investment variables, I first imputed whether investment was zero or positive, following the same procedure as for foreign ownership; I then took predicted values from a regression of investment on Group 1-4 variables to replace the missing values. Schafer and Olsen (2000) argue that this "two-part" method is preferable to a tobit model in cases such as this one where zero values are economically meaningful, rather than being stand-ins for latent negative values. ${ }^{64}$ For export share, I first imputed domestic sales using Group 1-4 variables as in step 6c above, then imputed export sales using the same method as for investment in this step, then calculated export share and used it to rescale domestic and export sales to sum to total sales from step $6 \mathrm{~b}$. For imported inputs share, I followed the same procedure as for export share.

7. I re-checked the imputed values from the previous step to see whether values changed by more than a factor of five from one year to the next, and, if so, set them again to missing.

8. I removed establishments that were missing data on key variables after steps 1-7. Establishments classified as non-exiters were removed if they were missing data in any year over the 1993-2001 period. Establishments classified as non-random exiters were removed if they were missing data in any year prior to the year of exit. The key variables were blue-collar employment, white-collar employment, total employment, blue-collar hours, white-collar hours, total hours, blue-collar remuneration, whitecollar remuneration, total remuneration, domestic sales, export sales total sales, the

\footnotetext{
${ }^{63}$ If a lead and/or lag was missing, I used the predicted value from an analogous regression without a lead and/or lag.

${ }^{64}$ Note that the two-part method is equivalent a Heckman (1976) selection model with the correlation between the errors in the two stages set to zero.
} 
investment variables, the initial capital stock variables, foreign ownership, geographical location (state), materials costs, and electricity costs.

Appendix Table 4 summarizes the numbers of plants lost in each step. In the end we are left with a balanced panel of 3,263 plants that have complete data over the entire 1993-2001 period, and an unbalanced panel that includes 1,139 additional plants that went out of business during the period.

Following a suggestion of Angrist and Krueger (1999), I "winsorized" the key variables at the tails, replacing values in the lower or upper $1 \%$ tails with values at the 1 st and 99 th percentiles, respectively. The following variables were winsorized: total employment, bluecollar employment, white-collar employment, total hours, blue-collar hours, white-collar hours, real average wage, real blue-collar wage, real white-collar wage, white-collar/bluecollar wage ratio, real domestic sales, real revenues, real capital-labor ratio.

The cleaning procedure for the 1984-1994 EIA dataset was similar to that for the 19932001 dataset. The 1984-1994 dataset indicates neither whether multi-establishment firms have consolidated information under one establishment nor whether plants have public ownership, so steps 1 and 2 were skipped. Also, the 1984-1994 EIA dataset does not contain information on the reason for exit, so step 4 was skipped as well. I took the information from 1984-1992 from the 1984-1994 dataset, and information for 1993-2001 from the 1993-2001 dataset. $^{65}$

The facts that we do not know the reason for exit in 1984-1994 and that the sampling design of the EIA changed for the 1993-2001 dataset would make the analysis of an unbalanced 1984-2001 panel difficult. Instead, I focus on the balanced 1984-2001 panel. After the cleaning procedure, there are 1,114 establishments that appear with complete data over the entire 1984-2001 period.

Capital stock was constructed using the perpetual-inventory method. I classified capital into three types: machinery and equipment, land and buildings, and transportation equipment and other fixed assets. Following Olley and Pakes (1996), each type of capital was assumed to evolve according to:

$$
K_{j t}=\left(1-\delta_{j}\right) K_{j t-1}+i_{j t-1}
$$

where $j$ indexes the three types of capital. Following Levinsohn and Petrin (2003), the depreciation rates, $\delta_{j}$ for machinery and equipment, land and buildings, and transportation equipment were assumed to be $10 \%, 5 \%$ and $20 \%$ respectively. Total capital stock is the sum of the three types of capital. I took the book value of capital stock in the initial year (1984 or 1993 depending on the panel) as the initial value. Both the initial book value and subsequent investments are measured in thousands of 1994 pesos, deflated by the producer price index. ${ }^{66}$

\footnotetext{
${ }^{65}$ As mentioned above, the 1984-1994 dataset does not include information on export vs. domestic sales or imported vs. domestic inputs in 1984, 1985 or 1991. These variables were not included in the cleaning procedure for those years.

${ }^{66}$ The raw data contains some negative values for fixed assets and investment. I set these to zero before calculating capital stock.
} 


\section{B.1.3 Variable Definitions}

Employment (white-collar, blue-collar, total) = average yearly employment for non-production workers (empleados), production workers (obreros), and all workers, respectively.

White-collar hourly wage $=$ total white-collar wage bill/total hours worked by white-collar workers, deflated to 1994 pesos using the main consumer price index (INPC) from Banco de Mexico, the Mexican central bank.

Blue-collar hourly wage $=$ total blue-collar wage bill/total hours worked by blue-collar workers, deflated to 1994 pesos by consumer price index.

Wage ratio $=$ white-collar hourly wage/blue-collar real hourly wage.

White-collar employment share $=$ white-collar hours worked/total hours worked

Domestic sales $=$ domestic sales as reported, measured in thousands of 1994 pesos, deflated by the producer price index (INPP) from Banco de Mexico.

Export sales $=$ export sales as reported, measured in thousands of 1994 pesos, deflated by the producer price index.

Export share of sales $=$ export sales $/$ (domestic sales + export sales $)$.

Exporter $=1$ if export percentage of sales $>0,=0$ otherwise.

Capital-labor ratio $=$ real capital stock/total employment.

Foreign ownership indicator $=1$ if plant had $\geq 10 \%$ foreign ownership in 1994 (the only year for which data were available during 1993-2001), $=0$ otherwise.

Revenues $=$ total sales + income from subcontracting for other plants - expenditures on subcontracting by other plants, in thousands of 1994 pesos, deflated by producer price index. ${ }^{67}$

\section{B.2 Encuesta Nacional de Empleo, Salarios, Tecnología y Capacitacion (ENESTyC)}

The Encuesta Nacional de Empleo, Salarios, Tecnología y Capacitacion (ENESTyC) [National Survey of Employment, Wages, Technology and Training] is a special survey that includes qualitative questions regarding training, turnover, technology use and a variety of workplace practices. It was carried out in 1992, 1995, 1999, and 2001 with many of the questions referring to the previous calendar year. The survey covered 5,071 establishments in 1992, 5,242 in 1995, 7,429 in 1999, and 8,856 in 2001. Unlike the EIA, the ENESTyC is based on a representative sample of plants and includes maquiladoras. The sampling frame in each year was stratified by total employment, with plants with 100 or more employees sampled with certainty, and a sample of plants with fewer than 100 employees drawn at random. In 1995, two samples were drawn. One was a probabilistic sample similar to the samples in 1992, 1999, and 2001, with the difference that maquiladoras were excluded. The second sample was a follow-up sample for the 1992 sample. All respondents to the 1992 survey that could be located were included. A few maquiladoras were included in the 1995 survey through this follow-up sample.

\footnotetext{
${ }^{67}$ The convention in the EIA for plants producing under subcontract is to report earnings from subcontracting as income from subcontracting services (ingresos por servicios de maquila), not under value of production or sales. For plants subcontracting out, payments to subcontractors are classified under costs, and sales of the subcontracted goods are reported under total value of production and sales.
} 
The surveys were designed as separate cross-sections, not as a panel, but because of the fact that large establishments are sampled with certainty, it is possible to link a fair number of plants over time. The different waves of the survey did not employ the same identification codes, and many of the establishments had to be linked across years by establishment name and street address. Although many questions changed in the questionnaires between waves, several key variables are comparable across waves.

My judgment after working extensively with these data is that the EIA is the more reliable source because plants are followed more closely by INEGI personnel. For this reason, I focus on plants that appear in both the ENESTyC and the EIA, and use information (i.e. on domestic sales) from the EIA when possible. To construct the EIA-ENESTyC Panel, I limited the sample to plants in the balanced EIA 1993-2001 Panel that could be linked to the ENESTyC and had non-missing data for ISO 9000 certification - the most important ENESTyC variable for testing the quality-upgrading hypothesis - in the three waves in which ISO 9000 is available: 1995, 1999, and 2001. This yielded a panel of 844 plants. Limiting the panel to plants with complete data on all variables included in Table 4 would have made the panel prohibitively small. Instead, I allow the sample size to change when focusing on the different dependent variables in Table 4.

The ENESTyC asked a number of different questions about employee training. It appears from the pattern of responses, however, that respondents misunderstood many of the specific questions, or used different rules of thumb to guide their answers. The most reliable measure of training appears to be simply whether or not a formal training program exists at the plant, rather than how many workers received training.

The ENESTyC reports wage and employment data by 4 occupational categories: unskilled blue-collar workers, skilled blue-collar workers, administrative and technical workers, and managers. The definitions of the categories in the official documentation, however, are imprecise, especially on the distinction between unskilled and skilled blue-collar workers, and this seems to have led to a significant amount of noise in the data, with some plants reporting all their blue-collar workers under the skilled blue-collar category, and others under the unskilled blue-collar category. The coarser distinction between blue-collar and white-collar workers is more familiar to survey respondents and appears to be more reliable.

The information on white-collar and blue-collar schooling is available only in the 1992, 1999 and 2001 waves. I used information from the 1992 wave rather than the 1995 wave as the pre-peso-crisis information.

I censored outliers for the turnover rate, the accident rate, and the absentee rate following the same procedure as for the EIA, assigning all variables in the bottom and top $1 \%$ to the values at the 1st and 99th percentiles respectively.

The variables used from the EIA-ENESTyC panel were defined as follows:

ISO 9000 indicator $=1$ if the establishment has ISO 9000 or similar quality certification, $=0$ otherwise.

Average schooling of blue-collar workers $=\left(3^{*}\right.$ (\# with less than primary school $)+6^{*}(\#$ with primary school $)+9^{*}(\#$ with junior high school $)+12^{*}(\#$ with high school $)+$ $16^{*}(\#$ with college/professional degree $)+18^{*}(\#$ with postgraduate education $\left.)\right) /$ employment of blue-collar workers at time of survey

Average schooling of white-collar workers: similar to blue-collar average schooling.

Formal training indicator $=1$ if establishment reports that is has a formal training program, $=0$ otherwise. 
Turnover rate $=100^{*}\left(2^{*}(\right.$ separations + new hires over previous 6 months $\left.)\right) /$ total employment at time of survey.

Accident rate $=100^{*}$ (number of accidents over previous calendar year)/average employment for previous calendar year.

Absentee rate $=$ average number of daily absences/employment at time of survey.

\section{B.3 Estadísticas Mensuales de la Industria Maquiladora de Exportación (EMIME)}

In order to remain in the Mexican government export-promotion program, maquiladora plants must report monthly production statistics. These administrative records are collected in a datafile referred to by INEGI as the Estadísticas Mensuales de la Industria Maquiladora de Exportación (EMIME) [Monthly Statistics on Maquiladora Export Industry], which represents a census of participants in the program each month. The EMIME contains information on employment and wages by occupational categories and spending on inputs. Hours worked by occupational category is available beginning in 1997. The EMIME does not contain a measure of total sales, nor does it include measures of the share of inputs that are imported or the share of output that is exported. The industrial classification used by the EMIME is grupo económico [economic group], of which there are $12 .{ }^{68}$ Data are available from 1990-2004. To maximize comparability with the EIA 1993-2001 Panel, I draw the set of plants with complete data in every year over the 1993-2001 period. I refer to these 1,088 plants as the EMIME panel.

The variables used from the EIA-ENESTyC panel were defined as follows:

Average hourly wage $=$ total wage bill (all workers)/total hours. Note that hours by occupation are not available prior to 1997.

Blue-collar yearly earnings = total blue-collar (obrero) wage bill/average blue-collar employment over 12 months, deflated to 1994 pesos by consumer price index.

White-collar yearly earnings $=$ total white-collar (empleados + técnicos) wage bill/average white-collar employment over 12 months, deflated to 1994 pesos by consumer price index.

\section{B.4 Encuesta Nacional de Empleo Urbano (ENEU)}

The Encuesta Nacional de Empleo Urbano (ENEU) [National Urban Employment Survey] is a household survey modeled on the Current Population Survey (CPS) in the U.S. Households are interviewed quarterly for five quarters, and then rotate out of the sample. The original ENEU sample focused on the 16 largest Mexican cities. ${ }^{69}$ Over time, the coverage of cities

\footnotetext{
${ }^{68}$ The 12 groups are: 1 . Selection, preparation, packaging and canning of food; 2 . Assembly of apparel and other textile products; 3 . Shoes and leather goods; 4. Furniture and accessories and other metal and wood products; 5 . Chemical products; 6 . Construction, reconstruction and assembly of transportation equipment and accessories; 7. Assembly and repair of tools and machinery (not electric); 8. Assembly and repair of machinery (electric and electronic); 9. Materials and accessories (electric and electronic); 10. Assembly of toys and sporting goods; 11. Other manufacturing; 12. Services.

${ }^{69}$ The 16 cities are: Mexico City, Guadalajara, Monterrey, Puebla, Leon, Torreon, San Luis Potosi, Merida, Chihuahua, Tampico, Orizaba, Veracruz, Ciudad Juarez, Tijuana, Matamoros and Nuevo Laredo.
} 
expanded but I focus on the original 16 cities in order to maximize comparability across years. ${ }^{70}$

The ENEU sample used in this paper consists of men, ages 16-64, who worked 35 or more hours in previous week, in 16 cities in original (1987) ENEU sample. ${ }^{71}$ Self-employed workers are excluded.

The hourly wage figures were constructed as follows:

1. I recovered monthly wages for the job worked last week as converted from weekly or bi-weekly basis by INEGI enumerators. Top-coded reports were assigned 1.5 times the top-code value. Individuals who reported not working in previous week were dropped.

2. Monthly hours were calculated as 4.3 times hours worked in the previous week. Responses of "irregular hours, less than 35", "irregular hours, between 35 and 48" and "irregular hours, more than 48" were assigned values of 20, 42 and 60 hours per week, respectively.

3. Hourly wage was calculated as monthly wage/monthly hours. The wage was deflated to constant 1994 pesos using the main consumer price index (INPC) from Banco de Mexico, the Mexican central bank.

4. I winsorized the wage data at the 1 st and 99th percentiles.

Average schooling by 4-digit industry (Figure 2) is calculated as an average of years of schooling of workers in industry. All calculations for wages and average schooling use the sampling weights reported by INEGI.

\section{B.5 Administrative Records of the Instituto Mexicano del Seguro Social (IMSS)}

All private, formal-sector Mexican employers are required to report wages for their employees, and pay social-security taxes on the basis of their reports to the Mexican social security agency, Instituto Mexicano del Seguro Social (IMSS). The raw data can be considered a census of private, formal-sector establishments and their workforces for 1985-2001. The number of workers in the raw data at a given point in time ranges from approximately 5 million in 1985 to approximately 11 million in 2001. These data are the basis for Kaplan and Verhoogen (2006), and readers are referred there for further details. To mimic the EIA sample, we drew balanced panels of plants with 50 or more workers in all years 1993-2001 in two broad sectors, tradables (manufacturing) and non-tradables (construction, retail trade, transportation, and services). The panels have 3628 and 3672 establishments respectively.

The IMSS data contain information on the daily wage of individuals. The figures are based on a measure of total compensation, called the salario base de cotización, which includes both wages and benefits, including payments made in cash, bonuses, commissions, room and board, overtime payments, and in-kind benefits. We extracted data for September

\footnotetext{
${ }^{70}$ Mexico also had a nationally representative survey that covered rural areas, the Encuesta Nacional de Empleo (ENE), but until it was combined with the ENEU in 2000 it was carried out at less regular intervals.

${ }^{71}$ The processing of the ENEU data in Figure 1b of Robertson (2004) differs from this sample in that it includes women and 8 of the original 16 cities. These differences do not explain the discrepancy between that figure and Figure 1 of this paper, and I have not been able to replicate his figure to determine the source of the discrepancy.
} 
30 for each year. At the establishment level, the data contain information only on location and industry (using the IMSS's own 4-digit industrial categories).

The wage variable used in Appendix Table 3 is an average over all individuals in a given plant of the log real daily wage on Sept. 30 of the given year.

\section{B.6 Alternative Proxies}

The alternative proxy variables used in Table 5 were constructed as follows:

Predicted export share index: I ran a tobit of the export share of sales on log hours worked for each occupation, log total sales, log capital-labor ratio, log electricity intensity (kilowatt hours used per hour worked), an indicator for whether the plant has $\geq 10 \%$ foreign ownership, and 4-digit industry effects. I then recovered the predicted values $x^{\prime} \hat{\beta}$, deviated from 6 -digit industry means, and standardized the variable to have variance 1 .

Predicted ISO 9000 index: Using the EIA-ENESTyC panel, I ran a probit of ISO 9000 certification on the same covariates as for the export share index plus the export share itself. With the estimate of $\hat{\beta}$ from this probit, I calculated $x^{\prime} \hat{\beta}$ for all plants in the EIA 1993-2001 Panel, then deviated from 6-digit industry means and standardized to have variance 1 .

First principal component: I deviated the co-variates used for the ISO 9000 index from 6-digit industry means, took the first principal component (the linear combination capturing the maximum variance of the joint distribution of the variables), and standardized the variable to have variance 1 .

Total factor productivity (TFP): I pooled data for two years (i.e. 1993 and 1994, or 1997 and 1998) and regressed log revenues on log hours worked for each occupation, log capital-labor ratio, log materials costs, log electricity costs, and plant fixed effects. I recovered the coefficients on the plant fixed effects, deviated them from 6-digit industry means, and standardized. ${ }^{72}$ Note that this approach to estimating TFP is attractive because, unlike other standard TFP measures, it does not mechanically include year-specific measurement error in revenues. ${ }^{73}$

Domestic sales per worker $=$ total real domestic sales/average employment for year.

Since wages are the primary outcome variables of interest, they are omitted from the construction of these proxies, so that mean reversion in wages due to measurement error does not bias the estimates. An FDI indicator is included; although this variable does not enter into the theoretical model, it seems plausible that foreign-owned plants have greater access to the knowledge and technologies of their parent companies, and hence that foreign ownership is a predictor for unobserved know-how or productivity.

\footnotetext{
${ }^{72}$ I am indebted to Matthias Schuendeln for suggesting this approach.

${ }^{73} \mathrm{It}$ is important to note that standard methods for estimating TFP impose assumptions on the production function and market structure that are inconsistent with the model presented in this paper. I include the TFP proxy for the sake of completeness.
} 

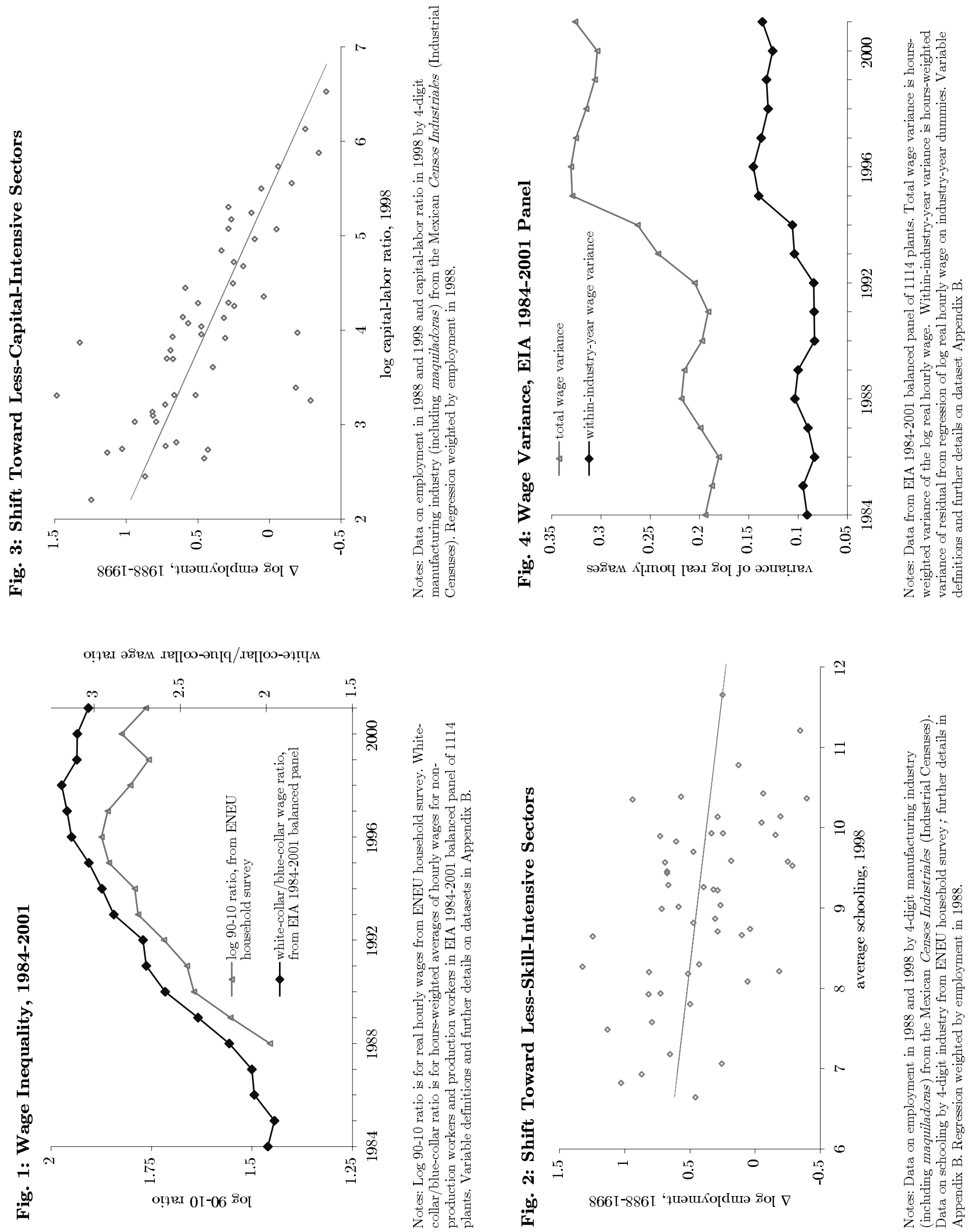

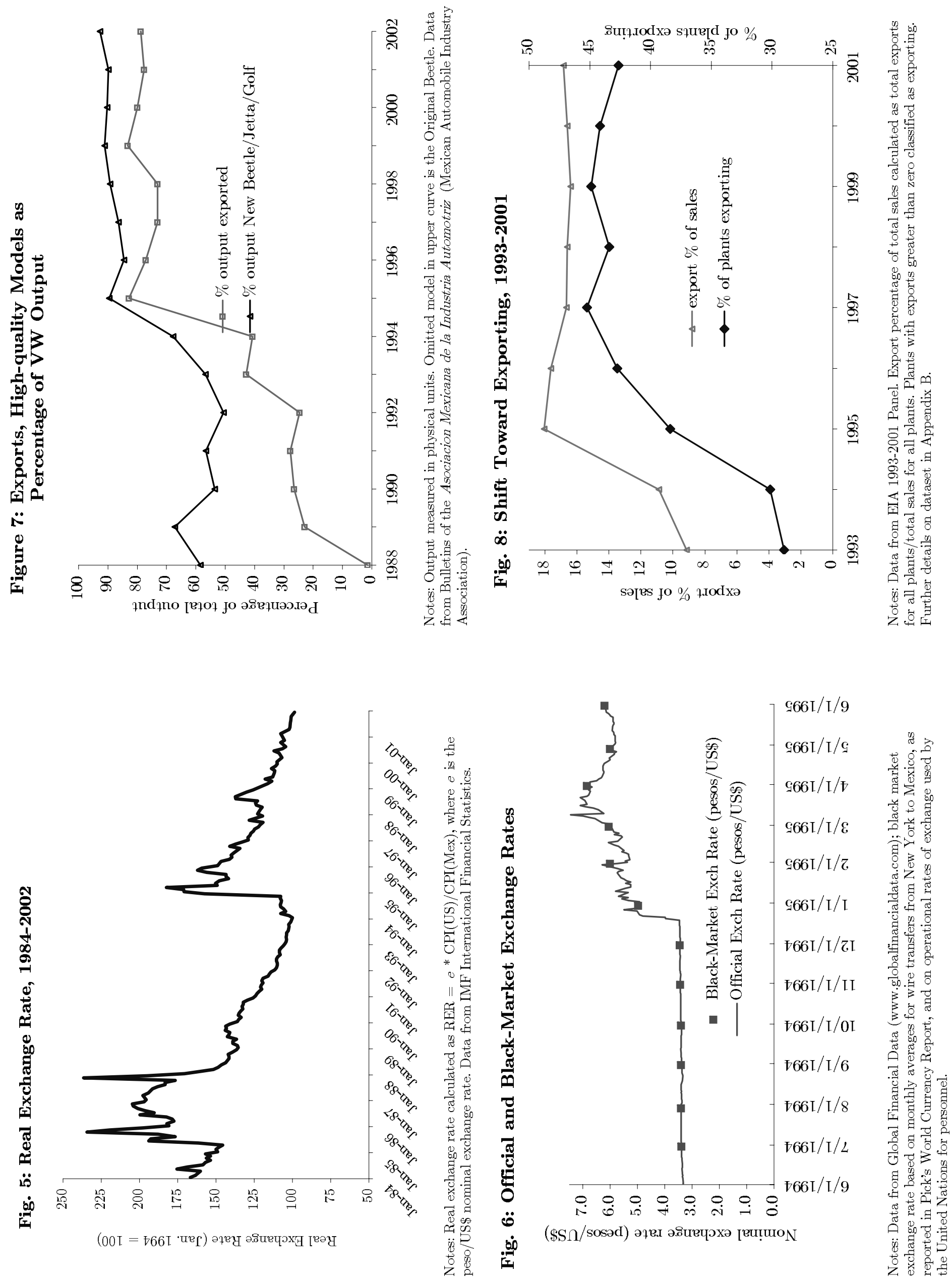

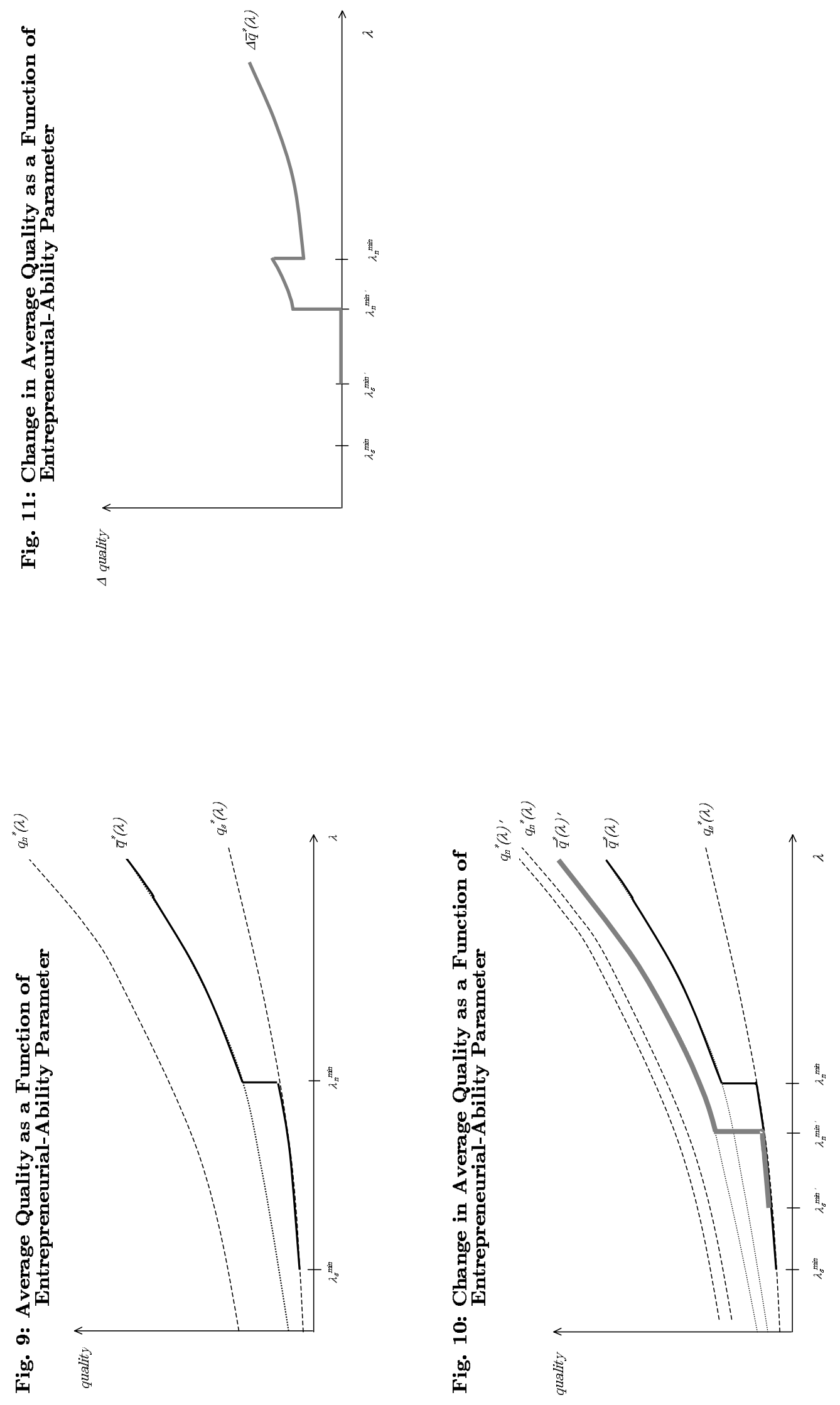


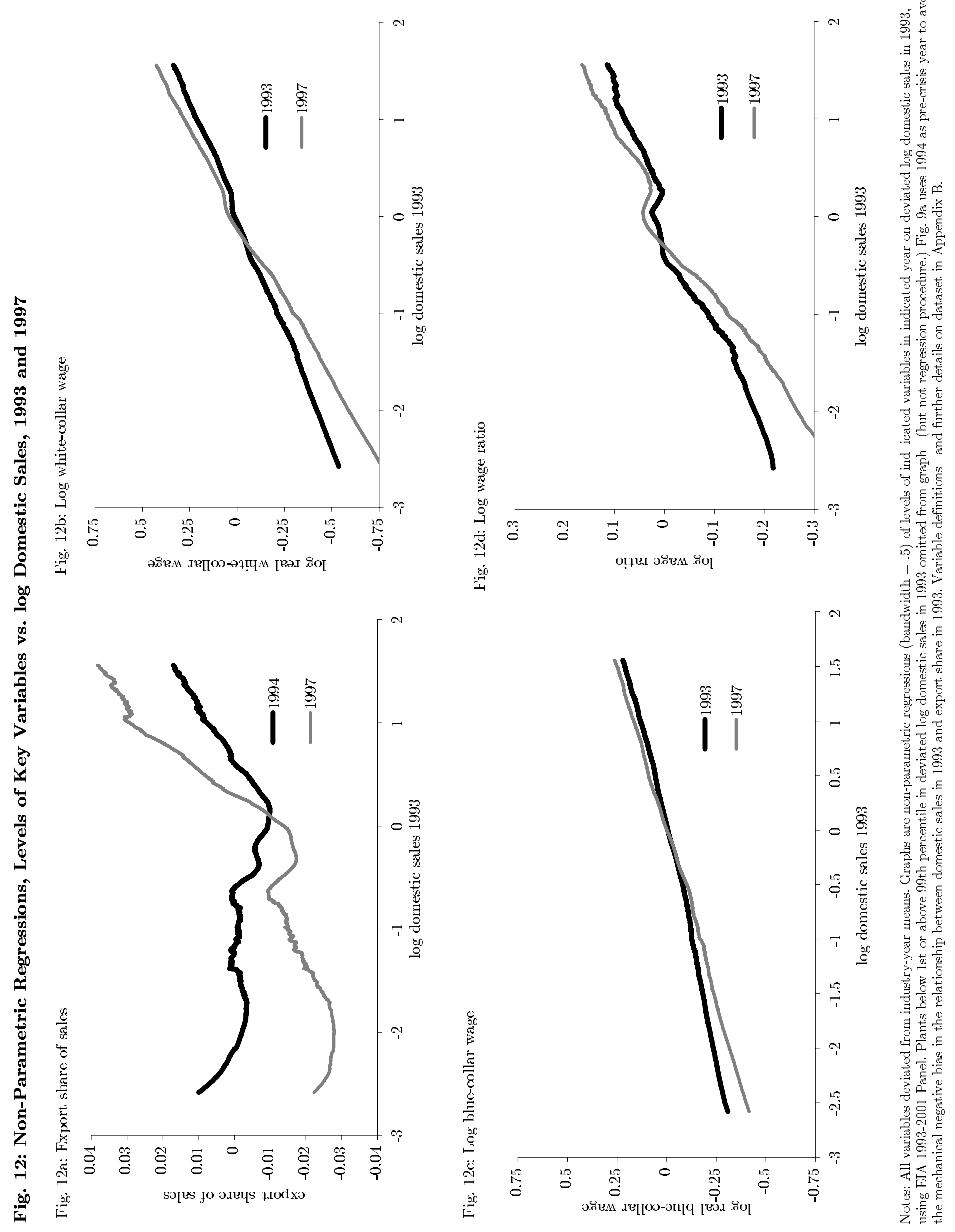




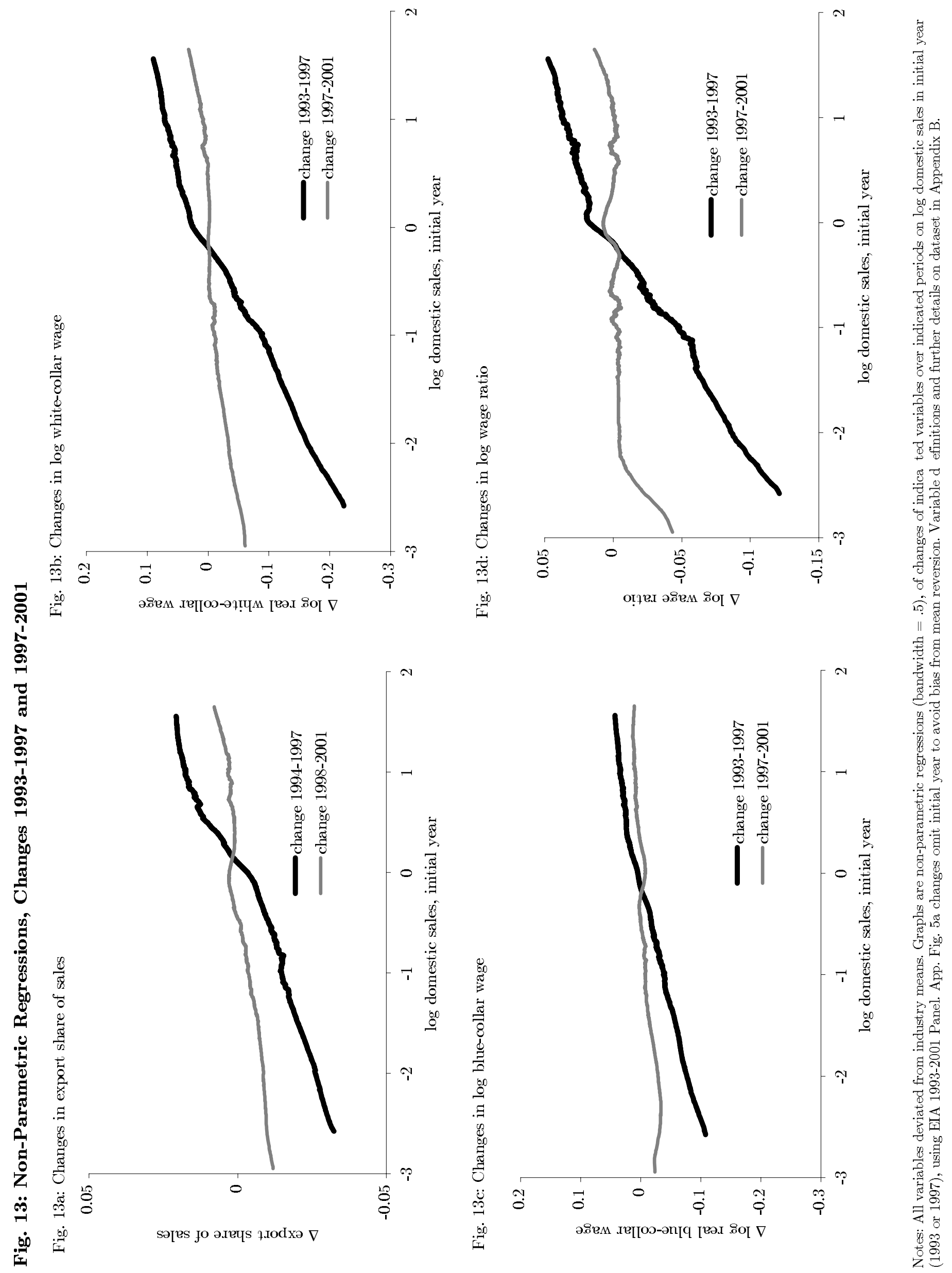


Table 1

Summary Statistics by Export Status

\begin{tabular}{|c|c|c|c|}
\hline A. EIA 1993-2001 Panel, 1993 & Non-exporters & Exporters & All \\
\hline employment & $\begin{array}{l}182.39 \\
(4.94)\end{array}$ & $\begin{array}{c}333.76 \\
(11.98)\end{array}$ & $\begin{array}{r}226.32 \\
(5.08)\end{array}$ \\
\hline revenues & $\begin{array}{l}42.24 \\
(1.75)\end{array}$ & $\begin{array}{l}89.84 \\
(4.59)\end{array}$ & $\begin{array}{c}56.05 \\
(1.86)\end{array}$ \\
\hline domestic sales & $\begin{array}{l}41.17 \\
(1.71)\end{array}$ & $\begin{array}{l}70.16 \\
(3.59)\end{array}$ & $\begin{array}{l}49.58 \\
(1.61)\end{array}$ \\
\hline $\mathrm{K} / \mathrm{L}$ ratio & $\begin{array}{l}42.58 \\
(1.40)\end{array}$ & $\begin{array}{l}55.59 \\
(2.60)\end{array}$ & $\begin{array}{c}46.36 \\
(1.25)\end{array}$ \\
\hline white-collar hourly wage & $\begin{array}{l}20.53 \\
(0.27)\end{array}$ & $\begin{array}{l}28.40 \\
(0.50)\end{array}$ & $\begin{array}{l}22.81 \\
(0.25)\end{array}$ \\
\hline blue-collar hourly wage & $\begin{array}{c}8.04 \\
(0.08)\end{array}$ & $\begin{array}{c}9.64 \\
(0.15)\end{array}$ & $\begin{array}{c}8.50 \\
(0.07)\end{array}$ \\
\hline white-collar employment share & $\begin{array}{c}0.30 \\
(0.004)\end{array}$ & $\begin{array}{c}0.33 \\
(0.005)\end{array}$ & $\begin{array}{c}0.31 \\
(0.003)\end{array}$ \\
\hline export share of sales & & $\begin{array}{c}0.16 \\
(0.01)\end{array}$ & \\
\hline share with foreign ownership & $\begin{array}{c}0.09 \\
(0.01)\end{array}$ & $\begin{array}{c}0.30 \\
(0.01)\end{array}$ & $\begin{array}{c}0.15 \\
(0.01)\end{array}$ \\
\hline $\mathrm{N}$ & 2316 & 747 & 3263 \\
\hline B. EIA-ENESTyC Panel & Non-exporters & Exporters & All \\
\hline employment & $\begin{array}{l}308.37 \\
(12.18)\end{array}$ & $\begin{array}{l}414.29 \\
(21.08)\end{array}$ & $\begin{array}{c}348.91 \\
(11.16)\end{array}$ \\
\hline share with ISO 9000 certification & $\begin{array}{c}0.09 \\
(0.01)\end{array}$ & $\begin{array}{c}0.12 \\
(0.02)\end{array}$ & $\begin{array}{c}0.10 \\
(0.01)\end{array}$ \\
\hline share with formal training program & $\begin{array}{l}0.69 \\
(0.02)\end{array}$ & $\begin{array}{l}0.79 \\
(0.02)\end{array}$ & $\begin{array}{c}0.73 \\
(0.02)\end{array}$ \\
\hline avg. schooling, white-collar & $\begin{array}{l}12.04 \\
(0.08)\end{array}$ & $\begin{array}{l}12.47 \\
(0.10)\end{array}$ & $\begin{array}{l}12.20 \\
(0.06)\end{array}$ \\
\hline avg. schooling, blue-collar & $\begin{array}{c}7.26 \\
(0.07)\end{array}$ & $\begin{array}{c}7.38 \\
(0.09)\end{array}$ & $\begin{array}{c}7.30 \\
(0.05)\end{array}$ \\
\hline absentee rate & $\begin{array}{c}1.41 \\
(0.07)\end{array}$ & $\begin{array}{c}1.20 \\
(0.08)\end{array}$ & $\begin{array}{c}1.33 \\
(0.05)\end{array}$ \\
\hline turnover rate & $\begin{array}{l}74.70 \\
(3.66)\end{array}$ & $\begin{array}{l}66.62 \\
(4.44)\end{array}$ & $\begin{array}{l}71.56 \\
(2.83)\end{array}$ \\
\hline accident rate & $\begin{array}{c}5.01 \\
(0.29)\end{array}$ & $\begin{array}{c}4.63 \\
(0.31)\end{array}$ & $\begin{array}{c}4.87 \\
(0.21)\end{array}$ \\
\hline
\end{tabular}

Notes: Standard errors of means in parentheses. Exporter means export sales $>0$. Has foreign ownership means FDI share $>0$. Data on FDI from 1994; other data from EIA Balanced panel from 1993. Revenues, domestic sales measured in millions of 1994 pesos, K/L $\mathrm{r}$ atio in thousands of 1994 pesos, wages in 1994 pesos per hour, employment in number of workers, employment share in hours. Data on ISO 9000, training, accidents from ENESTyC 1995, reporting for 1994; data on schooling from ENESTyC 1992, reporting for 1991. Numbers of observations for non-exporters (exporters) are 521 (323) for employment and ISO 9000, 366 (224) for white-collar schooling, 367 (223) for blue-collar schooling, 510 (318) for accident rate, $317(198)$ for absentee rate, 459 (292) for turnover rate; otherwise as repo rted above. Variable definitions and further details on datasets in Appendix B. 


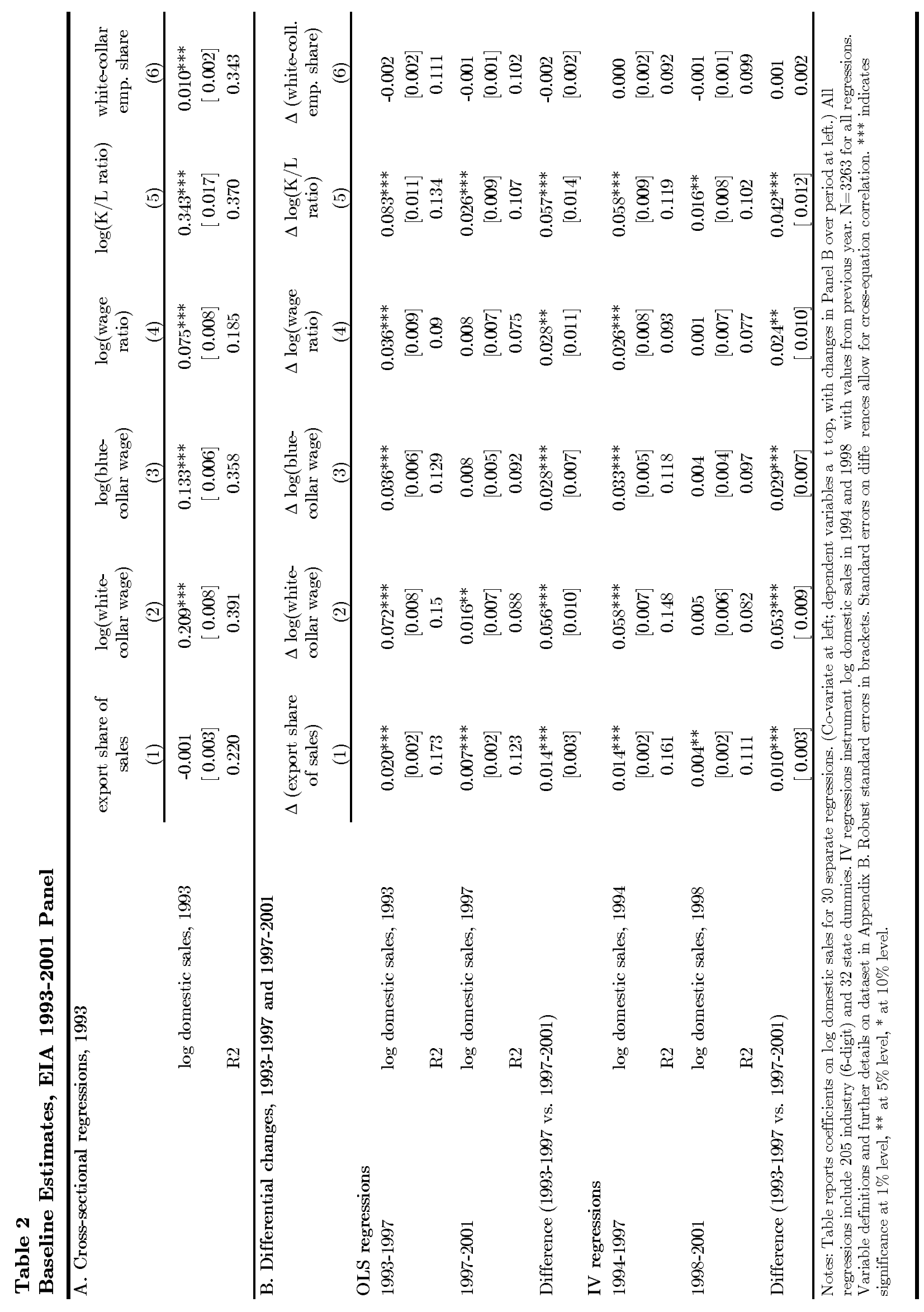




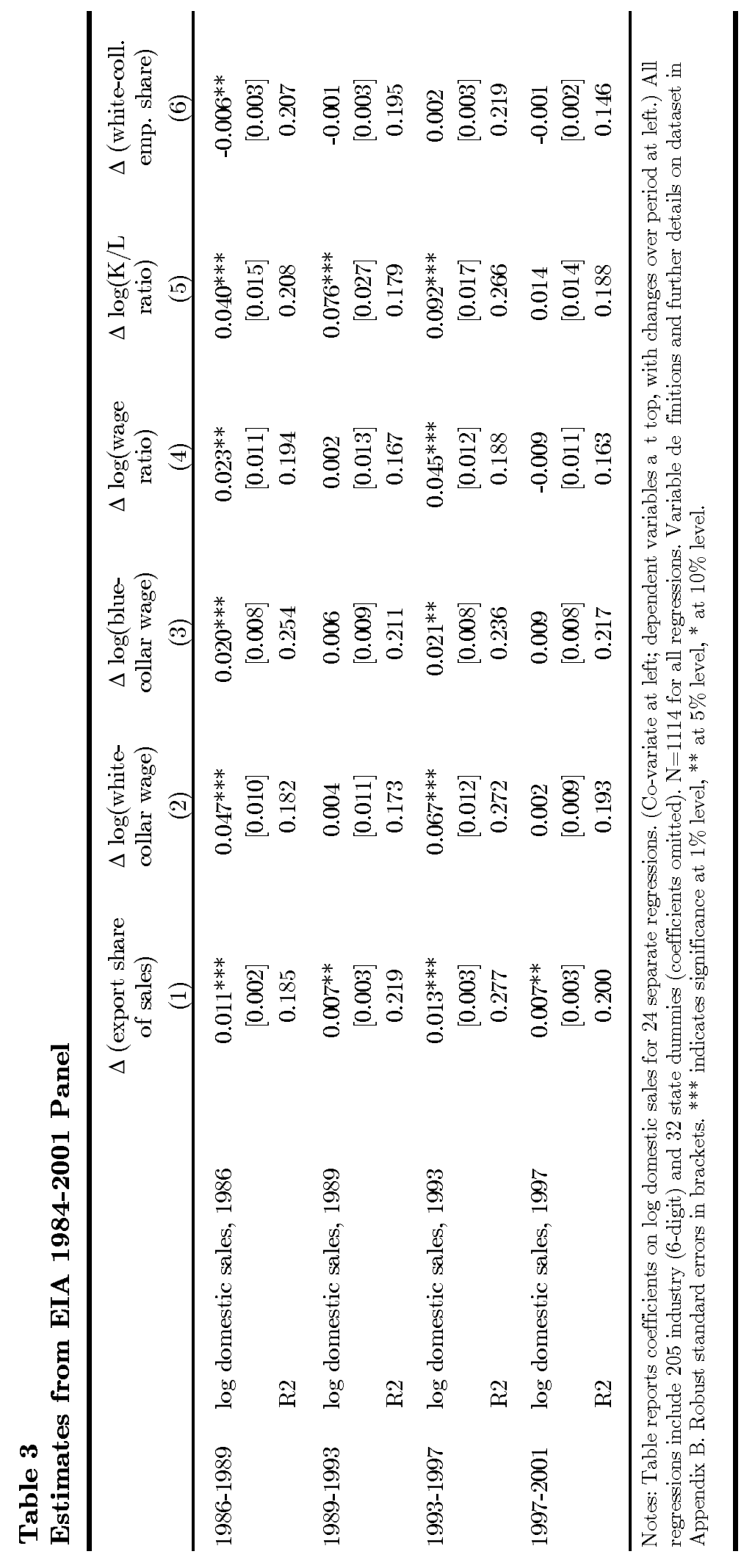




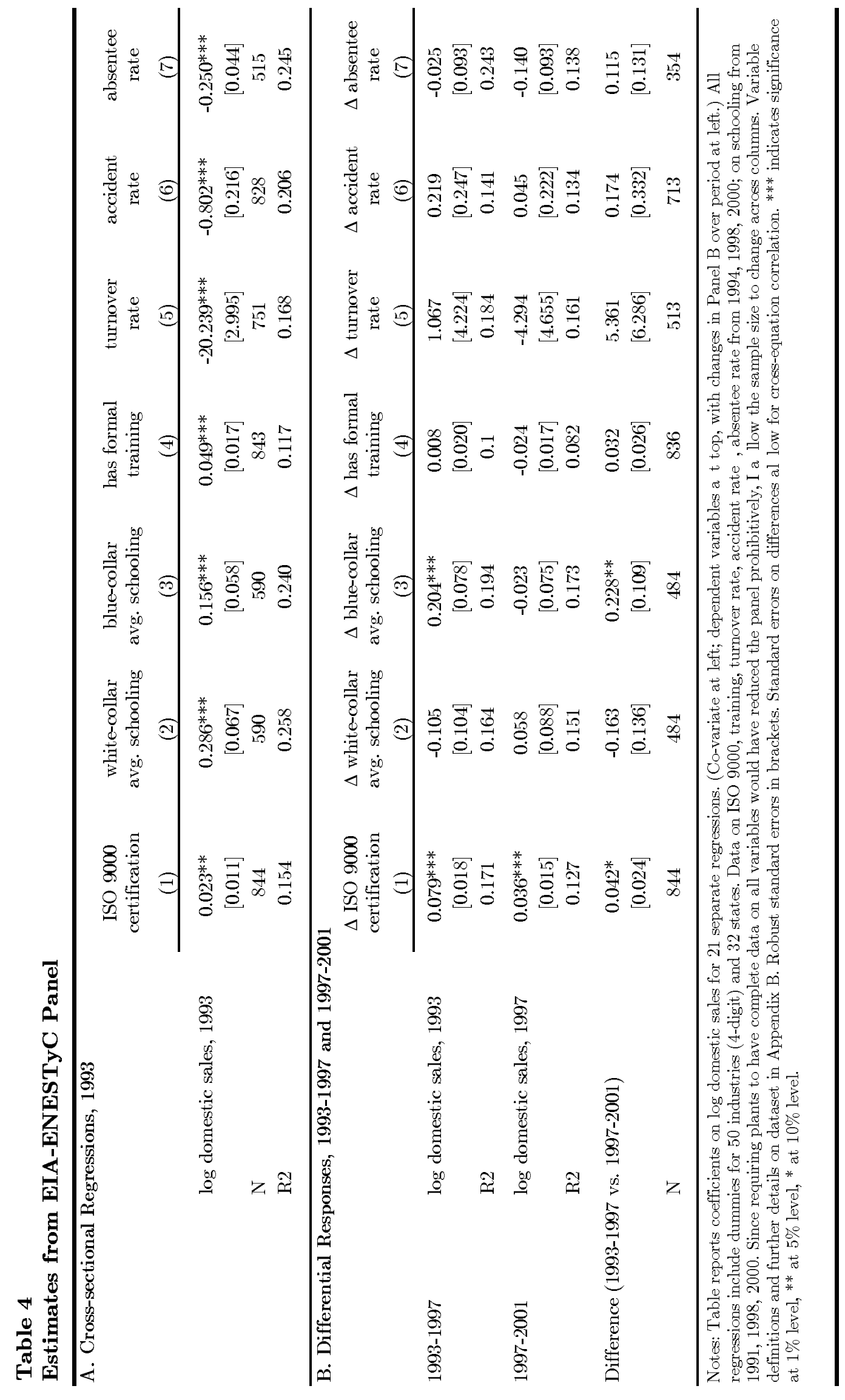




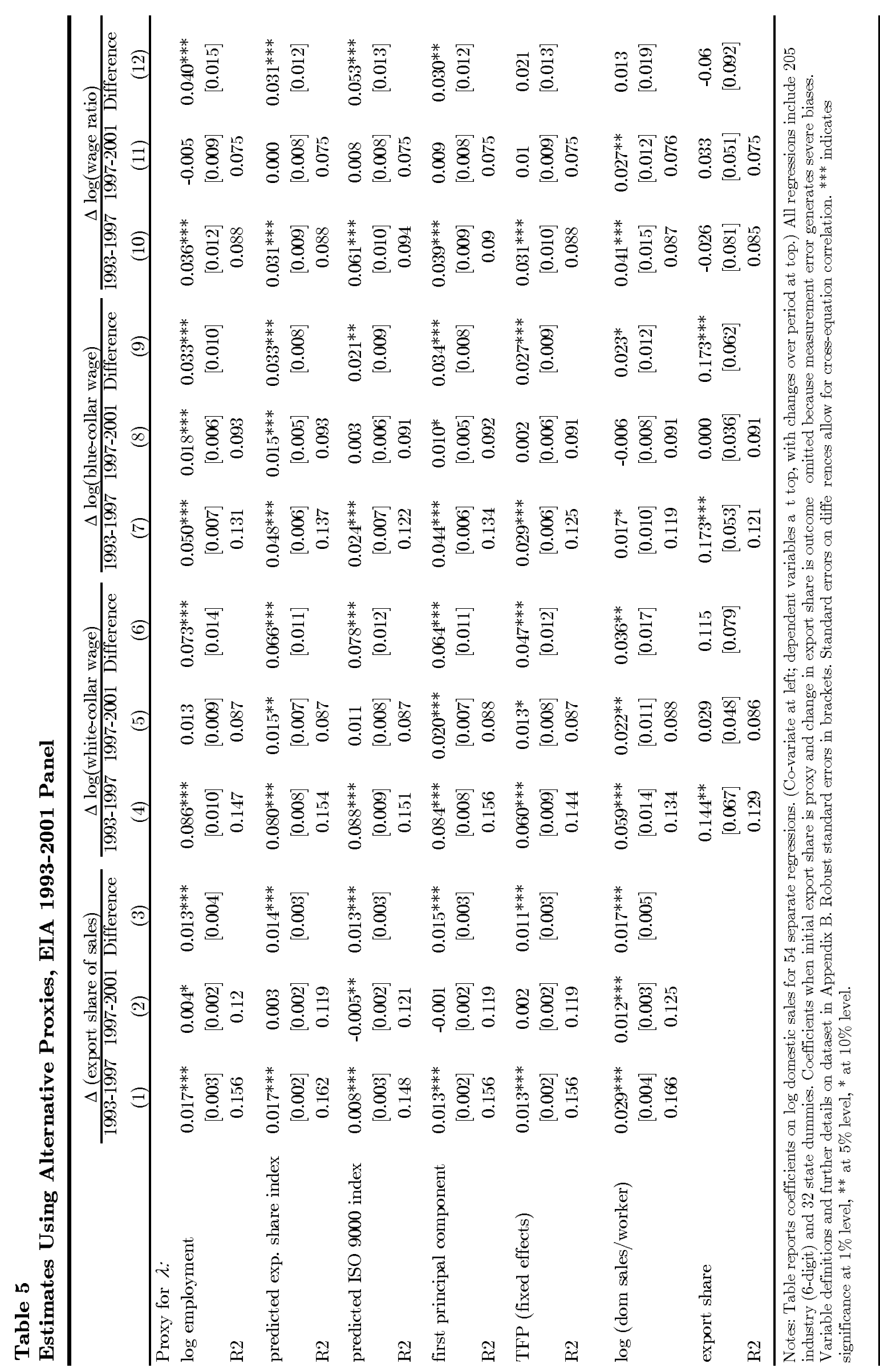




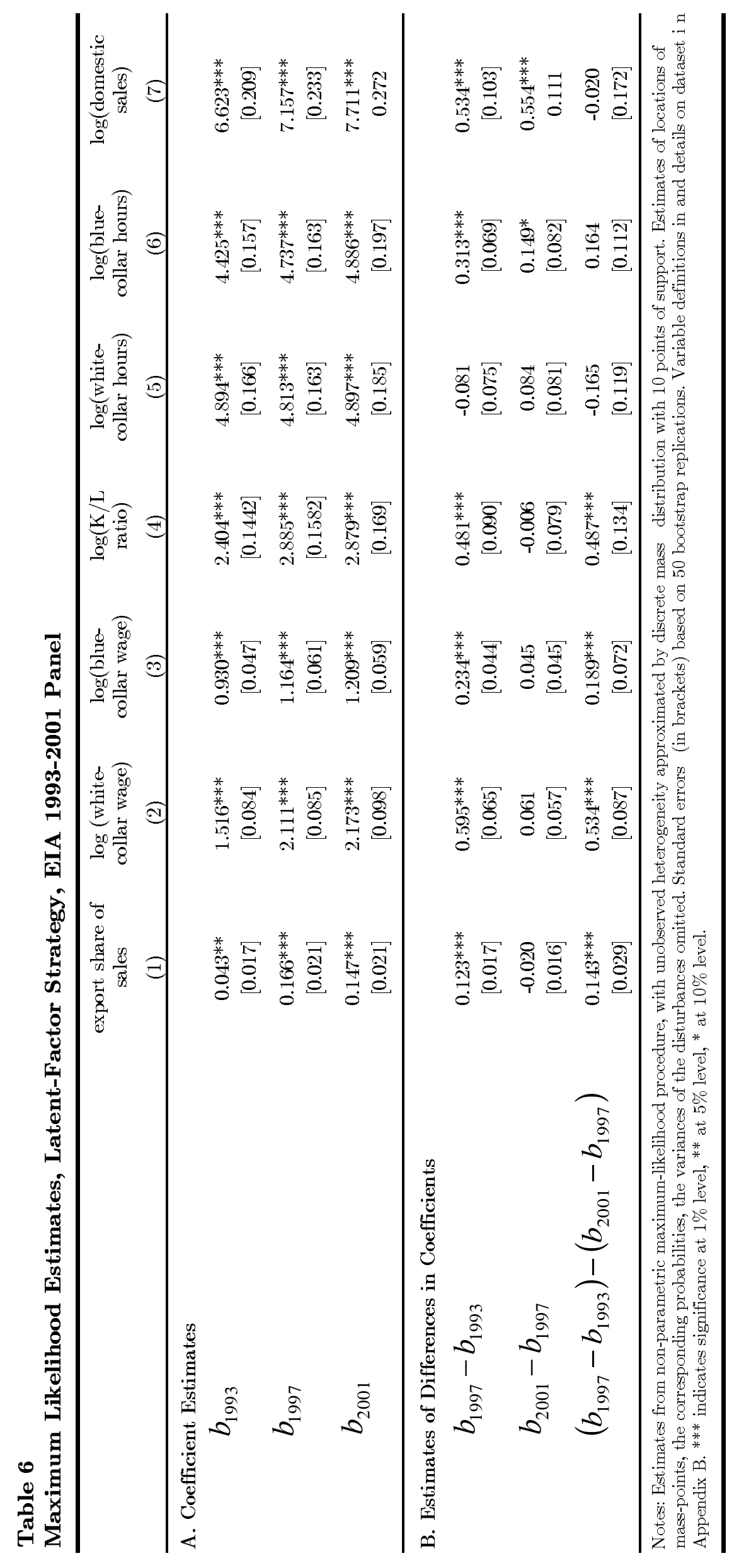




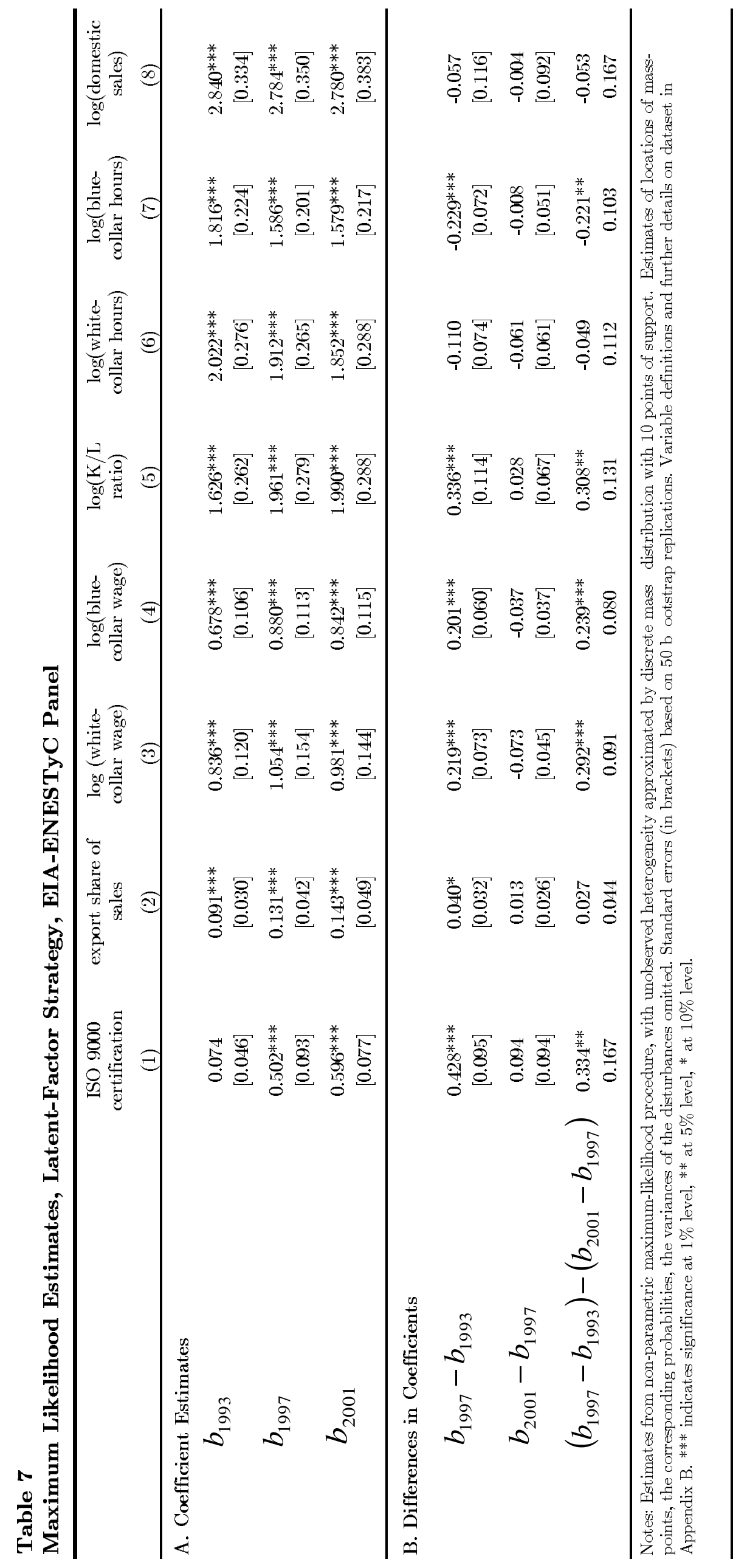




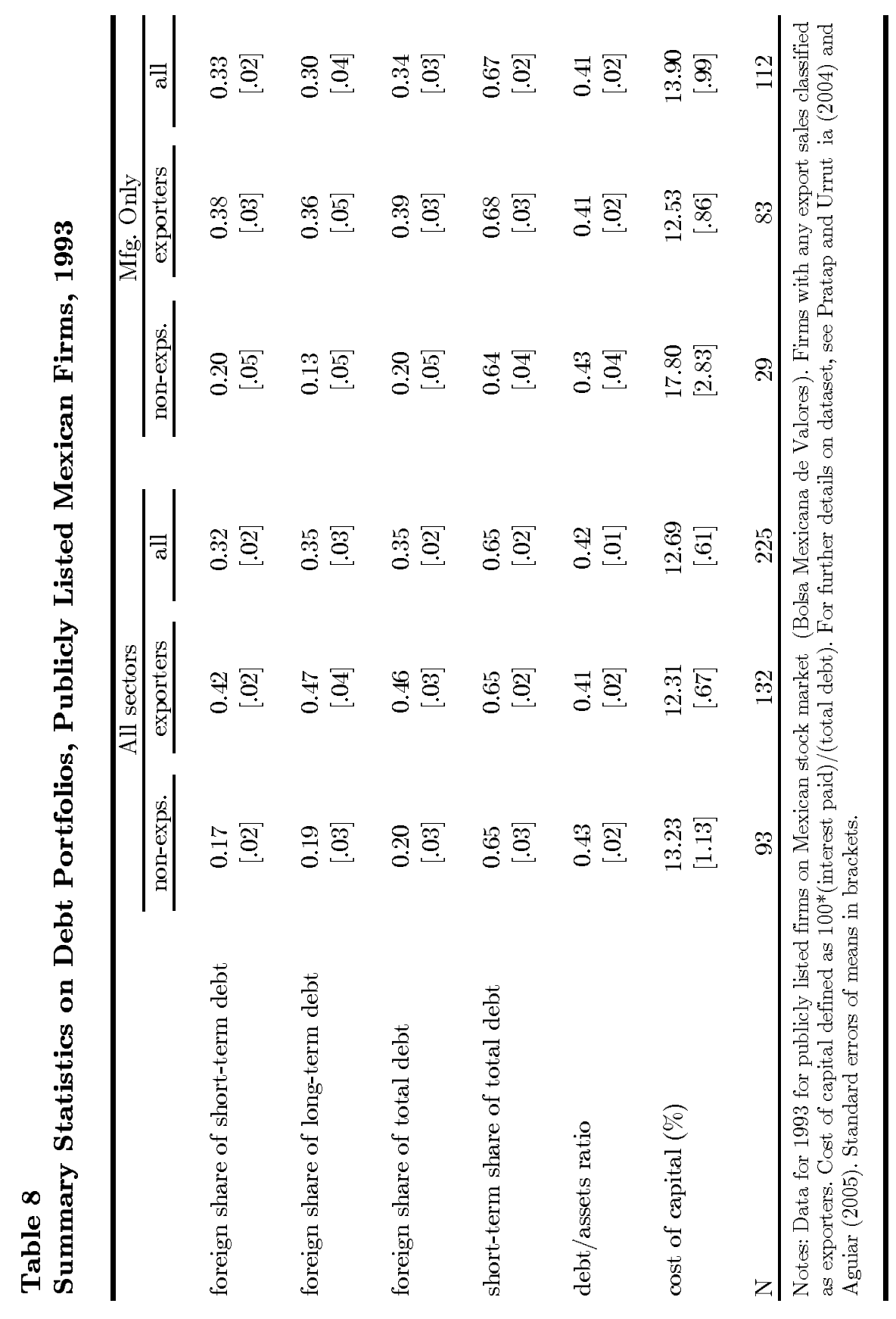




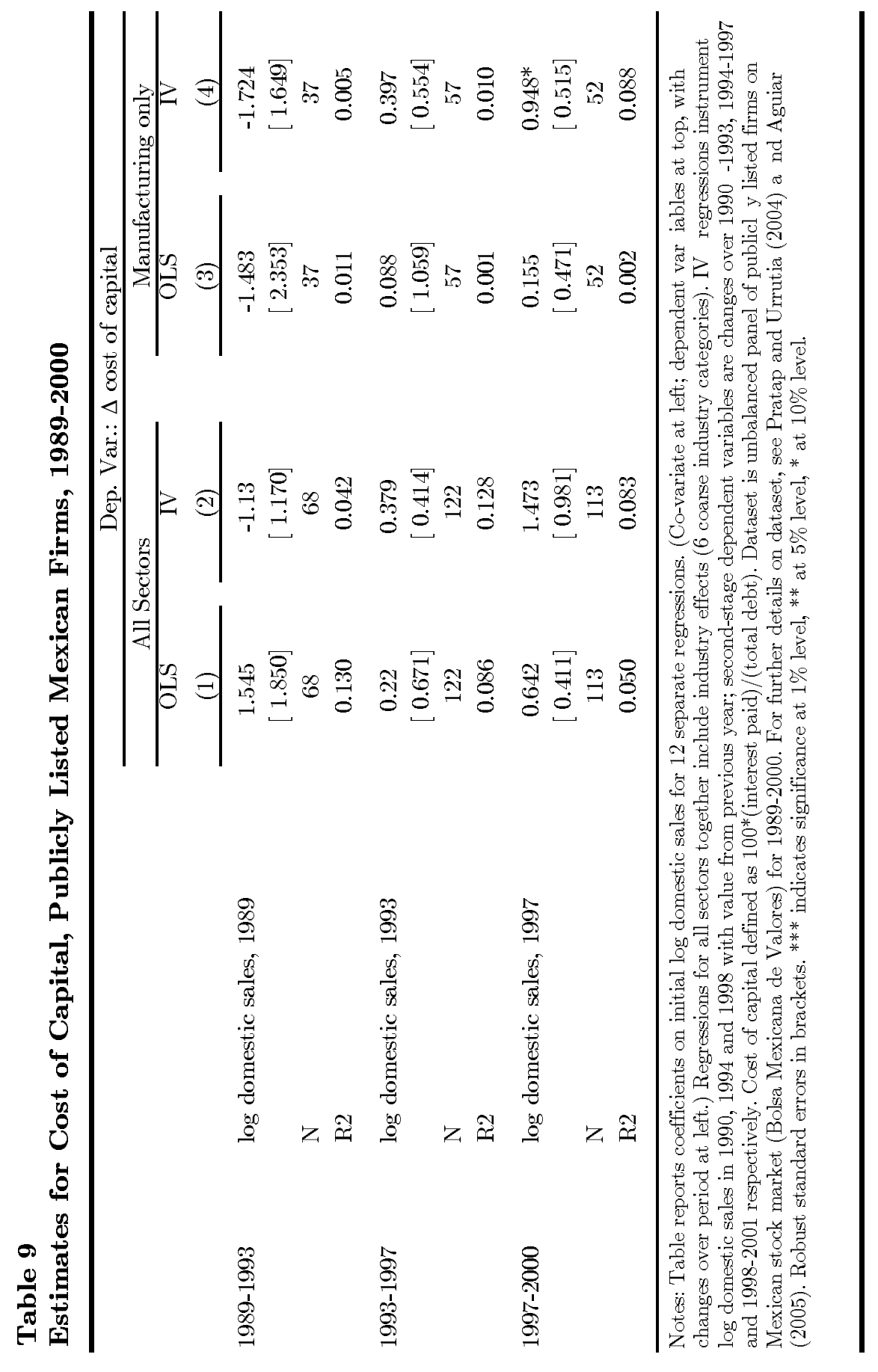




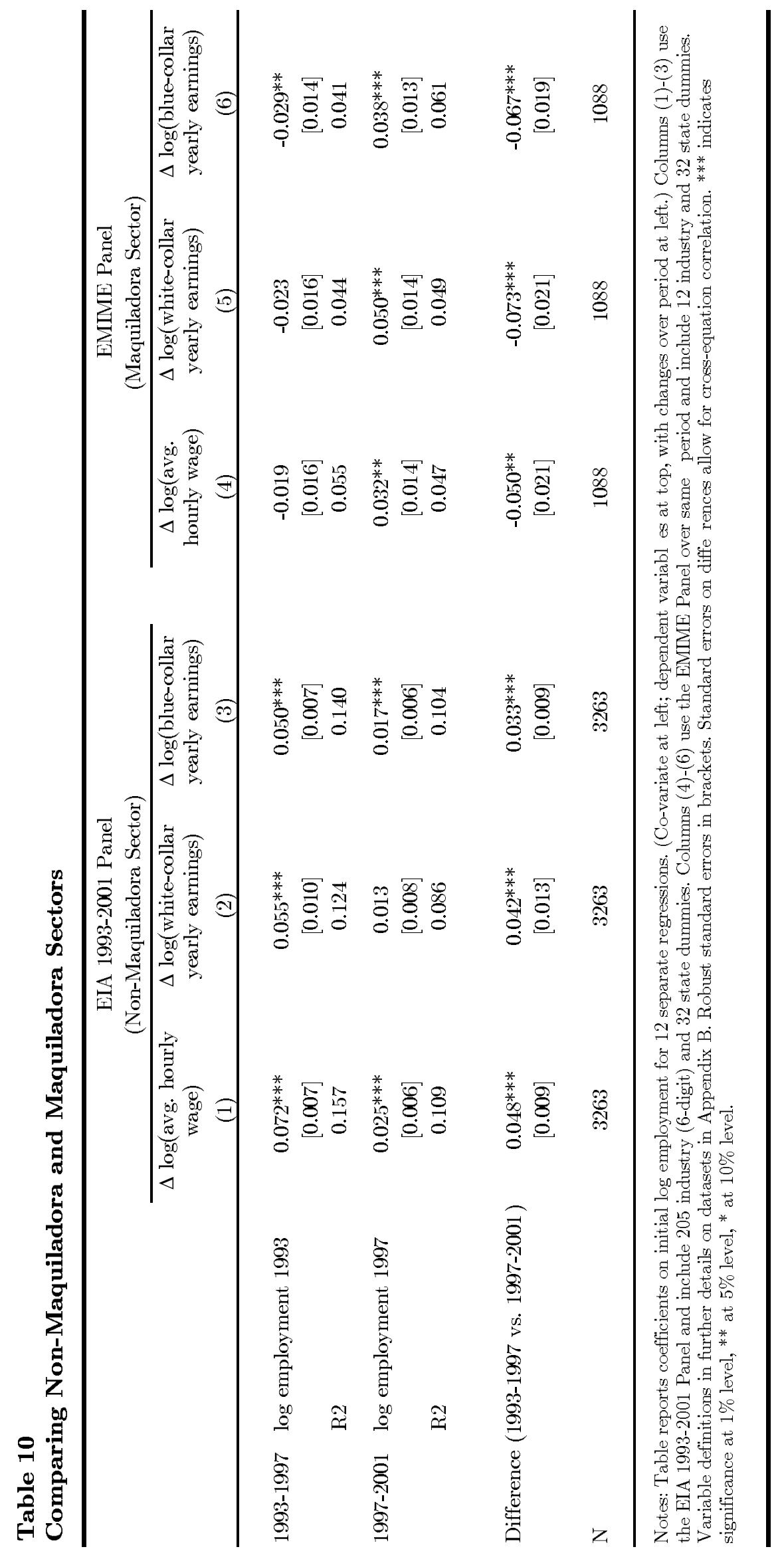




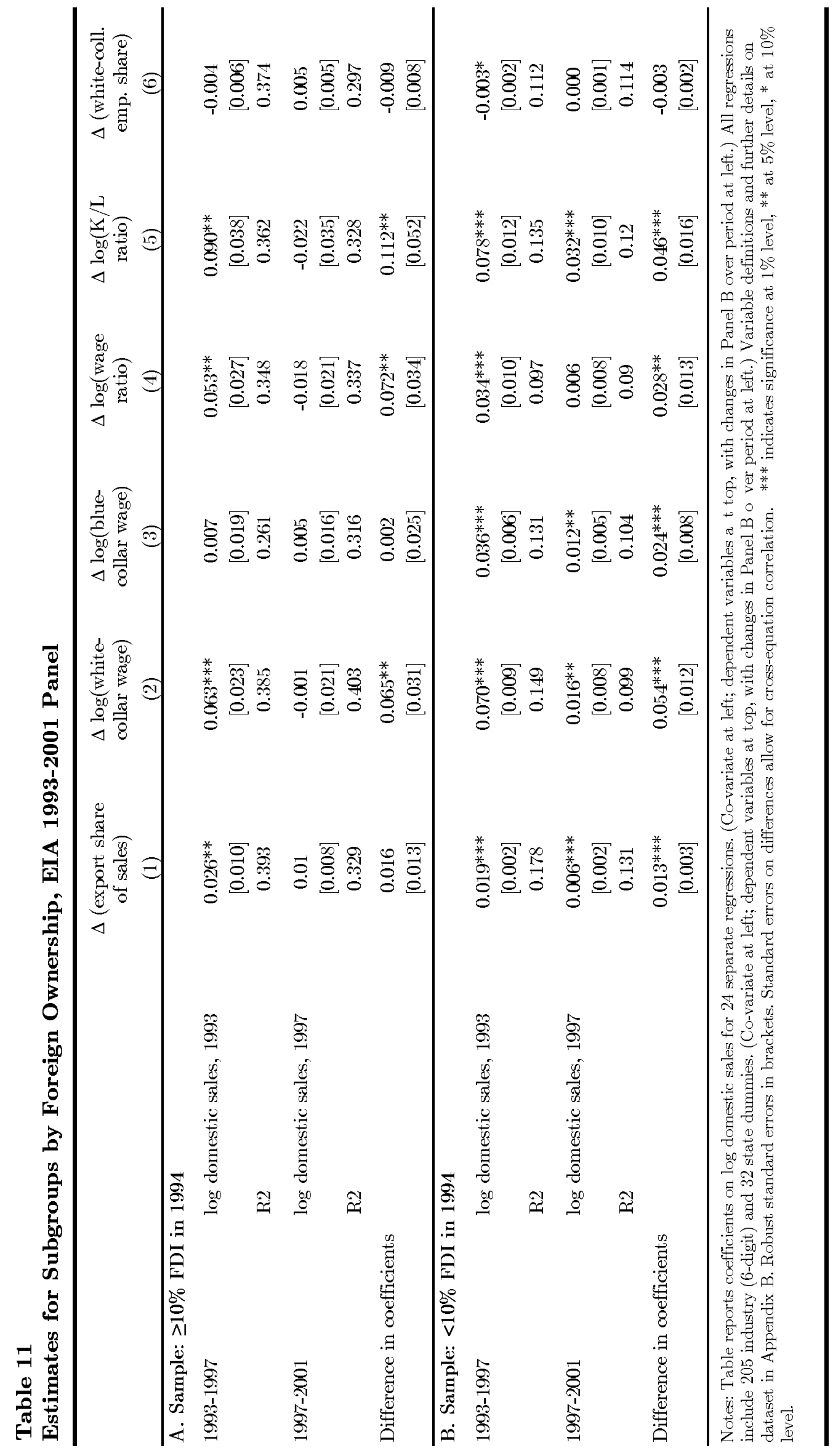




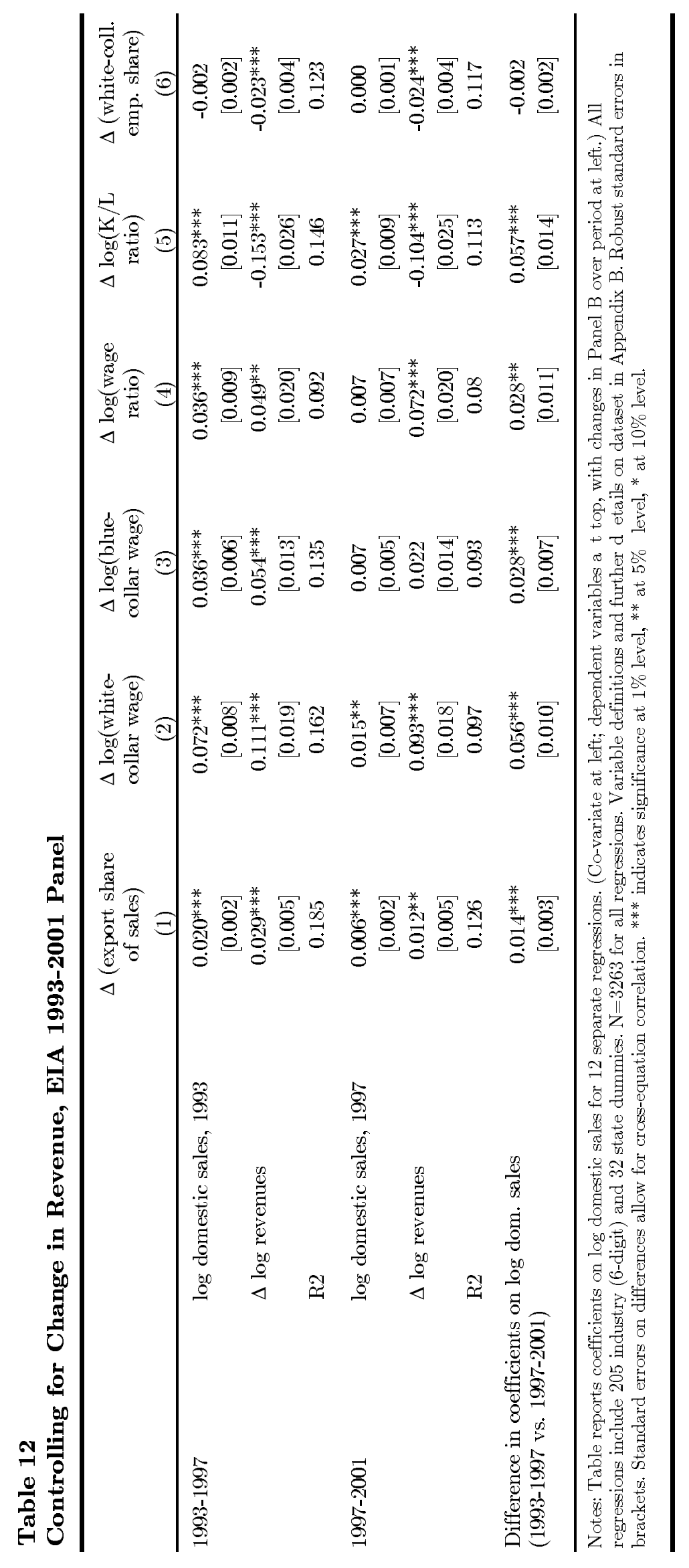




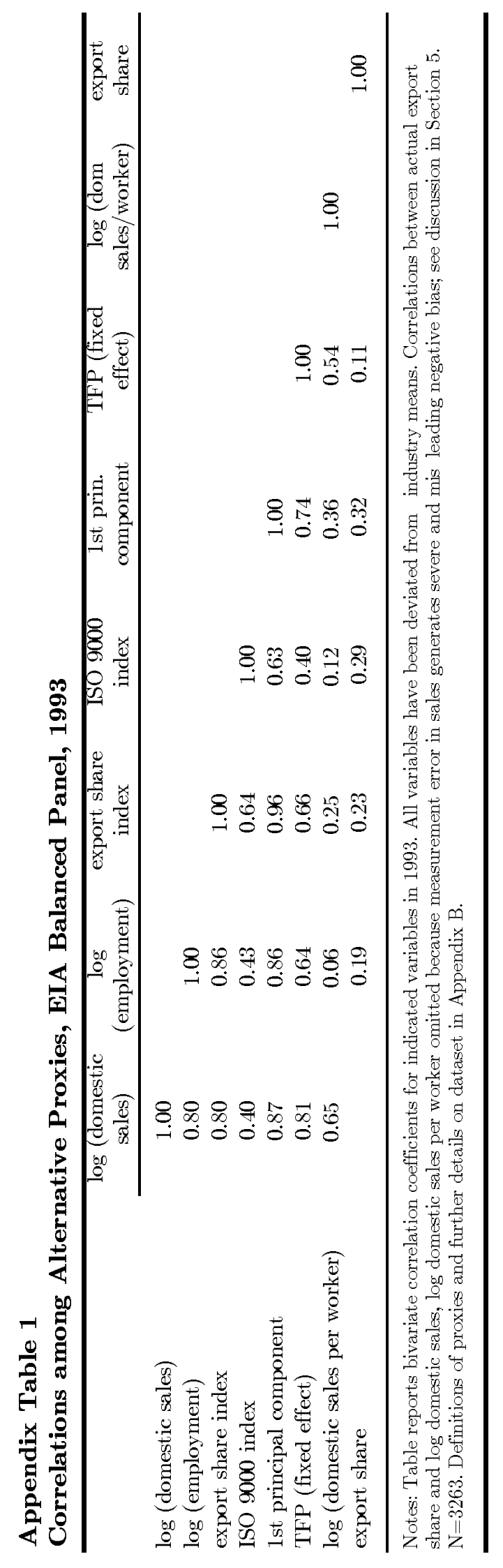




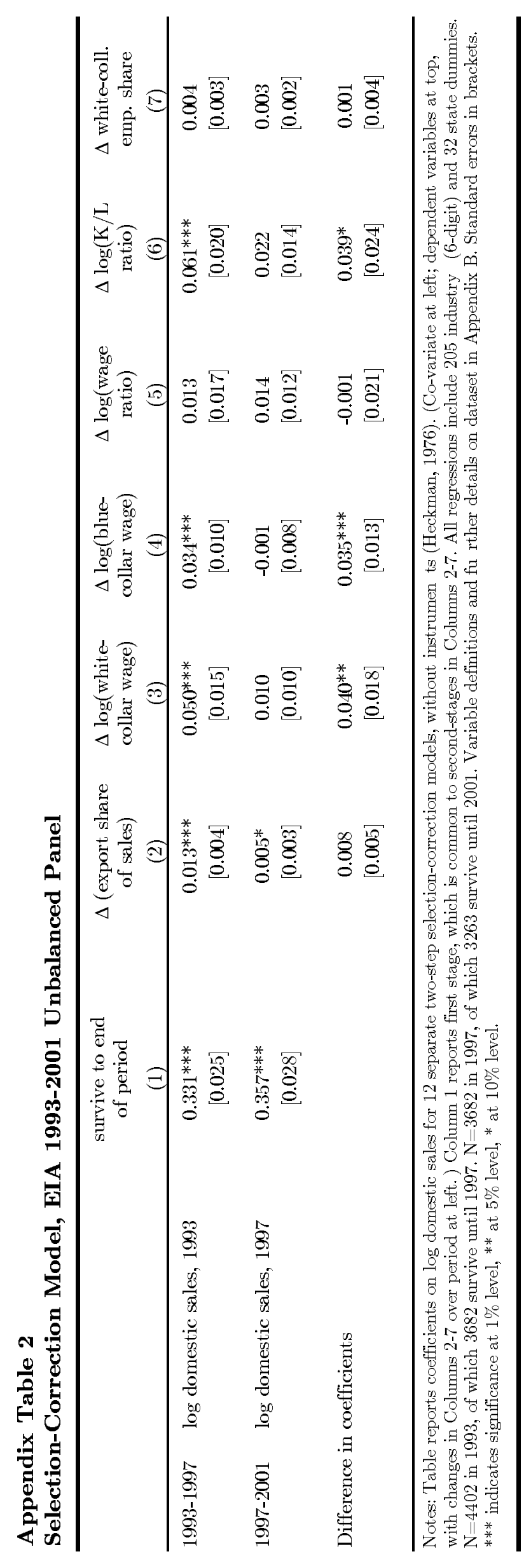




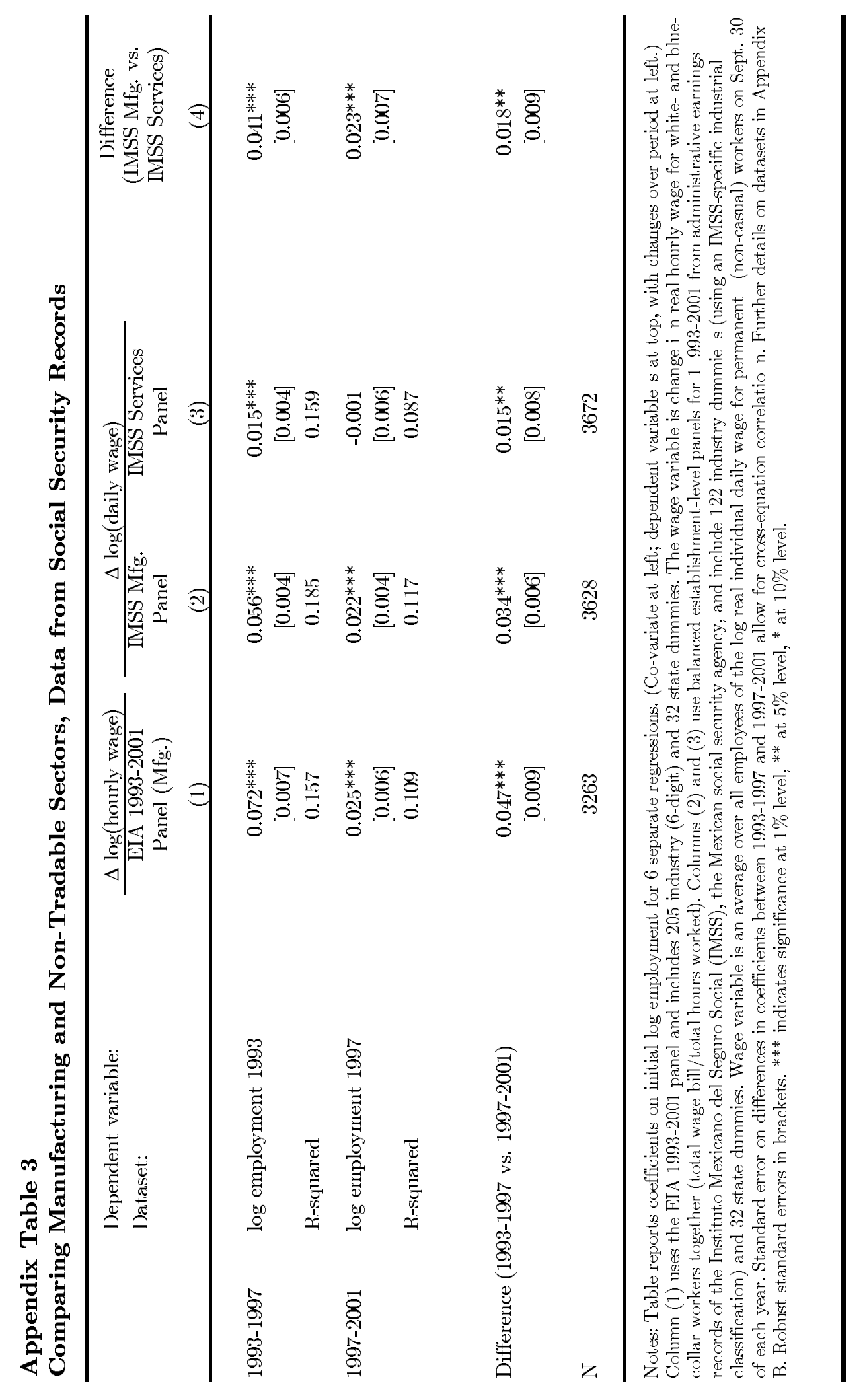




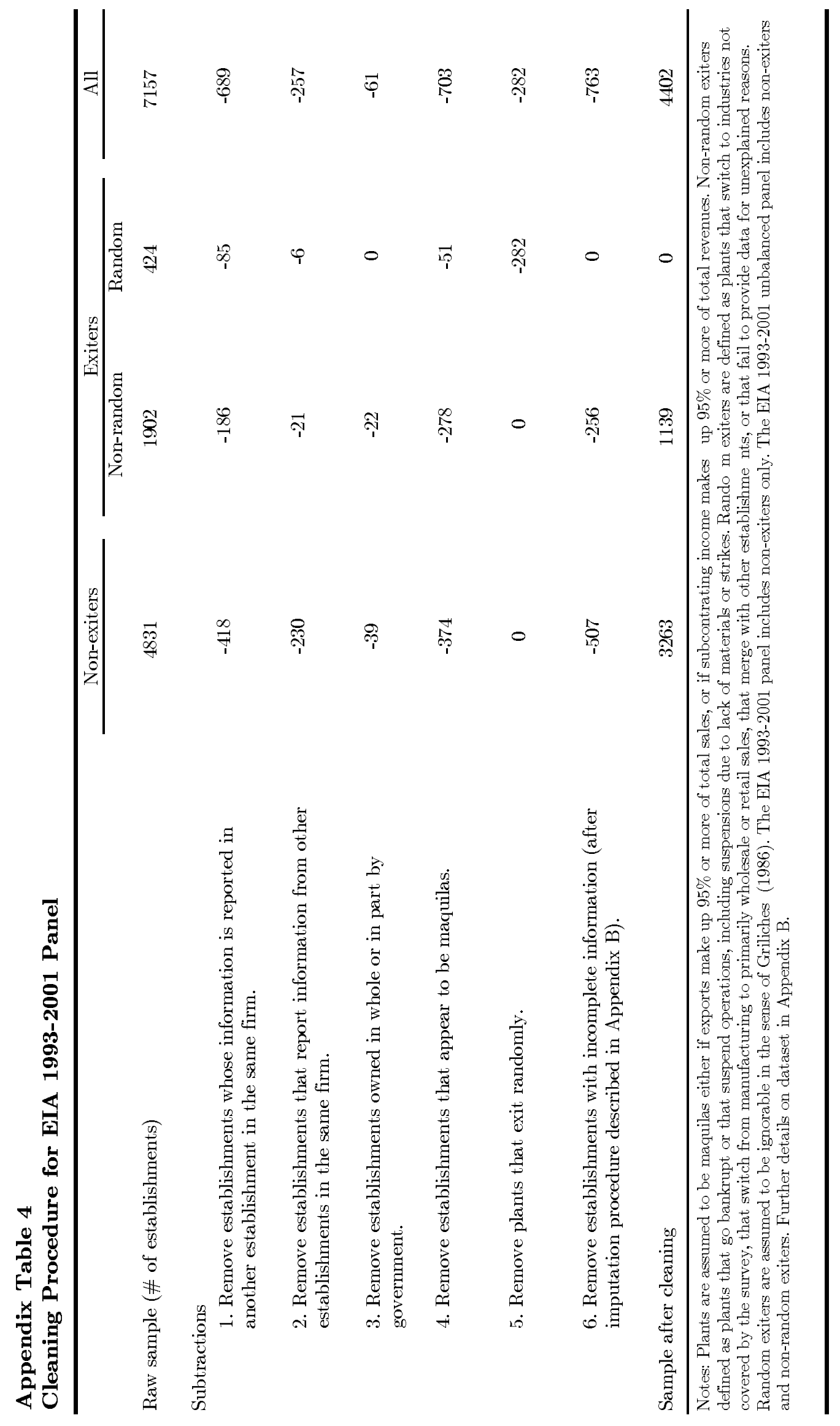

